\title{
Design of a multi-piece removable mandrel mold tool to fabricate and control inner mold surface contour of a composite wing spar
}

\author{
Eric J. Thompson \\ West Virginia University
}

Follow this and additional works at: https://researchrepository.wvu.edu/etd

\section{Recommended Citation}

Thompson, Eric J., "Design of a multi-piece removable mandrel mold tool to fabricate and control inner mold surface contour of a composite wing spar" (2010). Graduate Theses, Dissertations, and Problem Reports. 4664.

https://researchrepository.wvu.edu/etd/4664

This Thesis is protected by copyright and/or related rights. It has been brought to you by the The Research Repository @ WVU with permission from the rights-holder(s). You are free to use this Thesis in any way that is permitted by the copyright and related rights legislation that applies to your use. For other uses you must obtain permission from the rights-holder(s) directly, unless additional rights are indicated by a Creative Commons license in the record and/ or on the work itself. This Thesis has been accepted for inclusion in WVU Graduate Theses, Dissertations, and Problem Reports collection by an authorized administrator of The Research Repository @ WVU. For more information, please contact researchrepository@mail.wvu.edu. 


\title{
Design of a Multi-Piece Removable Mandrel Mold Tool to Fabricate and Control Inner Mold Surface Contour of a Composite Wing Spar
}

\author{
Eric J. Thompson
}

Thesis submitted to the

\section{College of Engineering and Mineral Resources}

at West Virginia University in partial fulfillment of the requirements

for the degree of

Master of Science

in

Mechanical Engineering

Kenneth Means, Ph.D., Chair

Gregory Thompson, Ph.D.

Victor Mucino, Ph.D.

Department of Mechanical Engineering

\author{
Morgantown, West Virginia \\ 2010
}

Keywords: tooling, mandrel, CTE 


\title{
ABSTRACT \\ Design of a Multi-Piece Removable Mandrel Mold Tool to Fabricate and Control Inner Mold Surface Contour of a Composite Wing Spar
}

\author{
Eric J. Thompson
}

Composites technologies are advancing at a rapid rate. As engineers continue to find new ways to us fiber reinforced composites, the need for advanced tooling is greater than ever. In the ever expanding aircraft industry, wing spars are one of the most critical parts on the aircraft and typically require expensive custom tooling. They provide structural support for the entire aircraft under strong aerodynamic loading. The spars must be manufactured to the highest aircraft standards.

Many spars have closed section geometry which provides even more difficulty in the manufacturing and tooling process. Not only does the tooling have to be used to manufacture production rate composite parts, it must be fabricated and maintained to higher standards than the parts themselves. The original mandrel tool is disposable after every cycle and has too many variables in the manufacturing process to produce quality composites spars on a regular basis. The goal of the new design is to create a reusable tool and reduce the variability in the manufacturing process. This was accomplished by utilizing the unique structural properties of multiple materials machined to tight tolerances working in unison to create a mold tool. This tool can then be used as the primary component in the manufacturing process of a specialized composite wing spar. The following work describes the complete design and development of the new multi-piece removable mandrel tool. 


\section{ACKNOWLEDGMENTS}

It has been a long journey to get to the point I am today, and there are many people I want to give thanks to:

I'd like to thank my parents Jim and Carolyn for their immeasurable amount of support and encouragement throughout all of my life and years in school. Without their guidance I would not have made it as far as I have or be the person I am today.

I would like to thank my beautiful wife Amanda for never letting me give up. She never doubted me and was always there when I needed her. I don't know what I would do without her.

I would also like to thank my brother Brad and the rest of my family for always being

there for me. Also, a special thanks to my fellow grad students and friends Wesley Hardin and Kenny Williams for helping me along the way.

I would especially like to thank Dr. Ken Means for allowing me to work under him in pursuit of my graduate education and sticking with me as long as he has. He and the rest of the staff in the Mechanical and Aerospace Engineering Department at West Virginia University have opened up doors and extended possibilities to me that I never thought would be possible. 


\section{Table of Contents}

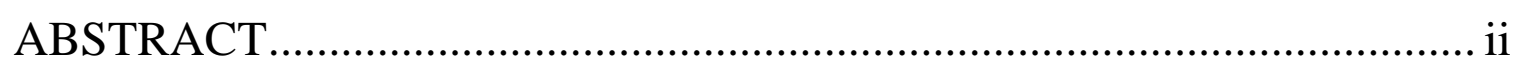

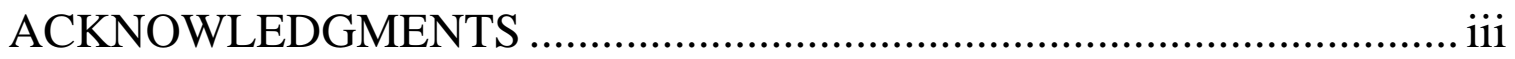

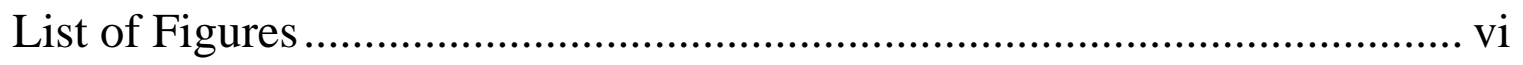

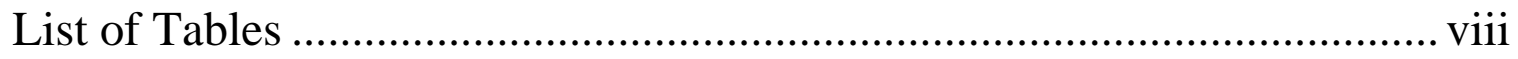

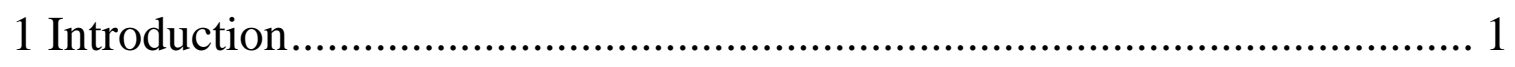

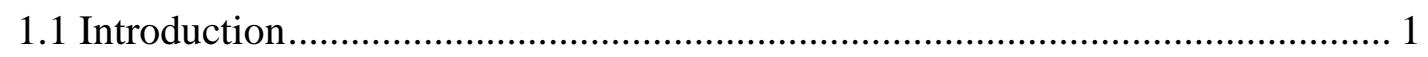

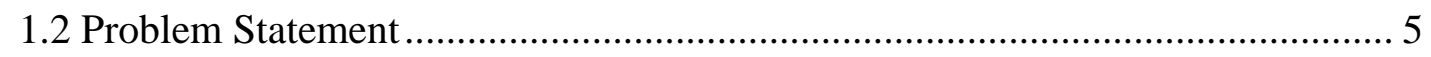

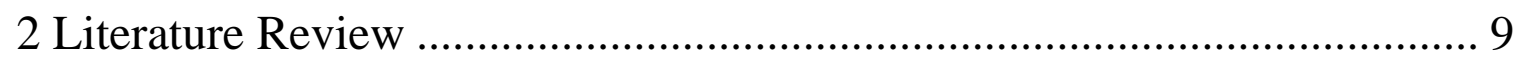

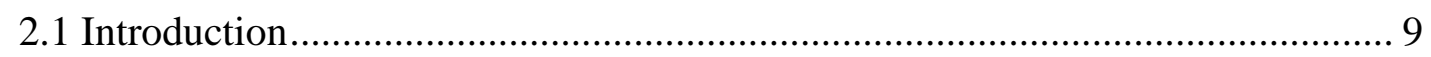

2.1.1 Types of Composites and Lay-up Techniques .................................................. 10

2.2 Advanced Tooling and Types of Mandrels....................................................... 16

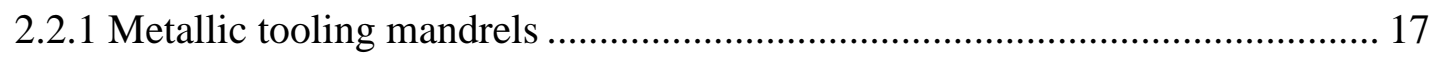

2.2.2 Inflatable and Flexible Mandrels and Molds .................................................. 18

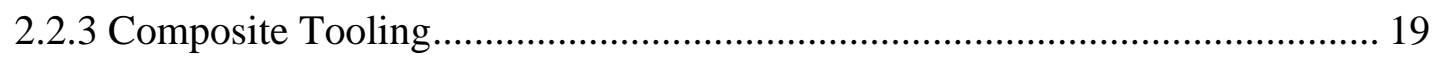

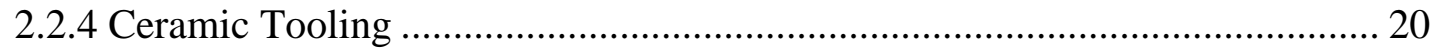

2.2.5 Dissolvable and Break-out Mandrels............................................................. 20

2.3 Industry Uses of Mandrels .......................................................................... 22

2.4 Literature Review Summary ........................................................................ 23

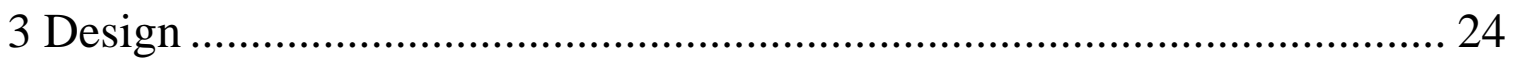

3.1 Design Constraints and Requirements ............................................................ 24 
3.2.1 Current Mandrel Manufacturing Process ........................................................ 29

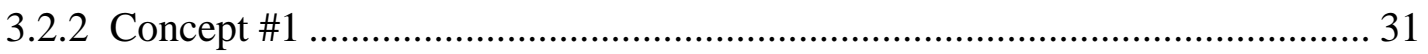

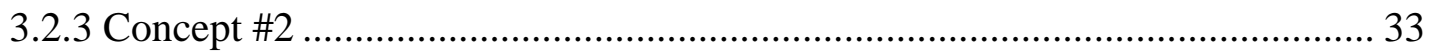

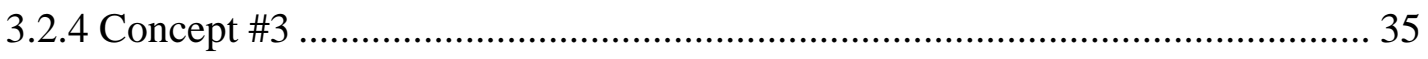

3.3 Spar Mandrel Design and Analysis........................................................... 37

3.3.1 Mandrel Assembly and Usage .............................................................. 56

4 Results and Conclusions ................................................................ 61

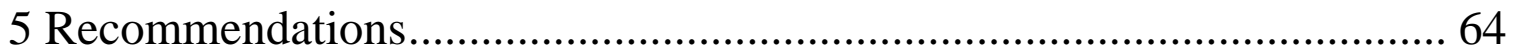

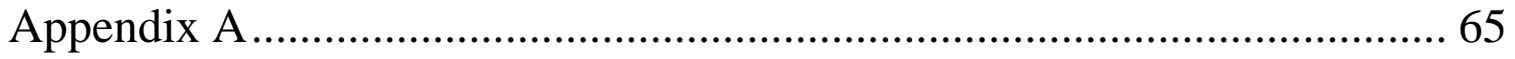

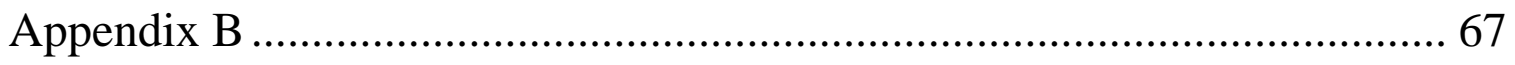

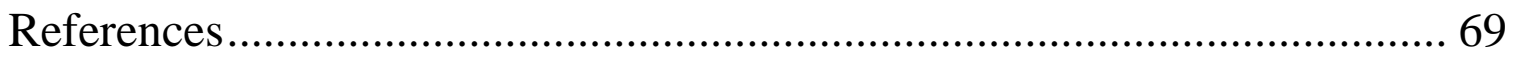




\section{List of Figures}

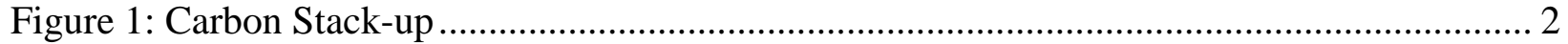

Figure 2: Digital Carbon Fiber Stack-up Representation .................................................... 2

Figure 3: Sample of a Composite Mold ............................................................................ 3

Figure 4: Sample of a Steel (Metallic) Mold .................................................................... 4

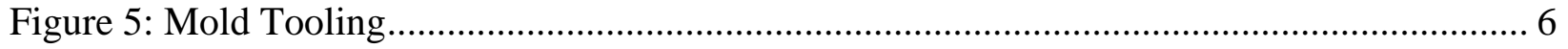

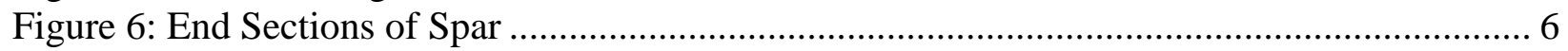

Figure 7: Existing OML "Clamshell" Mold......................................................................... 7

Figure 8: Composite Strength Properties Comparison [3] ................................................... 10

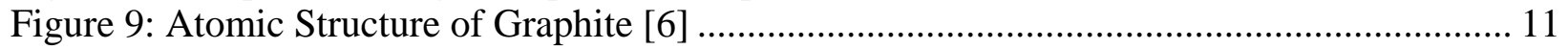

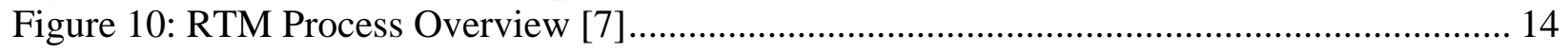

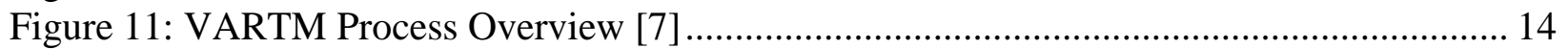

Figure 12: Composite Windmill Blade [14] ......................................................................... 23

Figure 13: Clamshell Mold .......................................................................................... 24

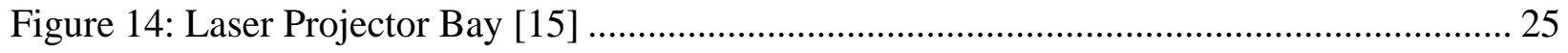

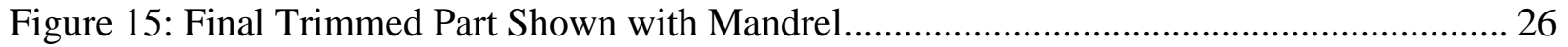

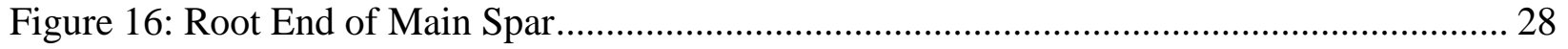

Figure 17: Areas to be Supported by Trunnion Fittings ........................................................ 29

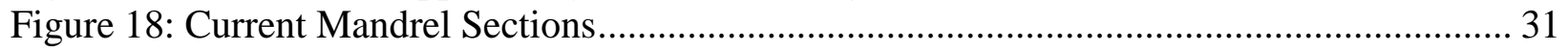

Figure 19: Concept \#1..................................................................................................... 32

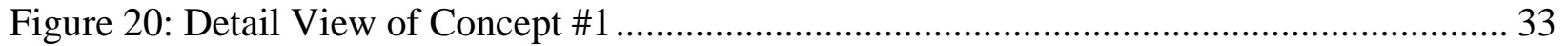

Figure 21: Segmented Mandrel Concept ............................................................................ 34

Figure 22: Assembled Segmented Mandrel Concept............................................................ 34

Figure 23: Hardened Excess Resin Which Has Flown From Mold.......................................... 35

Figure 24: Existing OML Mold with Modifications.............................................................. 36

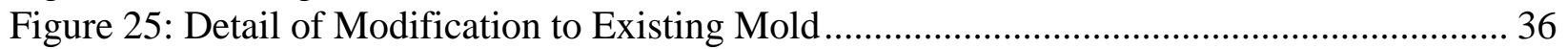

Figure 26: Design Process Flow Diagram ....................................................................... 38

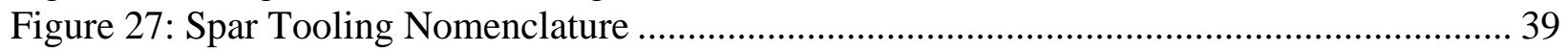

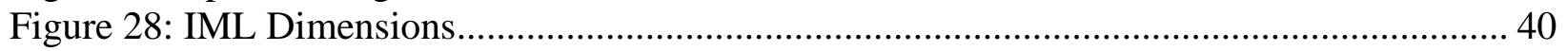

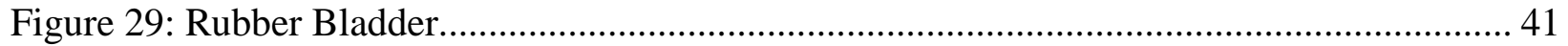

Figure 30: Pro/E Master Section Used to Build Tool Geometry ............................................... 43

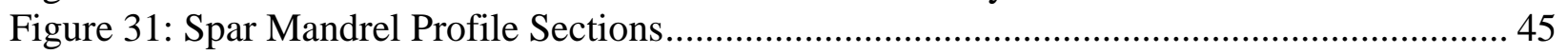

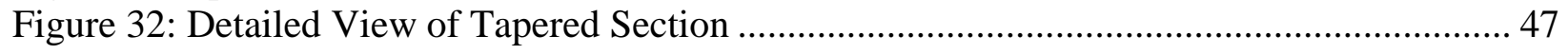

Figure 33: Cross Sectional View of Cap Section................................................................ 48

Figure 34: Pocketed Area of Tapered Segment to Accept Trapped Segments........................... 49

Figure 35: Clocking Feature Shown in Trapped Center Segment ............................................ 49

Figure 36: Machined Pockets Allow Sides to Fit on Center Section........................................ 50

Figure 37: Root End Closeout Fitting ............................................................................... 51

Figure 38: Root End Vacuum Fitting............................................................................... 52

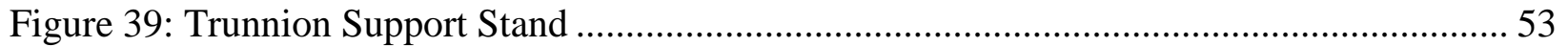

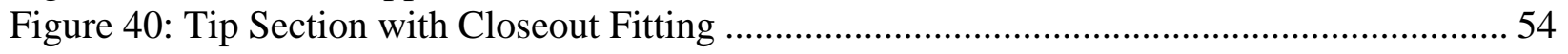

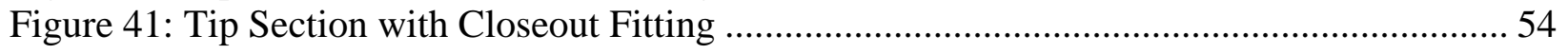

Figure 42: Worst Case Scenario Loading ........................................................................... 55

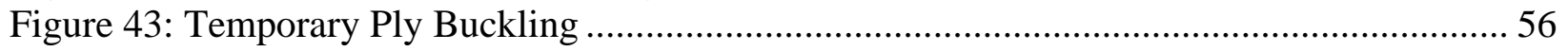

Figure 44: Assembly Step \#1: Tapered Section Halves......................................................... 57 
Figure 45: Assembly Step \#2: Stud and Trapped Sections.................................................... 58

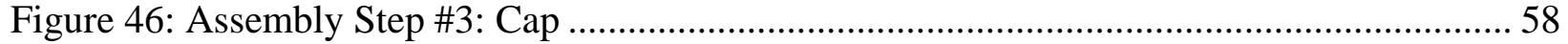

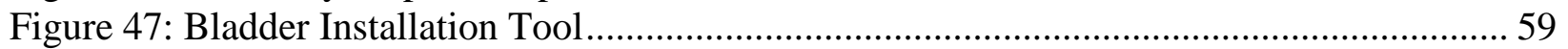

Figure 48: Actual Measurement under Worst Case Static Loading ........................................ 62

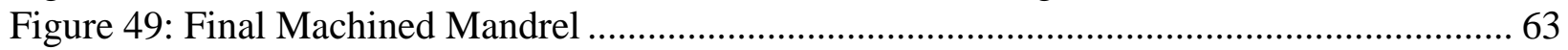




\section{List of Tables}

Table 1: Tooling Materials and CTE Growth ....................................................................... 27

Table 2: Comparison of Possible Tooling Materials [17]..................................................... 38

Table 3: Calculated Growth at Mandrel Stations................................................................. 42

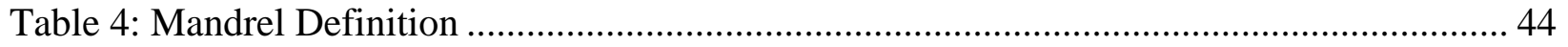




\section{Introduction}

\subsection{Introduction}

As engineers and designers continue to find new ways to use advanced composites, advanced tooling is needed to manufacture and support these structures. In the aerospace industry, the use of composite parts is advancing at a rapid rate. Composites on the new Boeing 787 account for $50 \%$ of the entire aircraft dry weight compared to the Boeing 777 (developed in the early 1990's) in which composites only account for $12 \%$ of the overall weight [1]. Composites were originally used to create flat or generally flat shapes for the primary purpose to reduce weight. Now designers and engineers are able to use existing composite knowledge coupled with new technology to lighten and strengthen aircraft parts or simplify complex parts by using the strength and versatility of a wide array of composite materials. Composites are being used to combine complex assemblies with multiple details into single parts by using complex shapes which are made possible by the versatility of composite lay-ups. Although composites are still in an early stage of replacing critical components, many companies are looking to use them in ways never previously imagined. Some aerospace and aircraft companies are even looking to use composites to replace flight critical components such as rotor blades and wing structures. There are many different ways to design composite layups. Composites can use various types of high strength materials such as carbon fiber or fiberglass with different weaves, the orientation of the strands, and the type and amount of resin used to bond the fibers together. All carbon fiber parts are a combination or "stack up" of carbon fibers held together with a bonding agent such as resin. A typical carbon stack up can be seen in Figure 1 and Figure 2 . 


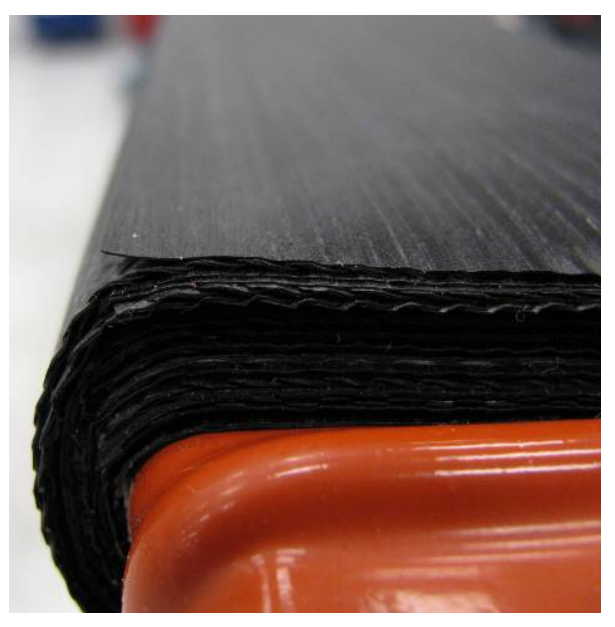

Figure 1: Carbon Stack-up

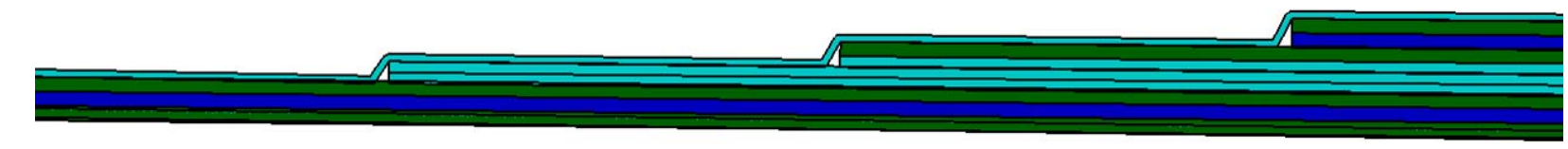

Figure 2: Digital Carbon Fiber Stack-up Representation

The application of the part will typically drive the design, but no matter which composite stack up is used, this material has a very high strength-to-weight ratio compared to other engineering materials that could be used in the same application (see Figure 8). The density and weight of carbon fiber is also considerably lower than that of comparative materials making it ideal for applications that require minimal weight (see Table 2). The drawbacks to using carbon fibers and composites is that they can be expensive to produce and are typically much more brittle than metallic materials so they cannot be used in applications where they may see shock or high impact loads. 
Modern day aircraft have capabilities and capacities far beyond those of previous years and continue to push the limits of contemporary engineering. The 50\% carbon fiber Boeing 787 Dreamliner is capable of flying 250 passengers up to 8,200 nautical miles using $20 \%$ less fuel than its competitors [2]. Composites have helped lead the way to stronger, lighter parts which allow aircraft to be faster and more versatile. Modern designs deviate from the ordinary and these designs require advancements in manufacturing and modern tooling. Tooling in the composites industry is an implement used to accomplish the task of creating carbon fiber parts. The pliable carbon cloth must have a hard surface to be laid on so its shape is held when the bonding agent cures. This tool material can be made from any number of materials including but not limited to steel, invar, aluminum, carbon fiber, or a combination of materials engineered to enhance performance of the tool as seen in Figure 3 and Figure 4.

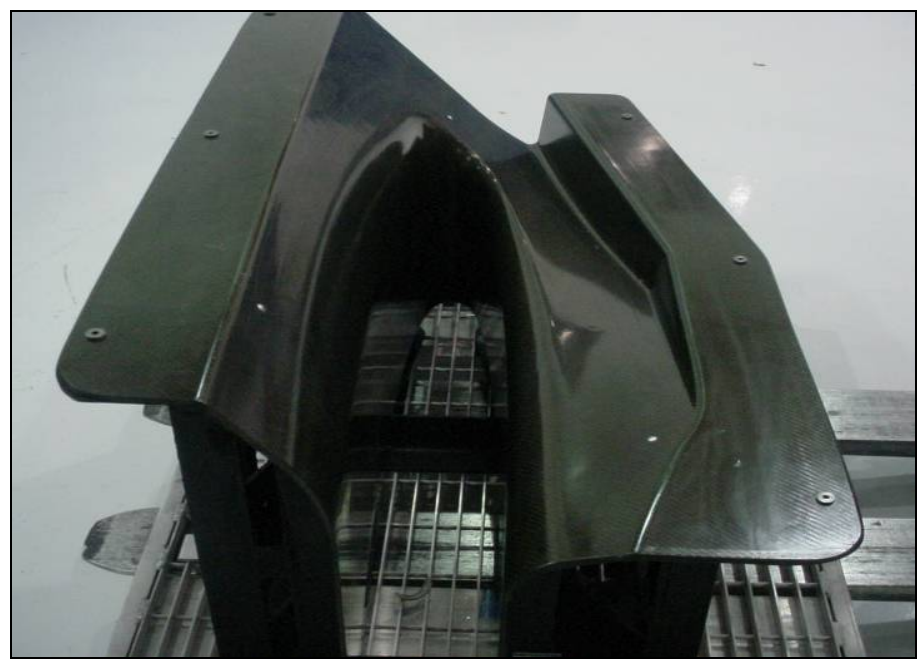

Figure 3: Sample of a Composite Mold 


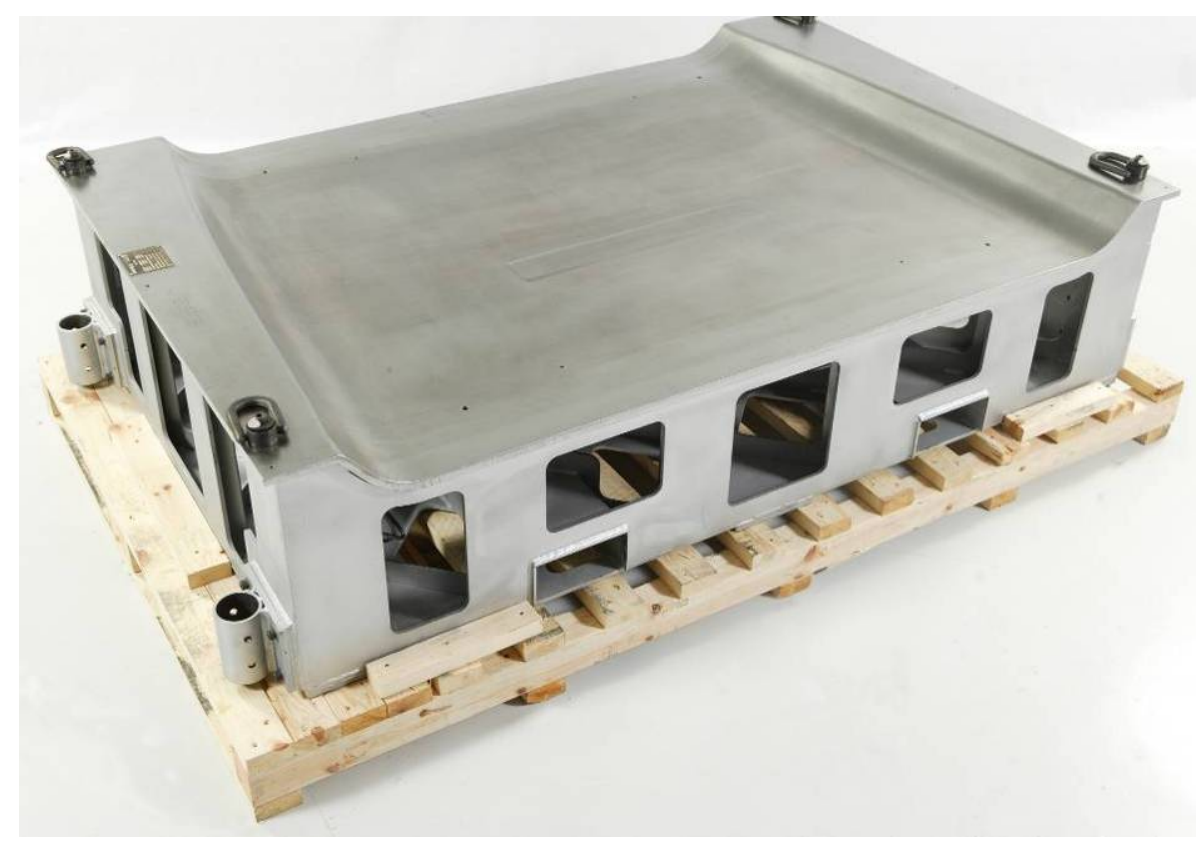

Figure 4: Sample of a Steel (Metallic) Mold

Classical tooling is sufficient for creating simple shapes, but cannot provide the capabilities to fabricate complex shapes and contours. Advanced aircraft tooling must hold tight tolerances that range from .0005 ” to .020 ” and meet the specifications of the newest designs of composite parts. Aircraft tooling typically must hold one third the tolerance of the aircraft part requirement. In some cases, parts are designed to .005” profile tolerance so the tooling surface in contact with the part must be fabricated to .0015”. In most companies, part designers work with tool designers to make sure the manufacturing processes are feasible; however, there are certain cases that required complex geometry where parts are trapped in the tool once it's cured. These particular parts require tools that can hold the correct geometry, but that have features that can be removed or the tool must come apart to allow the removal of the part after the cure cycle. 


\subsection{Problem Statement}

Wing spars in airplanes are the main component of the aircraft structure. The spar is the primary stress bearing structure of the entire aircraft. Since planes were first invented and flown in 1903, many types of wing spars have been designed and tested.

When designing composite shapes and tooling, many factors must be considered to achieve the best results. In this particular case, engineers have designed an aircraft wing spar with complex geometry. The geometry of the wing spar was based on stress reports and analysis of the wing and the aerodynamic loading the wing structure will see during long flights. Carbon fiber was chosen for this application because of the extreme temperature fluctuations $\left(80^{\circ} \mathrm{F}\right.$ to $-76^{\circ} \mathrm{F} @$ 60,000 feet) and possibility for moisture to cause corrosion in the structure if metallic components were used. Tooling exists for this particular engineering design; however, it is very inefficient tooling which requires 40 hours per cycle for upkeep, maintenance, and rework.

A complex mold tool along with special process tooling is required to fabricate this spar. Mold tooling or sometimes known as cure fixture tooling is a tool/fixture used to fabricate composite parts by means of bonding laminated composite plies on the tool face. A mold tool is typically used in an oven or autoclave which produces heat, pressure, and/or vacuum. In this application, thick rubber bladders must also be drawn over the tooling, which requires secondary vacuum tooling. After curing, extraction tools must also be designed to withdraw the mandrel and bladders from the cured spar. 


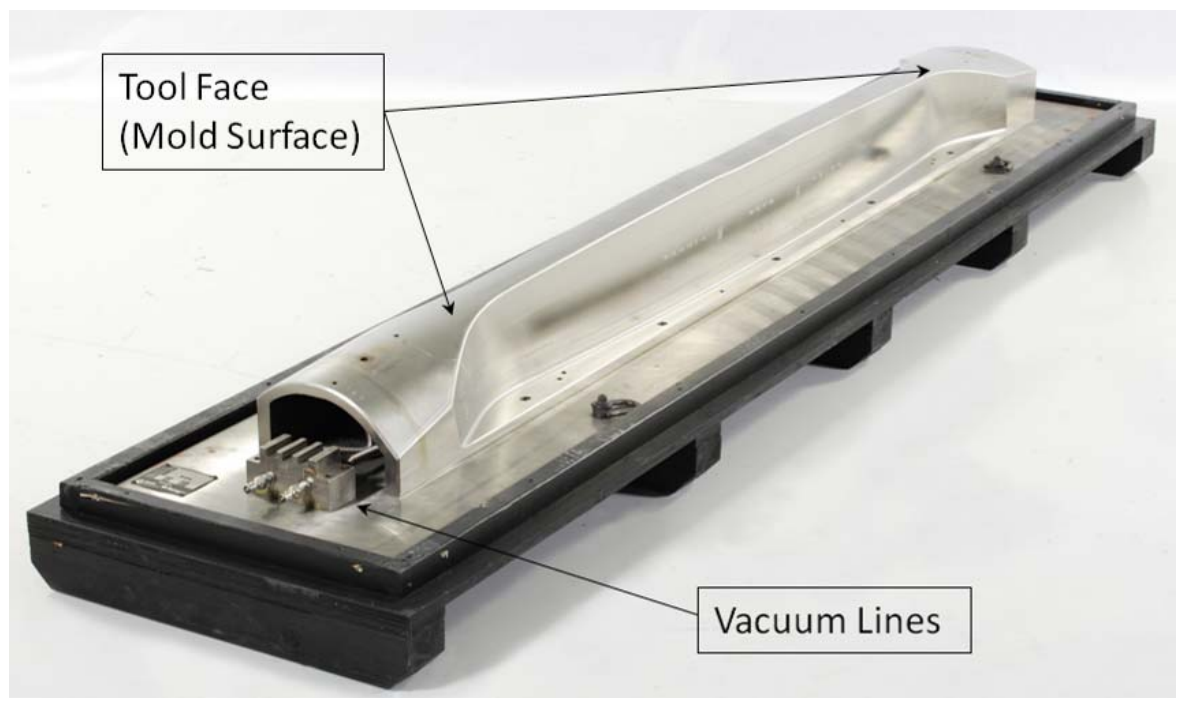

Figure 5: Mold Tooling

The composite wing spar being manufactured on the tool is 13.5 feet long and tapers from a 5.49" x 3.80" rectangular cross section at the root end (end that attaches to the aircraft) to a 2.65” x 1.86” square cross section at the tip end as illustrated in Figure 6. The material is a hand lay-up because the engineering requires precision placed plies and integrates unidirectional carbon along with a standard weave preimpregnated carbon fiber. Once the carbon is placed on the mandrel, the entire structure will be laid in an outer "clam-shell" type mold which will be used to control the outer mold surface and straightness of the spar during the cure cycle as seen in Figure 7.

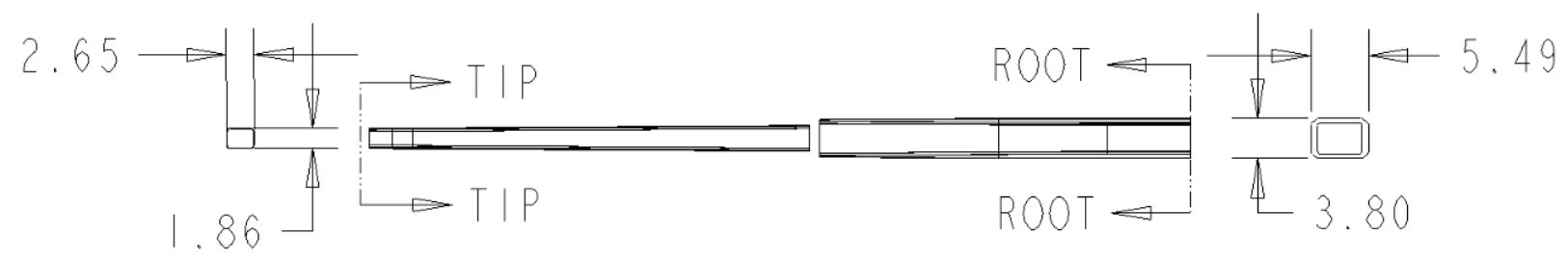

Figure 6: End Sections of Spar 


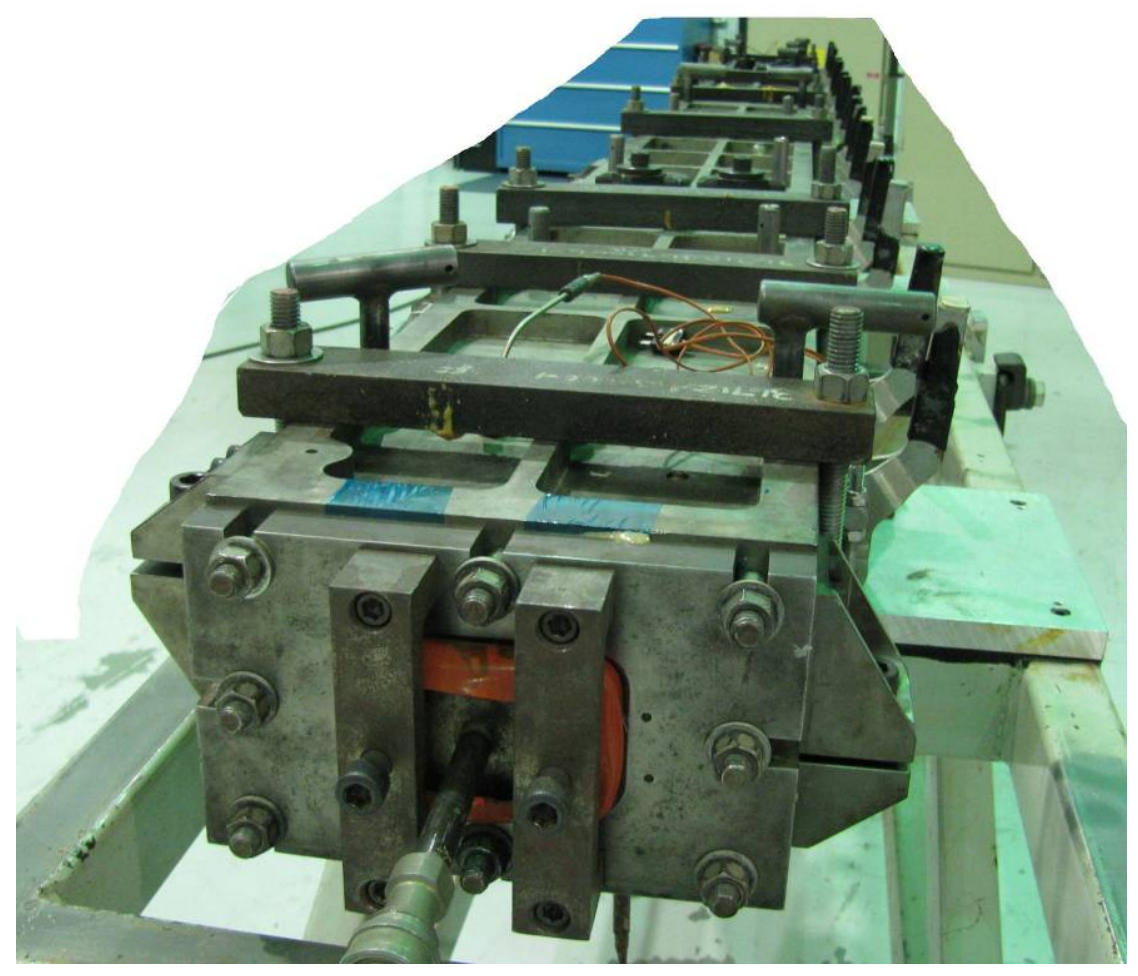

Figure 7: Existing OML "Clamshell" Mold

The material required to fabricate the spar has to be considered when designing the mandrel. It is a carbon weave preimpregnated with resin. The material is resin-rich so the current tool design of the outer mold tool allows for resin to flow out of the lay-up during the autoclave curing process. The resin flow is only controlled by the diameter of the holes and the number of the holes in the clamshell mold, so this creates a problem. Although the autoclave time is carefully monitored, the flow of resin can cause the carbon material to become dry which causes voids and potentially a part that does not meet customer quality specifications and cannot be used on a production aircraft.

The current engineering requires a segmented light-weight mandrel that can be used to support composite lay-up and provide thermal expansion during cure. It must be segmented or multi-piece because the design of the spar will cause the tool to be trapped after the spar is 
hardened in the curing cycle. The tool also has to have a streamline mold surface to produce a .020” surface profile inner mold surface, yet be removable from the solid spar after autoclave cure. The tool also has to maintain structural integrity when cycled in production use which will be taken into consideration when the joints of the tool are designed. This particular tool should last $100-200$ cycles of lay-up and $250^{\circ} \mathrm{F}$ cure. It also needs to maintain vacuum and structural integrity throughout all of the production cure cycles. Wear and tear must also be considered in the design. Throughout the cure cycles, the tool must withstand abrasion between the joints during reassembly following each cure cycle. 


\section{Literature Review}

\subsection{Introduction}

In today's advancing aerospace industry, as tooling advances it is possible to create new shapes such as tubular structures that can replace traditional "C" channel components. These simple structures are lightweight, durable, and strong. Many aircraft and aerospace companies are using high strength composites to enhance these tubular structures even further. Composites can be found in almost all new aircraft interiors and are increasingly being used in more vital structural and flight critical components. High strength advanced composites typically offer a combination of properties which can't be found in other structural materials. Some of the properties that designers find most useful are low weight, high strength, stiffness, good corrosion resistance, and in some cases, unique electrical properties [3]. Figure 8 shows how composites strength and density compare to other common engineering materials. 


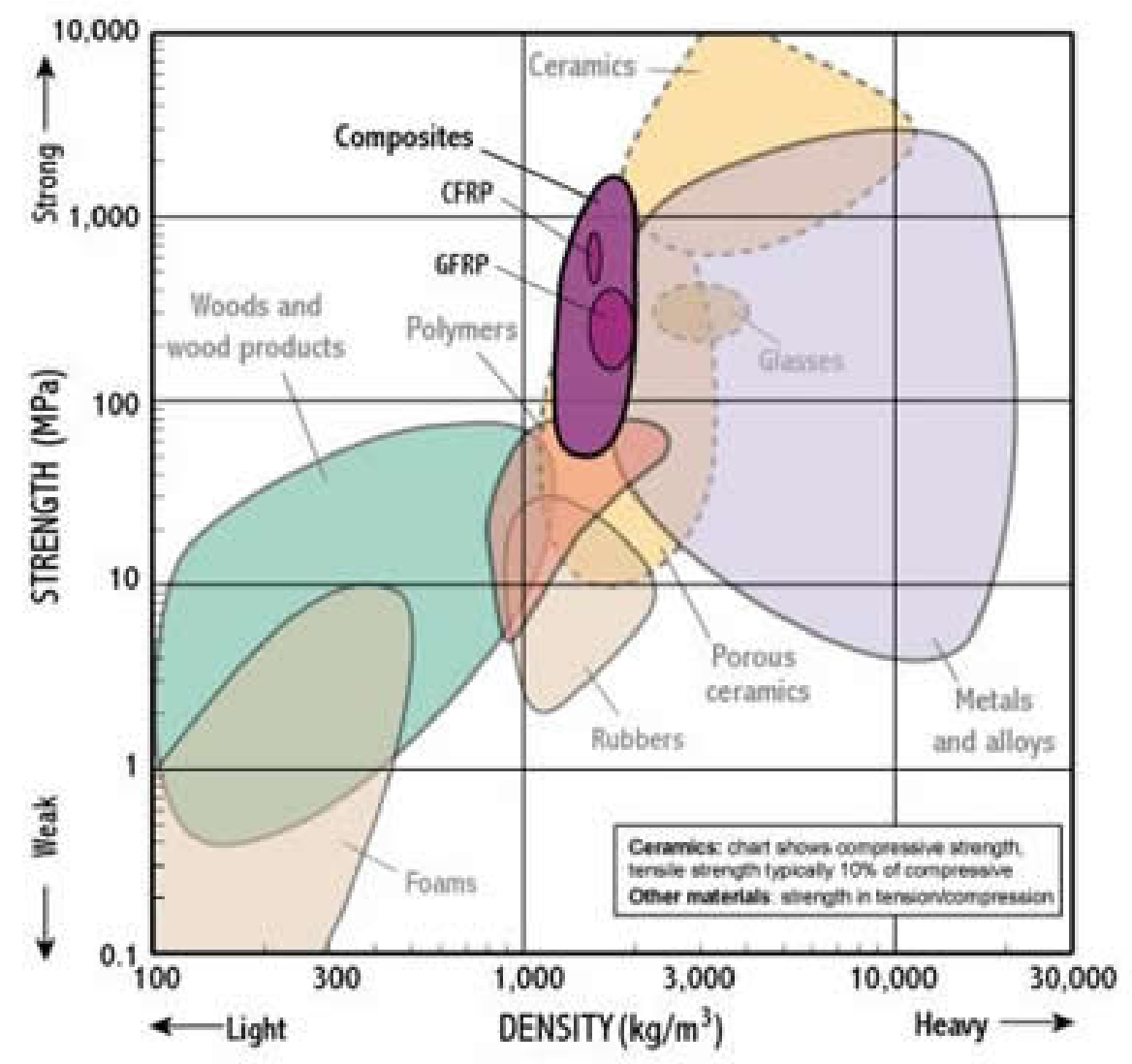

Figure 8: Composite Strength Properties Comparison [3]

Without the use of mandrels, composite tubular structures would not be possible to manufacture. Webster's online dictionary defines mandrels as “a tapered or cylindrical axle, spindle, or arbor inserted into a hole in a piece of work to support it during machining or a metal bar that serves as a core around which material may be cast, molded, forged, bent, or otherwise shaped" [4]. These mandrels serve as the foundation onto which soft composite material is placed and hardened.

\subsubsection{Types of Composites and Lay-up Techniques}

When designing composite shapes and tooling, many factors must be considered to achieve the best results. The first consideration is what type of material will be used to produce the part or structure. The most common types of carbon fiber are woven, unidirectional, or 
roving. Woven material is lightweight, has a high tensile strength, low coefficient of thermal expansion, and is flexible during the lay up process. The capabilities of the material make it very popular in the aerospace and automotive industries. Woven carbon fiber cloth is constructed by a process that heats, oxidizes, and then carbonizes polyacrylonitrile polymer fibers forming strands of carbon. This process gives the strands a stable atomic structure close to that of graphite which can bee seen in Figure 9. The resulting fibers are then woven into mats and used as carbon cloth [5].

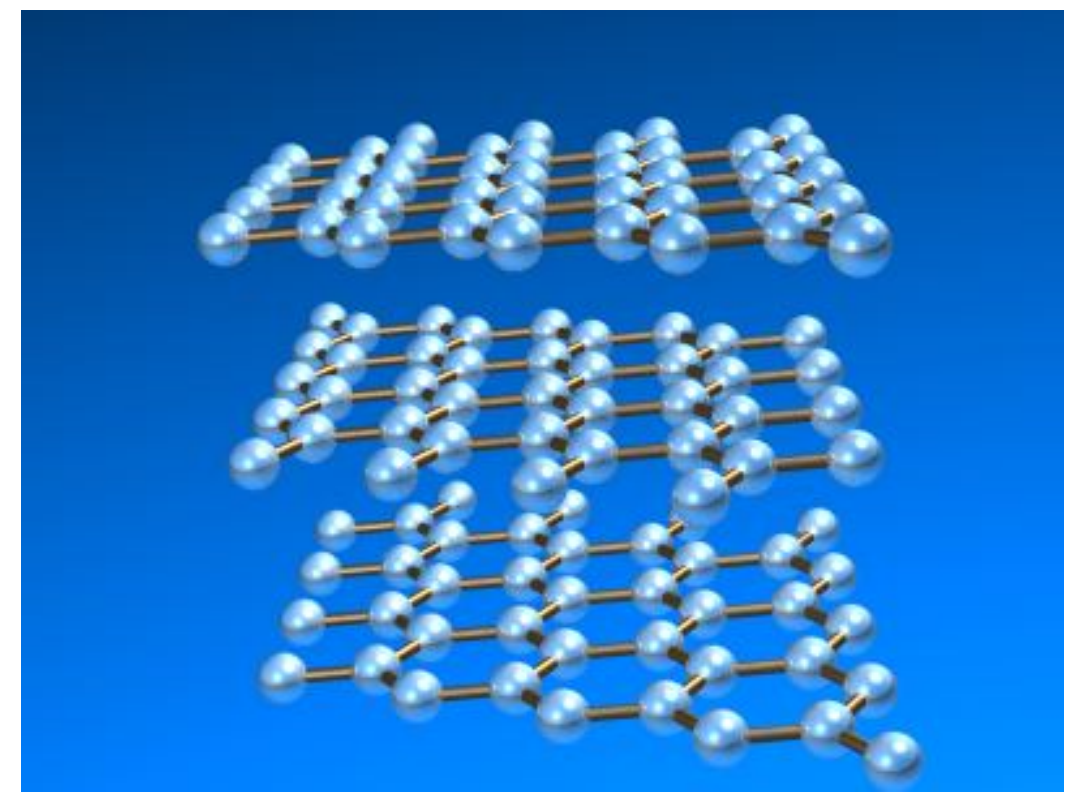

Figure 9: Atomic Structure of Graphite [6]

Unidirectional carbon fiber (uni tape) is a common lay-up material in which the carbon fibers are oriented parallel to the length of the material strip. Typically, unidirectional carbon (uni) is used in conjunction with woven mat in carbon fiber parts. The advantage of using uni as a doubler in a ply stack up is that it offers high fiber content and very high mechanical properties in the direction of the fibers.

Resin must be used in union with carbon fiber to cure a part. Resin is the hardening agent that begins as a viscous liquid and hardens after specific treatment. Most resins used in the 
aerospace industry require vacuum pressure and heat to fully cure (harden). To achieve the lightest possible parts with maximum strength, the lay-up is vacuum bagged and cured in an autoclave where pressure and temperature are monitored very closely. There are multiple ways that resin can be introduced to the carbon. The most common types of carbon fiber are preimpregnated (prepreg) material or dry cloth material. Prepreg material begins as a dry cloth material, but is saturated in precisely controlled amounts of resin before it is sent out of the factory for use. This type of material is much cleaner to use because the exact amount of resin has been added to the material and excess resin does not flow out during the lay up process. This also expedites the manufacturing process. Most preimpregnated materials have a shelf life so it is imperative that the material is used on time or stored in subzero ${ }^{\circ} \mathrm{F}$ freezers to prolong the life of the resin.

When using dry carbon fiber material, resin must be added immediately prior or during the lay-up process. Numerous processes are currently available to add resin to dry material. The simplest form of wet lay-up would be mixing a multiple part resin in its own container then manually applying the resin to each layer of dry cloth. Typically this is done by pouring an estimated amount of resin on the cloth and "painting" it on to ensure no dry spots or voids are left. There are many downfalls to this process. First, the amount of resin needed is an estimate so there is the possibility of waste or insufficient resin would result in a scrapped part and time wasted. The biggest risk of this process is that the resin is not applied evenly to the part, which will result in variable thicknesses or dry spots which would be a reason to reject the part. The setup and cleanup for this process is also very timely. Plastic sheeting must be laid down to ensure the resin does not get on the flooring and the technicians much be properly covered. Most 
resins are not soluble in water, so the tools must be cleaned in acetone or other types of potentially hazardous solvents.

A much cleaner and cost-effective alternative to the manual process is resin transfer molding (RTM) or vacuum assisted resin transfer molding (VARTM). Both techniques offer several advantages over other composite fabrication methods. With either method, high volume or very thick composites can be fabricated with low void contents. Highly complex shapes can also be molded in one step by integrating many components into a single perform die or mold. By incorporating multiple features in the same step, it greatly helps to reduce the cost, weight, and manufacturing time of the structure. Also, the elimination of hand lay-up processes allow production rates to go up and operating costs are reduced. Both procedures are also closed mold processes which reduce workers' exposure to harmful volatiles [7]. As seen in Figure 10, in the RTM process, resin is injected under pressure between two mold surfaces. The resin impregnates the dry cloth and fills all voids that are not filled by the cloth or composite medium. The downfall to the RTM process is that a secondary or upper mold must be machined which can be an expensive and timely process; however the final part thickness and both mold surfaces can be tightly controlled. VARTM replaces the upper mold with a vacuum bag, which greatly reduces the cost of the tooling, but has its own set of unique problems. A VARTM process overview can be seen in Figure 11. An even amount of vacuum must be drawn over the surface of the mold. Resin can then be released into the system which is pulled through the medium with vacuum assistance. Once resin has completely saturated the composite material, the resin flow is shut off and vacuum continues to be drawn over the entire system until the part is fully cured either at room temperature or in an autoclave process. The flexible nature of the vacuum bags makes it difficult to control the final thickness and bag side mold surface of the part. It also 
makes it more difficult to control the fiber volume fraction of the composite. Along with the variability of the vacuum bag, the complex process leads to much trial and error methodology during the design and optimization process [7].

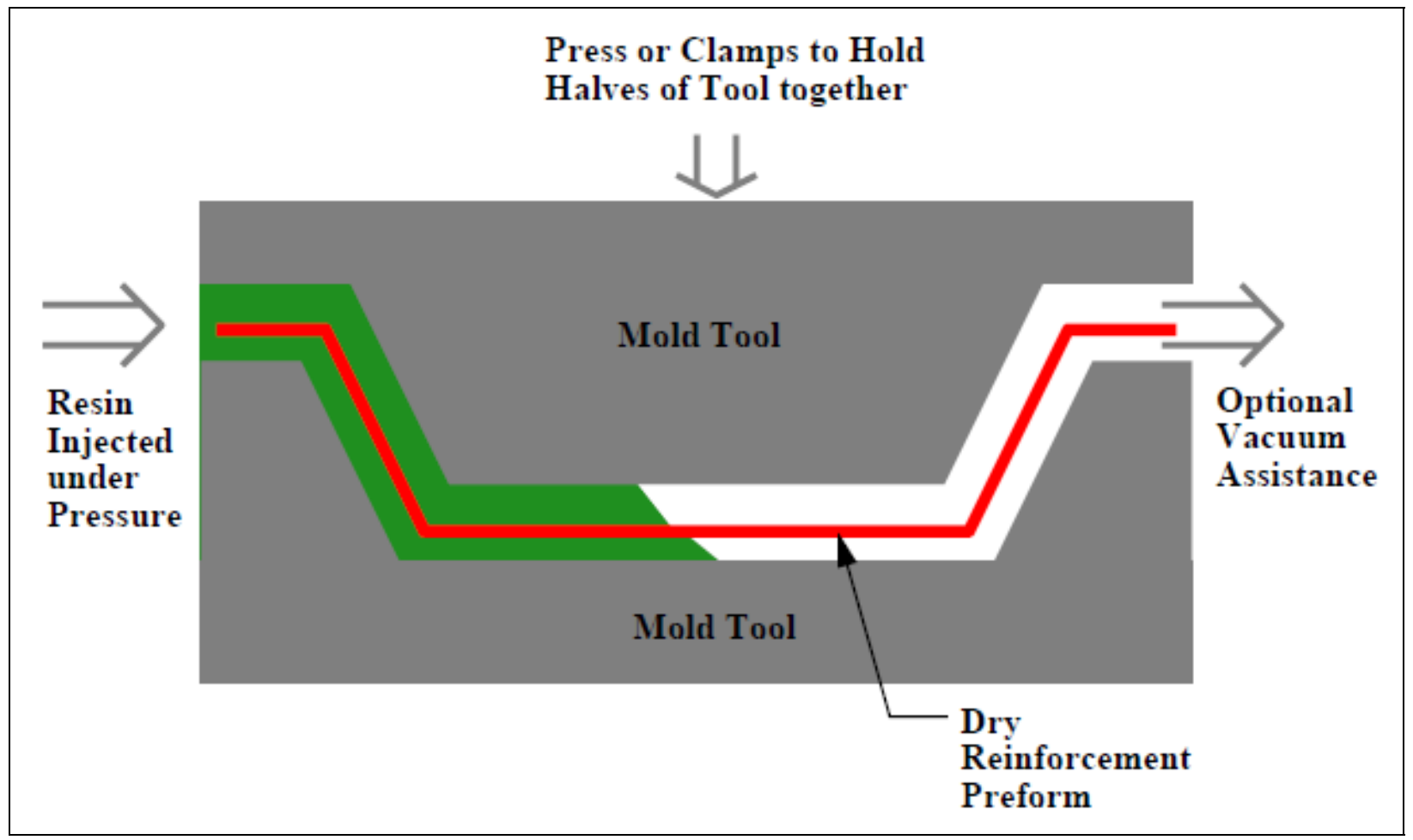

Figure 10: RTM Process Overview [7]

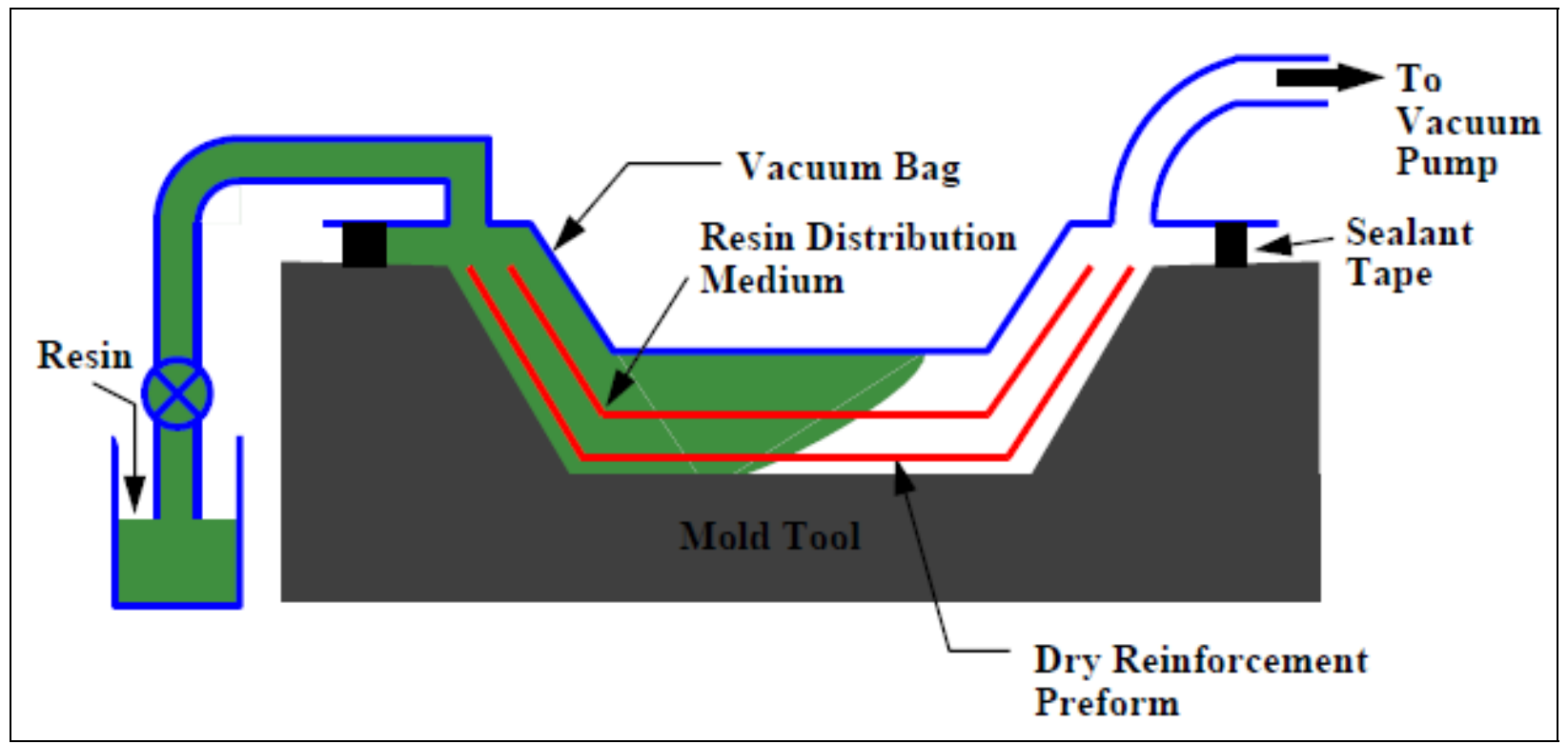

Figure 11: VARTM Process Overview [7] 
There are many types of fabrication techniques to lay-up composite material. The most common practices for constructing cylindrical, or closed section shapes are filament winding and hand lay-ups. Filament winding is an automated process known to make reliable parts using a predefined computerized lay-up program. It involves winding continuous fibers which are aligned by mechanical processes. Many modern filament winding machines are CNC controlled which gives precise control on the placement of the carbon fibers. The fibers are wound from a spool so the fibers can remain uncut throughout the entire process. In industry, filament winding is used to make all types of cylindrical shapes which vary from bicycle frame tubes to rocket shells and other types of pressure vessels [8].

One good example of an application for filament winding comes from the Air Force Research Laboratory. The Wilson Composites Group working for the Air Force Research Laboratory has demonstrated that it is feasible to create filament wound liquid propellant tanks which could eliminate the metallic liner and various other metallic components which saves significant weight and manufacturing costs. They first proved that they could fabricate 18 inch and 4 foot diameter liner less tanks which would meet all the requirements of the metallic lined tanks. The next step in the research was to replace the metallic closures and bosses which account for $85 \%$ of the overall weight of the tank. Closures were filament wound around a metallic mandrel and finish machined to ensure a good sealing surface. The machining of the composite closures was significantly less time consuming (4 hours compared to 16 hours from metal which yields a 75\% reduction in machine time) and minimal material was removed, whereas machining the closure from metal required that approximately $50 \%$ of the material was removed from the original solid billet. The bosses were hand laid up using a standard mold. The program demonstrated that it is feasible and cost effective to produce composite filament wound 
tanks with the same performance criteria as a metallic tank. Comparable diameter tanks also were much lighter which allows for a larger payload. An 18 inch diameter pressure vessel proved to be 69 pounds lighter when compared to the original metallic tank [9]. This is a great breakthrough for the aerospace industry and would not be possible without the use of high performance composites and filament winding. Many of these applications use cylindrical or slightly tapered mandrels, but more complex shapes require other types of tooling.

\subsection{Advanced Tooling and Types of Mandrels}

Mandrel design has been around for hundreds of years and is used in every type of industry. Although mandrel tooling design can be very advanced, early tooling for composites was used primarily to manufacture simple shapes using basic design techniques. Mandrels were typically designed with little or no taper and used mainly for manufacturing filament wound, cylindrical pressure vessels or piping. It was not until recently that manufacturers have begun pressing the limits of carbon fiber by using complex tooling to create parts which were previously thought of as unattainable. Many industries now incorporate advanced highperformance composites into their products.

As engineering composite parts advanced, the tooling has also become more complex and can be much more expensive to produce. Evolution of prototype tooling and other cost-reducing manufacturing processes have helped to offset the costs of the complicated tooling, but tooling continues to be the highest cost item in the fabrication of many designs. In an exceptional example, in large structures for space launch applications, tooling costs can be as high as ten percent of the cost of a launch [10]. Numbers such as these have insured ongoing efforts to design more affordable tooling — while, of course, maintaining or improving the quality of the parts produced from these tools [10]. 
Cost is only one of the challenges to overcome when designing tooling for specific applications. Demands of the tooling design and tooling engineers have become increasingly complex as part complexity progresses. A single tool may be made up of many parts, including parts made from different materials intentionally selected for their different thermal expansion coefficients, heat capacities and other properties with the goal of providing different compaction, heat rates and other properties in different areas of the design [10]. A particularly challenging area of tool making for composite materials is in accommodating "trapped" shapes [10]. An internal tool will be trapped, for example, whenever an internal dimension is larger than any of the exit dimensions or if an undercut prevents tool removal [10]. Many different applications and types of trapped tooling configurations have been proven to work and are widely accepted. There are also many new trapped tooling concepts that are being developed and provide significant challenges [10]. Some of these concepts are not cost effective to implement into production and other concepts use materials such as silicones that are not compatible with the engineering composites materials.

\subsubsection{Metallic tooling mandrels}

A variety of metals are used for tooling but the most common, due to its combination of fairly low coefficient of thermal expansion (CTE), durability, and tolerable cost, is steel. In addition, steel has the advantage of being machine-able to tight tolerances. Hard-metal steel tooling typically is the standard against which all other tooling is judged. However, steel tooling has the disadvantage of requiring long lead times (often several months) and being costly both to fabricate and to finish. It usually cannot be reworked, so if the tool design is in error or changes, the tool usually must be scrapped. Steel tools are also typically heavier than comparable carbon tools and require more lifting provisions such as hoist rings and fork lift tubes. 
Invar, a nickel alloy, has a CTE much closer to that of composites but is quite expensive both in initial material and fabrication costs. It also has a higher stiffness, and thus resistance to warping and is more durable than steel.

Aluminum is used in some applications. Aluminum is relatively easy to machine and thus less expensive, but its CTE is much larger than the typical composite so its use is typically limited to lower temperature applications. It is lighter than steel or Invar, but also less stiff and thus unsuited to high stress applications, where warping may occur. Aluminum has been used in some cases where larger thermal expansion can help the tooling process. It can be used as an intensifier when coupled with mold materials with less CTE. In our case, this high thermal expansion coefficient can provide useful when properly used to press against steel in high temperature cures.

Metallic tooling is reusable and, in fact, due to its high cost typically must be reused many times to amortize its cost over many parts. If trapped shapes are involved, metallic tooling must be made to separate along parting lines, otherwise be collapsible, in order to be removed. If the exit area for removal is small, this may be very difficult or even impossible. In addition, to reuse the tool it must be reassembled. If it involves multiple or complex parts, this operation can be very time consuming.

\subsubsection{Inflatable and Flexible Mandrels and Molds}

Flexible tooling is an alternative solution to fabricating trapped shapes that allows tooling to be both reusable and removable.

For applications where internal tooling is required, such as filament wound pressure vessels and other hollow structures, inflatable latex or other elastomeric bladder-type mandrels can be used. These have been very successful in some applications, but often cannot produce 
parts with high enough tolerances for high-performance applications, particularly when multiple sections must be mated together after cure. Bladder mandrels may be augmented with a collapsible support frame to improve dimensional accuracy, but this frame then presents some of the disadvantages of collapsible metal tooling. Bladder mandrels are designed to be reusable, but will deteriorate after repeated use making them unusable/consumable.

A unique extension of the bladder mandrel concept, but one that does not rely upon air or fluid to hold its shape is the shape-memory polymer (SMP). Cornerstone Research Group, (CRG) of Dayton Ohio has developed a series of SMP's that can be shaped with air pressure in a female clamshell mold at elevated temperature but when cooled to below their transition temperatures become and remain rigid. The tool, thus produced can serve as the internal mandrel for an operation such as filament winding, easily sustaining the pressures required. So long as the composite is cured below the temperature specified for that particular SMP the mandrel will remain rigid. The polymers currently being marketed by CRG will permit composite cure to $185^{\circ} \mathrm{F}$ [10]. Cornerstone Research Group is also developing a material system capable of curing parts at $350^{\circ} \mathrm{F}$. Although they continue to improve the material systems, the SMP mandrels available have demonstrated prototype aerospace-grade composite fabrication, but lack the durability to endure a traditional high production rate manufacturing environment [11].

\subsubsection{Composite Tooling}

Monolithic graphite (composite) tools have always been considered a viable option when designing tools. Tools built from the same material as the production part help to overcome differences in thermal expansion and scale factors are not required in the design. This material will handle high cure temperatures and has no CTE issues when laying up composite parts which 
means no scale factor needs to be designed into the tool which saves design time. Composite tooling also can reduce tooling costs as well as improved lead-times for tooling fabrication because the material is readily available [10]. There are several problems with using monolithic graphite as the material for the study mandrel. First, a tool made of graphite will still need to be a segmented or multipiece mandrel because of the geometry of the spar that needs to be fabricated. Although composite tooling is known to be rigid, the stiffness of a solid carbon tool with the dimensions required for the study spar will not allow a 13' span without significant sag, so if the tool needs to be segmented, it will not support its own weight while maintaining the straightness and a surface profile requirements. The second and possibly the most significant problem is that the graphite mandrel will not provide internal pressure to the plies which need to be pressed into the corners of the outer mold. Although the CTE of monolithic graphite is an excellent match with carbon in most cases, a tool is needed that will provide a larger CTE than the part material, so the tool will work as an intensifier.

\subsubsection{Ceramic Tooling}

Ceramics have many forms, and can be used when making tools which require very high cure temperatures. Some ceramic materials can be cast at room temperature and withstand curing temperatures in excess of $2000^{\circ} \mathrm{F}$ [12]. Most ceramics have a CTE around $2.3 \times 10^{-6}{ }^{\circ} \mathrm{F}$ which is valuable in many cases, but does not provide the expansion required in this case [13]. Cured ceramics are also known to be extremely brittle and heavy. This material is not a good choice for the spar mandrel in question.

\subsubsection{Dissolvable and Break-out Mandrels}

Dissolvable mandrels are typically seen as one time use tooling. Usually, they are constructed in a single piece which can later be washed-out or broken-out of the cured composite 
part. There are many types of materials that these mandrels can be produced from including, but not limited to, eutectic salts, ceramics, sand, and plaster. These types of mandrels allow a lot of versatility to the design of trapped shapes, but still have manufacturing issues. Some things to consider before choosing this type of tooling is the environment that the tool will be used, the requirements of the final part produced from this tool, and the rate of production. Another aspect that is sometimes overlooked is the fact that one time use tools must be remanufactured or molded each time so tooling must be designed to manufacture the one time use tools. If the manufacturing process of creating the tooling is not closely controlled, the tool must be machined to achieve good part surface profile. Some types of dissolvable mandrels can be machined within tight tolerances (surface profile of .005”) to produce a good mold surface however, since these tools are one time use, the machining must be done each time.

Many of the materials currently available for manufacturing dissolvable materials require special wash-out methods which may use harmful chemicals that will negatively react with the part material. Aircraft manufacturers typically require very special procedures for flight ready composite parts and many foreign materials are prohibited from coming in contact with the parts. The mandrels which can be washed out with water are hydroscopic and must be protected from moisture exposure prior to use. This means that the manufacturing plant and any area where the tool will be located must be humidity controlled. Since many of the mandrels in this section are water-castable as well as water-dissolvable the drying process of the tool must be closely controlled. Many types of these mandrels have problems with shrinkage and cracking when the tool is being fabricated. 


\subsection{Industry Uses of Mandrels}

Many aircraft designs require the use of mandrels, but there are many other industries that necessitate mandrels to fabricate parts or assemblies. Any types of cylindrical parts will require mandrel tooling. One application that has adopted carbon fiber cylinders is air tanks. They are light weight, durable, and lighter than traditional tanks. Although these tanks must be fabricated over a mandrel, typically they are uniform throughout the entire length and the tooling is much simpler than what is required for this wing spar design.

One industry in particular is using mandrels in unique ways. Current windmill fabrication across the world has implemented the use of fiberglass and carbon fiber blades which requires custom mandrel tooling. The windmill blades seen in Figure 12 are very similar to airplane propellers. The major difference is that the windmill blades must be light enough to turn a generator in even mildly windy conditions. To maximize the efficiency of the wind turbine, the blades must be light and sturdy enough to support their own weight and wind loads yet light enough to be turned easily so the majority of the wind power goes to making energy. These large propellers can range from 20 to $180 \mathrm{ft}$. in length and be made from many materials, but the majority of the newest wind turbines are fabricated from composites or fiberglass which require custom mandrel tooling. Some companies are using dissolvable mandrel tooling and others have been able to fabricate blades using flexible mandrels, but none are sufficient for the tolerances that aircraft tooling must hold which is sometimes as tight as .001”. 


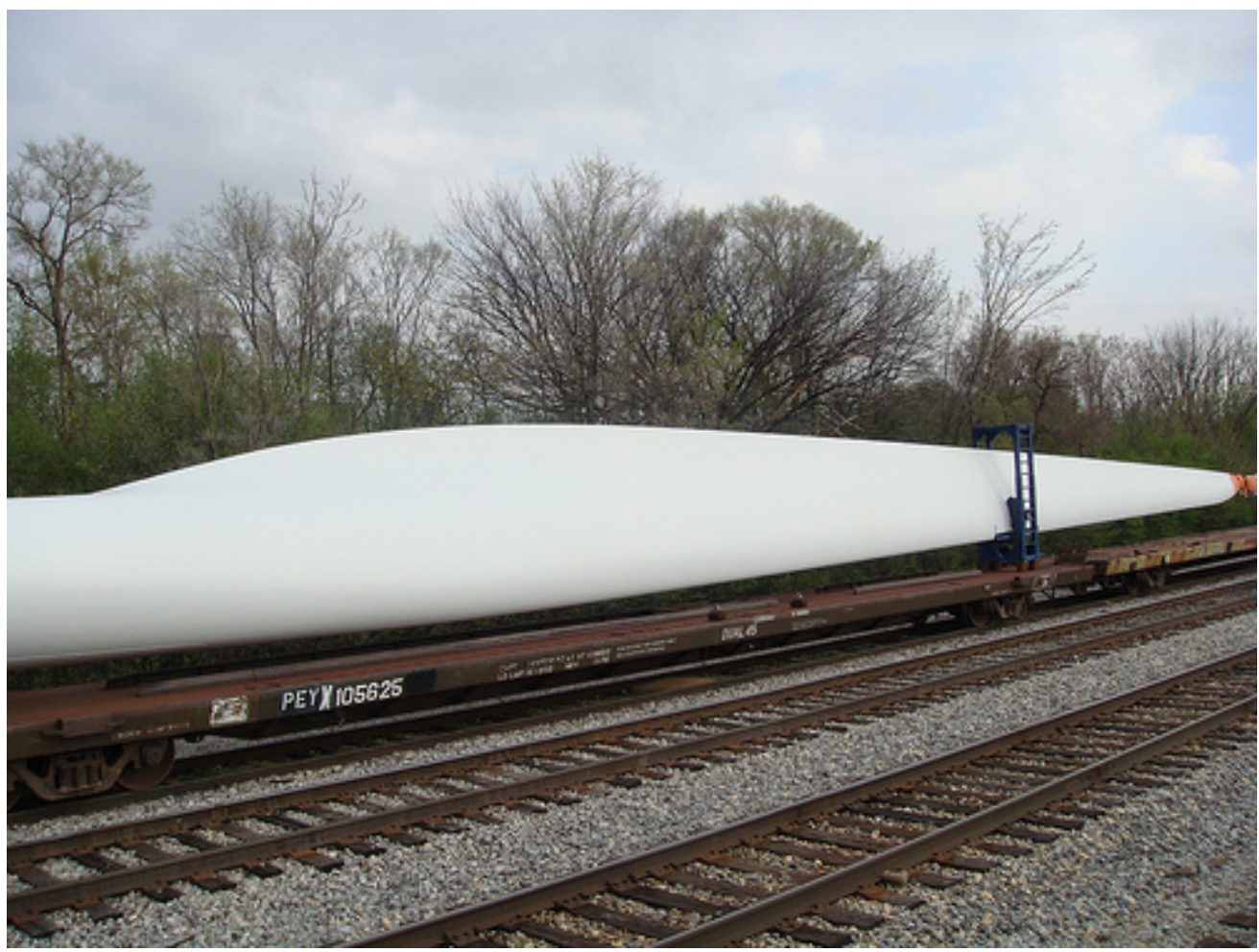

Figure 12: Composite Windmill Blade [14]

\subsection{Literature Review Summary}

Engineering design is always pushing the limits of current technology and engineers are faced with another challenge that must be met with new equipment that will support the latest designs. The current methods established by companies around the world are not sufficient to meet the needs of this particular spar so a tool must be designed that will work for this particular part. A single piece dissolvable or break-apart mandrel would be the best choice if one of the current methods described above must be used, but currently there is no good way to produce acceptable parts without destroying the mold each time. 


\section{Design}

\subsection{Design Constraints and Requirements}

The requirement of this project is to redesign the inner mandrel of the current spar tooling to create better wing spars and lower costs and maintenance of the tooling. The inner mold line geometry of the part causes a trapped section so the tool must be able to come out of the part after it is cured. The existing tooling components must be taken into consideration when designing the inner mandrel. The customer asked that the outer steel mold not be redesigned. It is a steel clamshell style mold that creates the outer mold line (OML) of the part during the cure cycle. A picture of the clamshell mold can be seen in Figure 13. This wing spar will consist of both woven and unidirectional preimpregnated carbon fiber material. To ensure consistency and proper placement, these materials must be hand laid on the mandrel in accordance with the ply design. Each ply has a tolerance of +/- .030” positional tolerances.

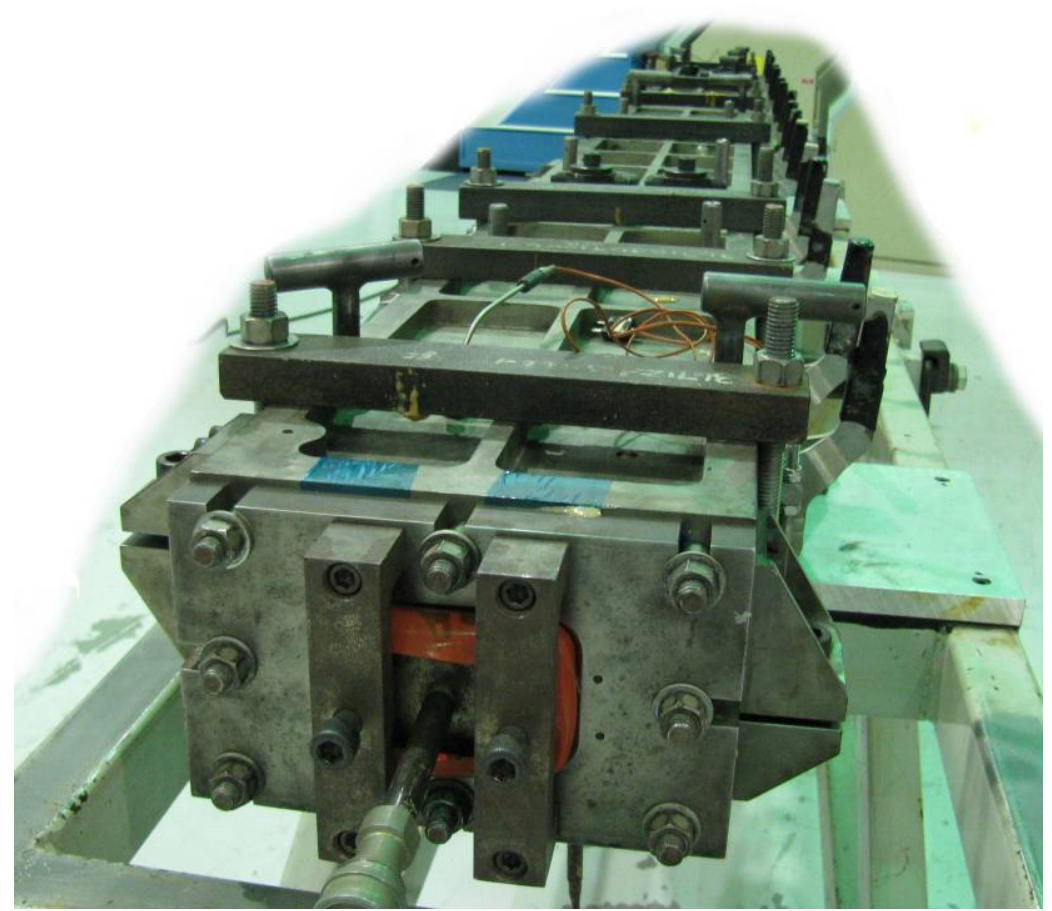

Figure 13: Clamshell Mold 
Typically, a tool with this many plies would be placed in a laser bay similar to the one shown in Figure 14 and the lasers would be used to locate each ply. The lasers have a tolerance of .020 " to locate the EOP of the plies. The requirement for this is that the tool is stationary throughout the lay-up process.

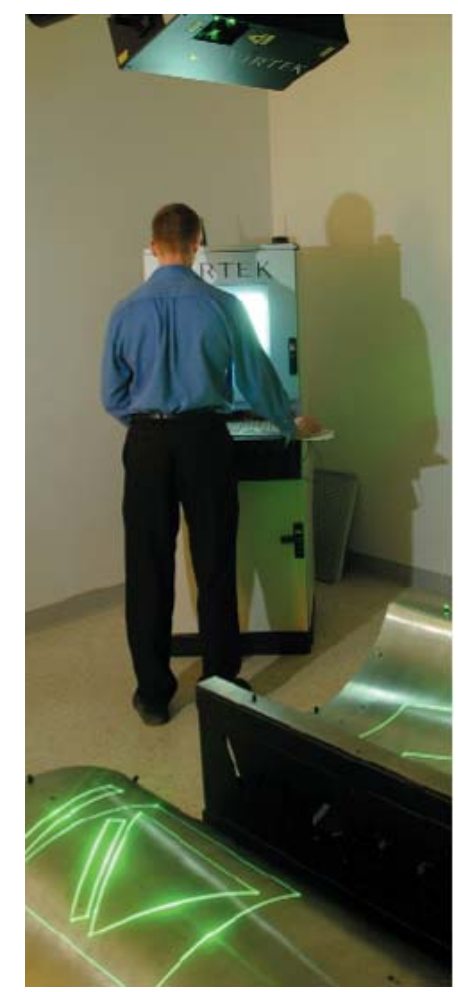

Figure 14: Laser Projector Bay [15]

In this case, the tool must continuously be rotated, which will not allow the laser projection system to be used. For this part, design engineering has come up with a ply placement chart that the technicians must follow. Although this is the most costly method of material placement, the low production rate and the tight engineering tolerances require it. This also requires that a trunnion system must be designed to rotate the mandrel during lay-up.

The functionality of the tool is an important part in making accurate and repeatable parts, and the success of the airframe relies heavily on the quality of the spar produced. Many factors must be considered when designing tools with such tight tolerances that must also be functional 
and repeatable. The engineering design of the spar was broken down and looked at in one inch intervals over the entire 162 inches of spar length. Appendix B shows the entire breakdown of the engineering detail inch by inch. The tool must also extend 7.25” beyond the length of the part in both the root and tip directions as seen in Figure 15. This will allow technicians to lay material past the edge of the part (EOP). Extra length on the tool is also required at the thickest section of the part which is the root end to lay up test samples which will be subject to destructive testing to ensure the quality of the cure and the material.

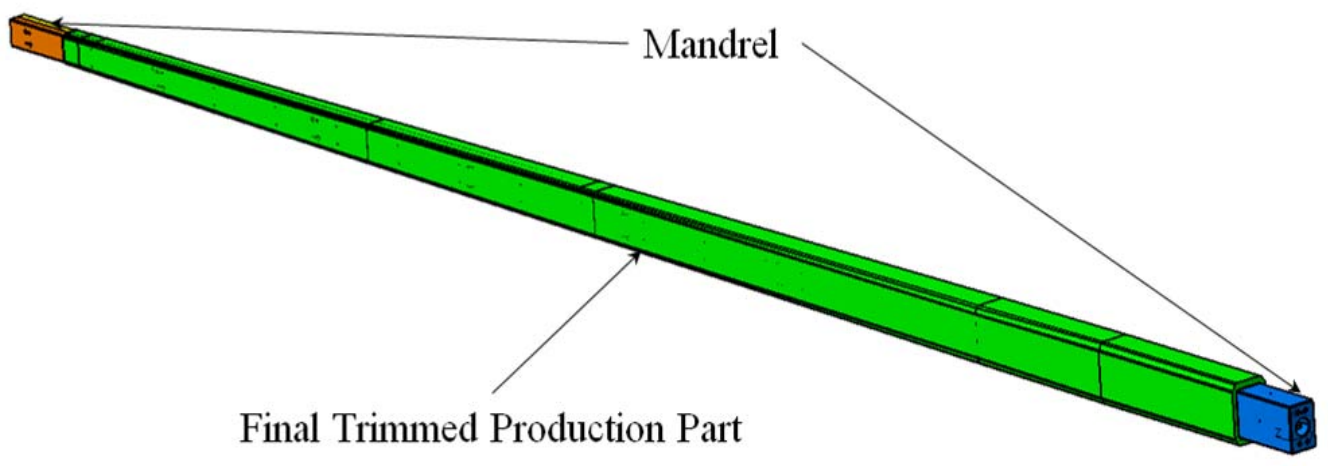

Figure 15: Final Trimmed Part Shown with Mandrel

The first step to designing the tooling is to understand the heat cycle and the growth of the materials involved. Since pressure must be put on the inside of the spar to reduce wrinkling and ensure pressure on the outer mold line, a material with a greater coefficient of thermal expansion than steel must be used. The cure cycle for this particular spar was designed to maximize the structural properties of the carbon blend chosen. The part and tool must be heated from ambient temperature of $68{ }^{\circ} \mathrm{F}$ to $300{ }^{\circ} \mathrm{F}$. The tool must also heat evenly so thickness and mass must be considered during the design phase. A list of tooling materials, their CTEs, and the growth over 176.7” (final length of mandrel tool) can be found in Table 1. 
Table 1: Tooling Materials and CTE Growth

\begin{tabular}{|c|c|}
\hline Ambient Temperature $\left({ }^{\circ} \mathrm{F}\right):$ & 68 \\
\hline Cure Temperature $\left({ }^{\circ} \mathrm{F}\right):$ & 250 \\
\hline
\end{tabular}

\begin{tabular}{|c|c|c|c|c|c|}
\hline Material & CTE $\left(\mathbf{1 0}^{-6}\right)$ & Original Length (in) & Length at $\mathbf{2 5} 0^{\circ} \mathrm{F}$ & $\mathbf{\Delta}$ Length & \% Increase in Length \\
\hline AL 6061-T6 & 13.1 & 176.7 & 177.12 & 0.42 & 0.24 \\
\hline A36 Steel & 6.5 & 176.7 & 176.91 & 0.21 & 0.12 \\
\hline $\begin{array}{c}\text { Annealed } \\
\text { Stainless AISI 302 }\end{array}$ & 9.6 & 176.7 & 177.01 & 0.31 & 0.17 \\
\hline
\end{tabular}

Aluminum was determined to be the best choice because of its CTE and its ability to maintain stiffness during the lay-up process. It will also expand further than the outer steel mold so it will apply pressure directly against the inside of the carbon. Aluminum is also easily machinable and has a Brinell hardness of 95 which will give the IML (inner mold line) a good finish while still providing the pressure at temperature to also form an acceptable OML against the clamshell outer mold. Although the mandrel tooling must provide an overall quality surface of the carbon, there are specific areas that have tighter tolerances. These areas include flats along the caps of the spar where it has an interface with the wing skins. The engineering design requires that the IML of the spar meets a profile tolerance of .060” so the tool must have a profile tolerance of .020”. The other tight tolerance area is the inner and outer mold line at the root end of the spar. The root end shown in Figure 16 is especially important because it will house the fitting that will connect the spar and the main aircraft framework. Other than drilled holes, there is no IML surface machining so the thickness in the area of the root fitting must be held to higher tolerances than the rest of the part. Outward from the root fitting the spar mandrel must continue to fabricate test coupons. These coupons will be destructively tested which will validate the layup and the quality of the material and cure cycle. The coupons will be tested for resin content, voids (air pockets), and wrinkling. The part that comes off the tool may look acceptable from the outside, but may have failing features that can only be found by using ultrasonic testing and cutting test coupons. If the material is past its expiration date or the cure cycle isn't correct, it's 
possible that the material may lose too much resin which would leave a part with dry cloth and would not meet the requirements of the aircraft.

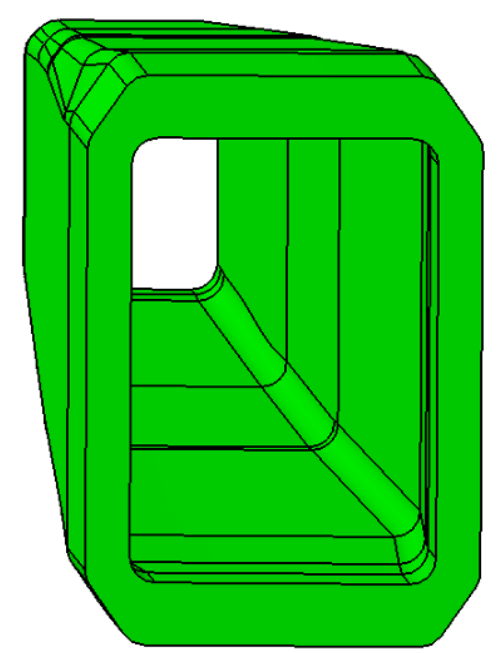

Figure 16: Root End of Main Spar

The most difficult area of the spar to control is the outer radii. The mandrel must have the correct contour when at the highest temperature during the cure cycle to provide sufficient pressure to push the material into the outer corner, but not too much pressure that could push material away from its placed location and cause wrinkling. The plies will be laid directly on a silicone bladder that is required to be on the mandrel. The mandrel will be pressurized in the autoclave which will help push the carbon plies away from the mandrel and against the outer mold surface.

While the spar is being laid up on the mandrel, the mandrel is only supported at each end by a trunnion fitting shown in Figure 17. A major concern is that the tool must first support its own weight over a length of $14^{\prime} 8^{\prime}$. It must also then be able to support all the weight of the prepreg material and forces of a technician applying the material on the tool. 
Figure 17: Areas to be Supported by Trunnion Fittings

The reason the tool is being redesigned is because the inner mandrel is trapped when the spar is cured. The main requirement of this tool is that it acts as a solid tool which produces acceptable parts and can be removed from the cured part without replacing the tool each time. This is especially difficult because the trapped area is located 15.25 inches inside the tool or 8 inches from the root end of the part.

\subsection{Design Concepts}

\subsubsection{Current Mandrel Manufacturing Process}

The current process uses a disposable mandrel which requires tribal knowledge to produce and repeatability is extremely difficult. As seen in Figure 18, the mandrel consists of nine (9) hand cut components. Each detail component of the tool must be hand cut using templates. The variability in this process does not produce the same results each time. Also this process requires 40 hours of work for each cure cycle. Currently, to meet customer needs, two acceptable spars must be built each month which is very difficult when using this process. The main problem area of this method is in the four (4) corner intensifiers. Each piece must be hand blended to ensure the final tool will produce a part that meets all specifications. Problems are encountered with the shapes and also the durability of the corner intensifiers made from dense foam material which is used for these details along with the upper and lower foam boards shown in Figure 18. The shape mandates that the material must be sanded thin so it becomes very difficult to hold and shape during the manufacturing process. 
After each detail is hand sanded to the correct shape using a series of templates, the tool must be assembled. First, the upper and lower foam boards are layered over a solid inner core (aluminum box structure) to achieve the desired basic geometry. A 14' long .060" thick bladder must then be rolled over the bonded foam cores. This bladder will serve as an intensifier in the curing process and helps to reduce bridging in the radii. The corner intensifiers can now be bonded to the outer side of the inner bladder. These corners are made from a dense foam with a higher CTE than that of carbon so when at temperature, they will expand and push the material into the corners of the outer mold. The final step of this tool fabrication process requires that another rubber bladder is tightly fit over the whole tool assembly. This outer bag pushes the material against the walls of the clamshell outer mold and helps to deter wrinkling in the finished spar.

The lay-up of the mandrel is a process that cannot change. Preliminary work must be done prior to laying the plies on the mandrel. Flat pattern files are created from an engineering design model which shows the periphery of each ply along with a unique ply number and the type of material located on the surface which will later be transferred onto the cut ply with a special pen that is made to write on the backing of the preimpregnated carbon fiber. The flat patterns are then nested to maximize material usage using a program called CutWorks. For this particular part there are 178 individual ply shapes that must be individually cut and strategically placed. Once the files are completed, the process is then moved to the clean room where the material will be cut and located on the tool.

During cure, 35PSI air pressure will be pumped into the inner box structure which contains holes running the entire length of the tube on both sides. This will allow the inner 
bladder to push the corner intensifiers and carbon laminate into the outer corners of the clamshell mold.

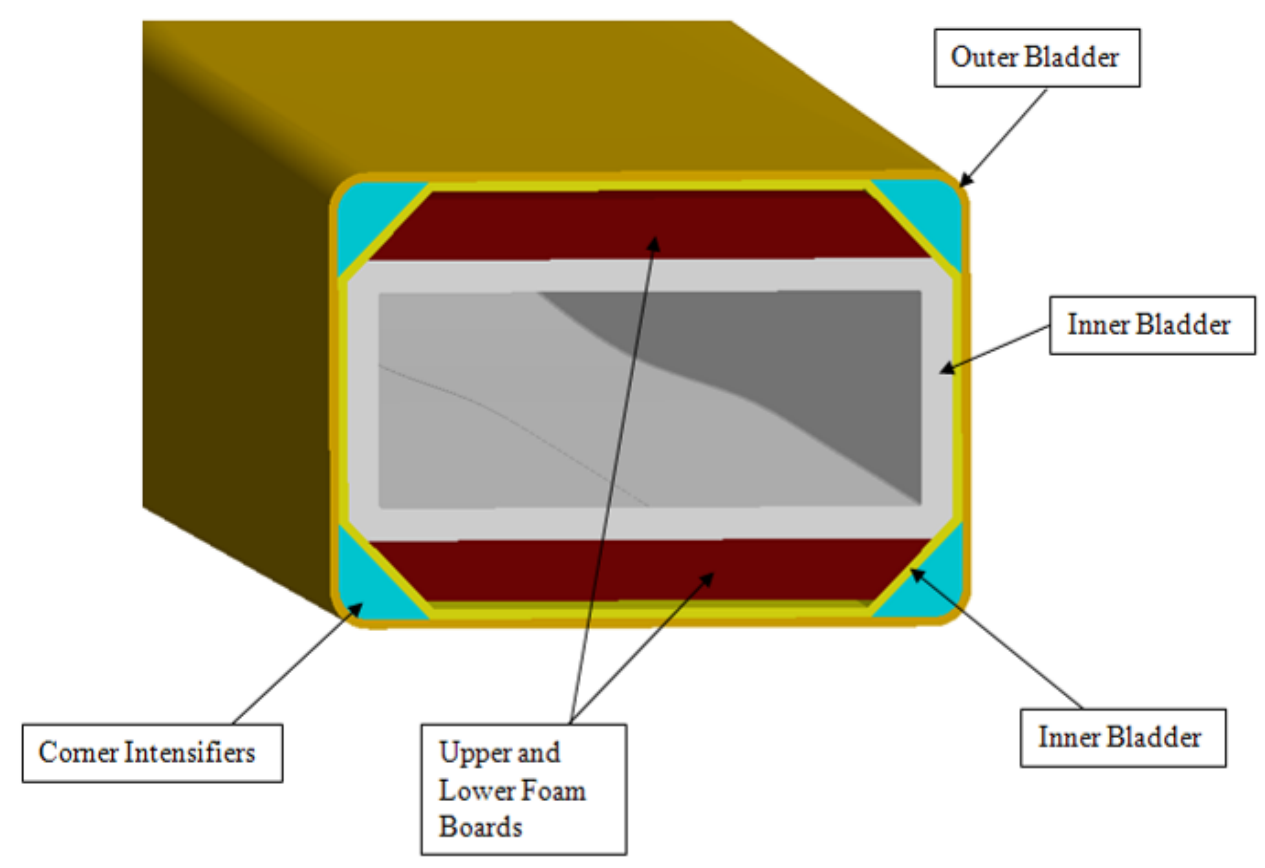

Figure 18: Current Mandrel Sections

The current spar manufacturing process is not efficient and requires an average of 48 man hours to fabricate each disposable mandrel. These factors, along with the fact that the mandrel does not give consistent results each time drove the decision to design a new method to create spars. The following sections show some of the concepts for a new mandrel tool that were presented to the customer.

\subsubsection{Concept \#1}

The first concept, seen in Figure 19, was to use aluminum expandable webs encapsulated in a silicone surround to counteract bridging in the radii of the spar (area of voids). The silicone encasement serves two purposes. Its main purpose is to support the material during lay-up and 
will keep any resin from contacting the collapsible webs. Its second purpose is such that the large CTE of encapsulation grade RTV silicone (111-161 $\mu$ in/in- ${ }^{\circ} \mathrm{F}$ [16]) will aid in the inner pressure during the cure cycle. This concept allowed for the use of air pressure coupled with the expansion of the aluminum and silicone against the carbon and the steel outer mold to compact the carbon material against the walls of the outer mold. The mandrel tool would also use vacuum assist to pull the aluminum webs inward to assist in removing the tool from the trapped part post cure.

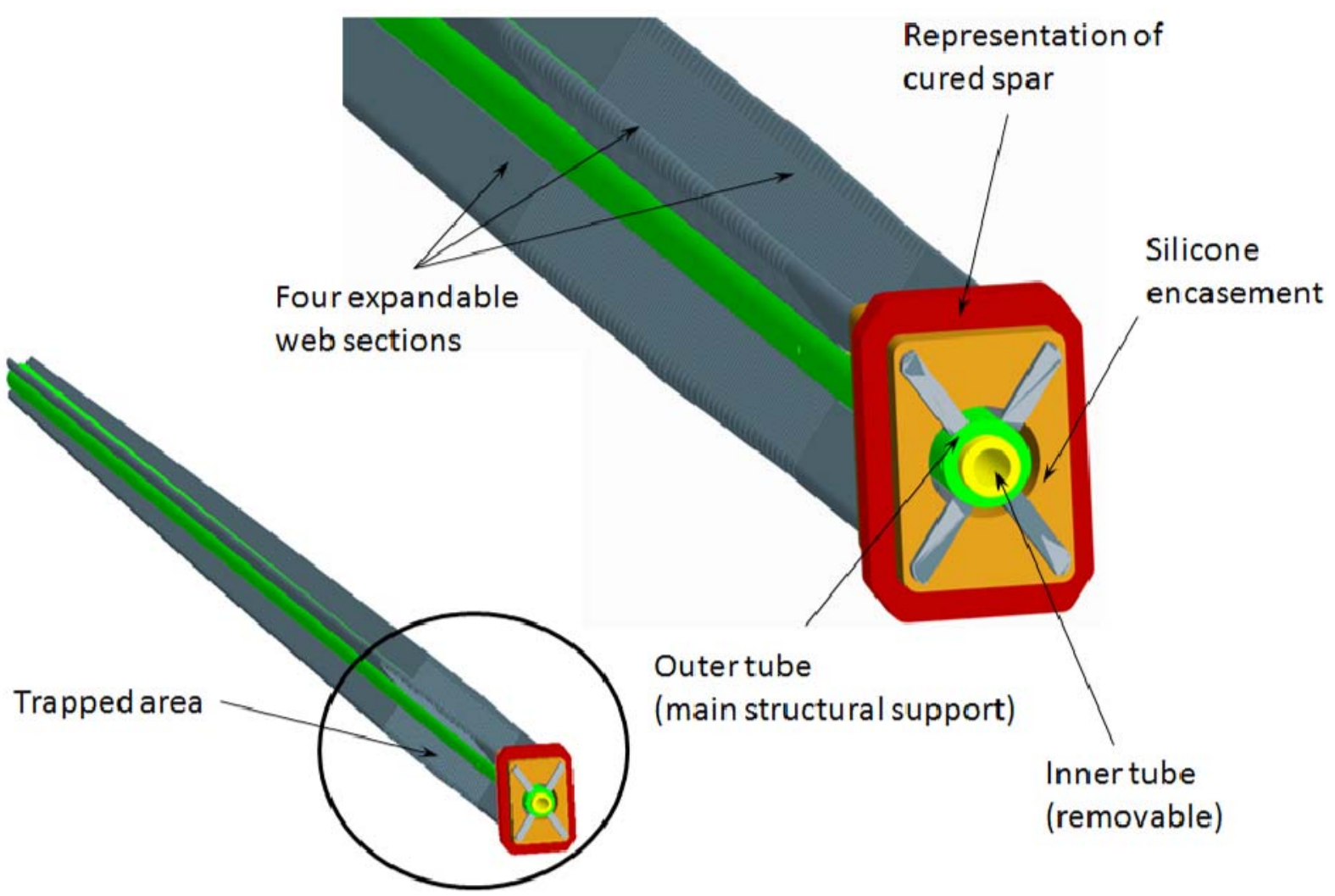

Figure 19: Concept \#1

As shown in Figure 20, four slots in the main tube will be cut to accept the expansion sections during removal of the tool. During lay-up and cure the removable inner tube will be in place to ensure that the expandable sections stay out to support lay-up and push only outward against the material during the cure cycle. 


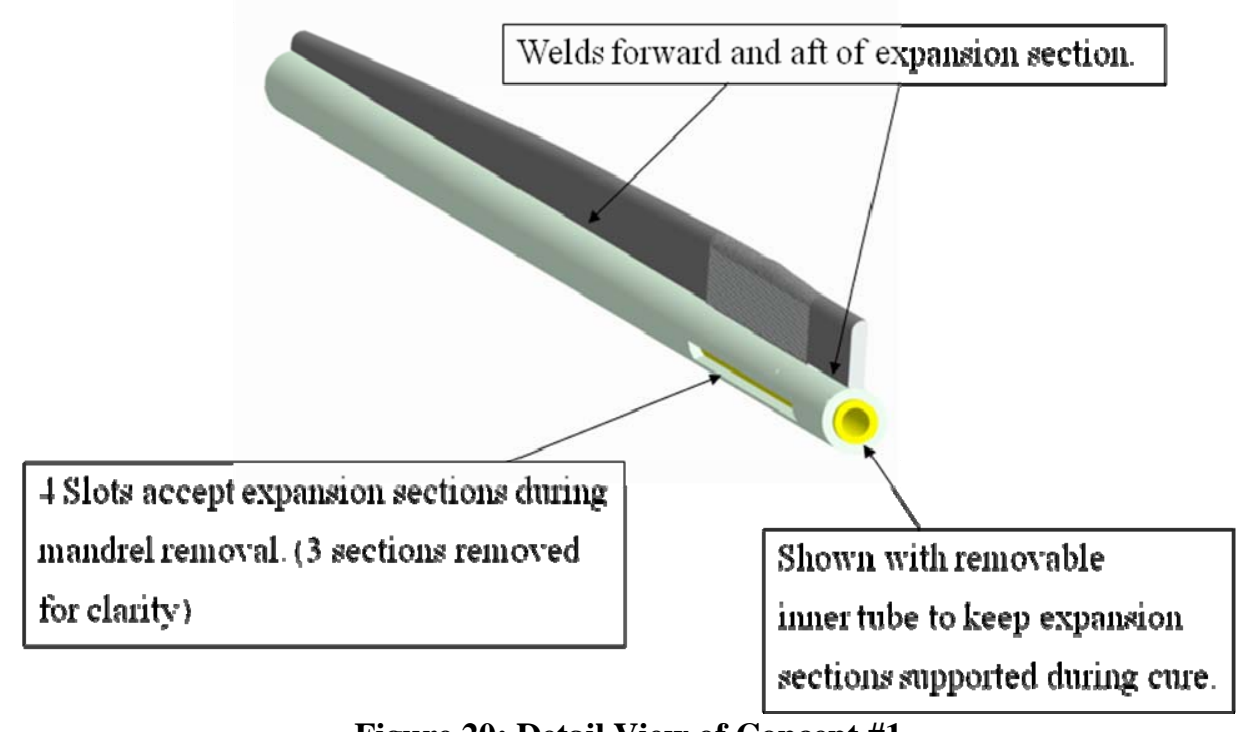

Figure 20: Detail View of Concept \#1

The main concerns of this concept are that the silicone will not withstand multiple cure cycles and need to be replaced often. This concept also requires that a secondary mold be machined to form the silicone encasement. The aluminum webs would also be difficult to machine and to allow the material to flex would require thin sections that may be susceptible to cracking which would result in tool failure and a scrapped part.

\subsubsection{Concept \#2}

The second concept is a metallic segmented mandrel. Figure 21 illustrates the multiple piece sections required to make the trapped tooling. The machined sections would be assembled as shown in Figure 22 to create one tool and incorporates a removable section in the area of the trapped feature. This concept will require a system that can hold the pieces together while lay-up and cure, but able to come apart after the cure cycle. Unlike concept \#1, this tool will not have the assistance of the silicone encasement to hold the sections of the tool together. The tool will have a silicone bag drawn over it, but it must be able to hold itself together with minimal deflection during the lay-up process. The sections cannot be bolted or secured from the sides because there will be no way of removing to bolts prior to curing to allow the tool to be removed 
from the part. The concept uses a central rod that ties all of the sections together to act as a solid tool. This rod can be accessed from the open root end of the part to be removed.

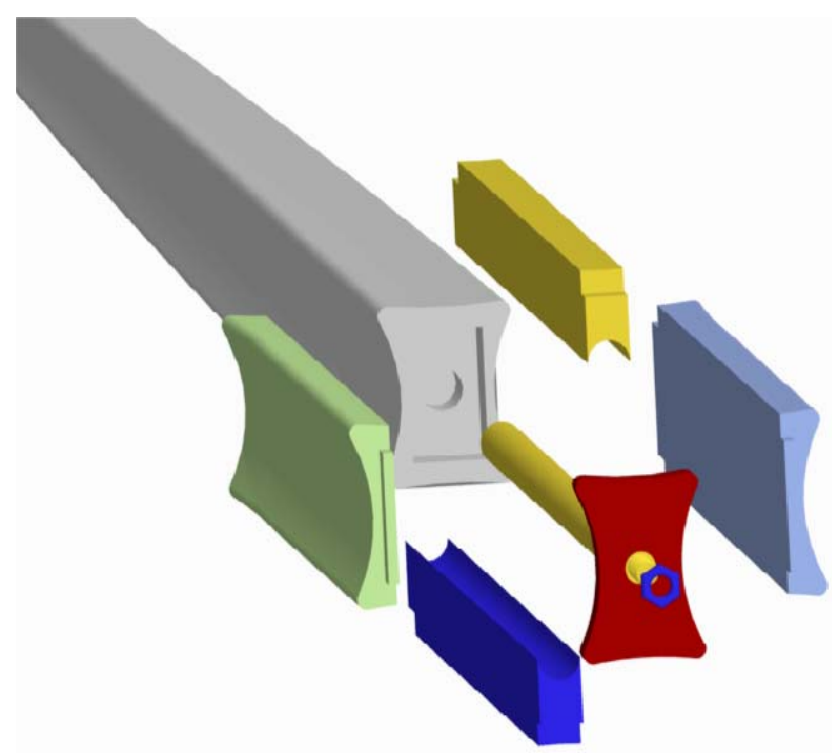

Figure 21: Segmented Mandrel Concept

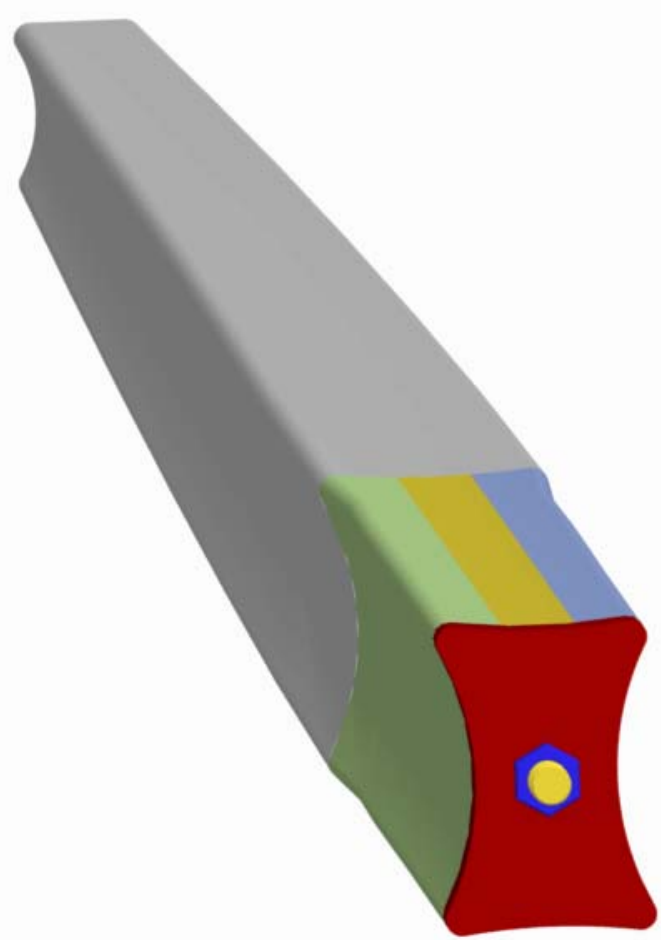

Figure 22: Assembled Segmented Mandrel Concept

The primary concerns of this concept are that the pieces will have to be machined to tight tolerances so they fit together and act as a solid tool with no variance in the fit of the parts. It 
must meet a surface profile of .020 ” to ensure that the part meets customer requirements. The second concern is that the tool will be too heavy to support itself over a span of 14 feet 8 inches and the multiple sections will not fit together tight enough to form a high quality mold tool.

\subsubsection{Concept \#3}

The third concept was a combination of selecting a new mandrel design and modifying the existing outer clamshell mold as well. The prepreg material used for the layup typically has a higher resin content than what is necessary for the final part. The current outer "clamshell” mold has holes in the bottom half which allows trapped air and resin to flow out during the cure cycle. Figure 23 shows a completed spar still in the clamshell mold and you can see the excess amount of resin which has flown out of the mold. The problem is there is no way to control the amount of resin coming out of the mold which causes voids in the final product and dry spots in the material.

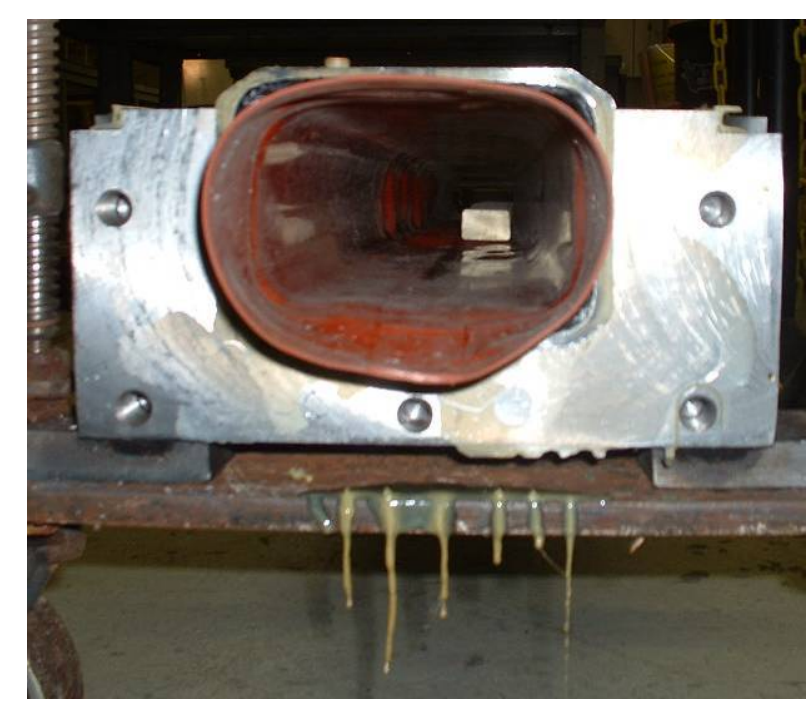

Figure 23: Hardened Excess Resin Which Has Flown From Mold

The proposed concept which can be seen in Figure 24 and Figure 25 plugs the existing holes in the outer mold. An o-ring seal will be added to the bottom layer and holes will be drilled at the top to accommodate vacuum fittings that will be used to pull any excess air and 
resin out of the mold in a controlled manner. A camera mounted in the autoclave can be used to monitor the amount of resin flowing out of mold, and vacuum pressure can be regulated or shut off remotely.

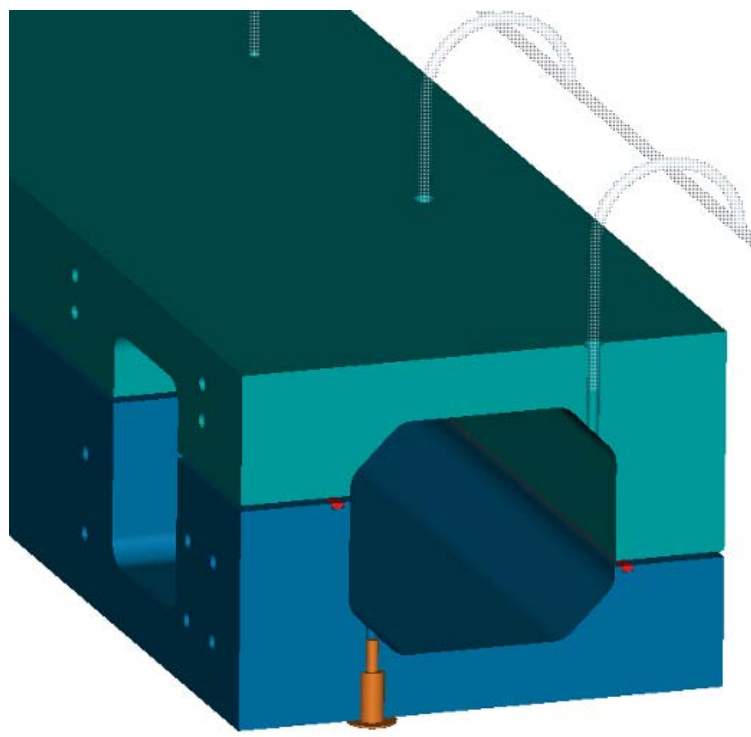

Figure 24: Existing OML Mold with Modifications

O-rings allow racum to be dramn on the entire lay-up.

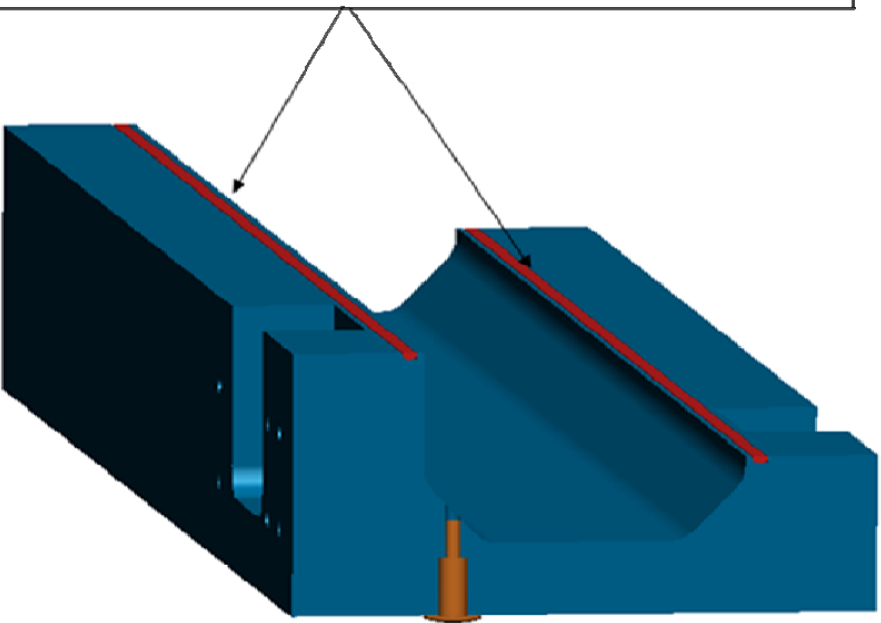

Figure 25: Detail of Modification to Existing Mold

(Upper Section Removed for Clarity) 


\subsection{Spar Mandrel Design and Analysis}

The final mandrel design was based on concept number two. All parties involved including design, manufacturing, and process engineers agreed that this concept will ensure the most quality part is made by the tooling. It will require more tooling design time, but the final product will be a high quality tool that will produce repeatable parts. This design will also be the most cost effective over the life of the tool by ensuring the least amount of maintenance. All major costs will be incurred during the initial design and fabrication costs.

Figure 26 shows the design process flow diagram for the spar mandrel and the critical steps through which the tool design will flow. In order to pass the deflection analysis criteria under worst case loading the mandrel must deflect less than the current tooling which has a maximum acceptable deflection of .26”. To pass the clash analysis criteria the newly designed tooling cannot clash with the cured spar during tool removal. .050" was set as a clearance zone all around the periphery of the tooling. Clash analysis will fail if .050” clearance is not held during removal. The inspection condition to pass is defined by the engineering tolerance. The tool must have a surface profile of .020 ” when assembled and each detail must meet tolerances as defined by tool engineering. 


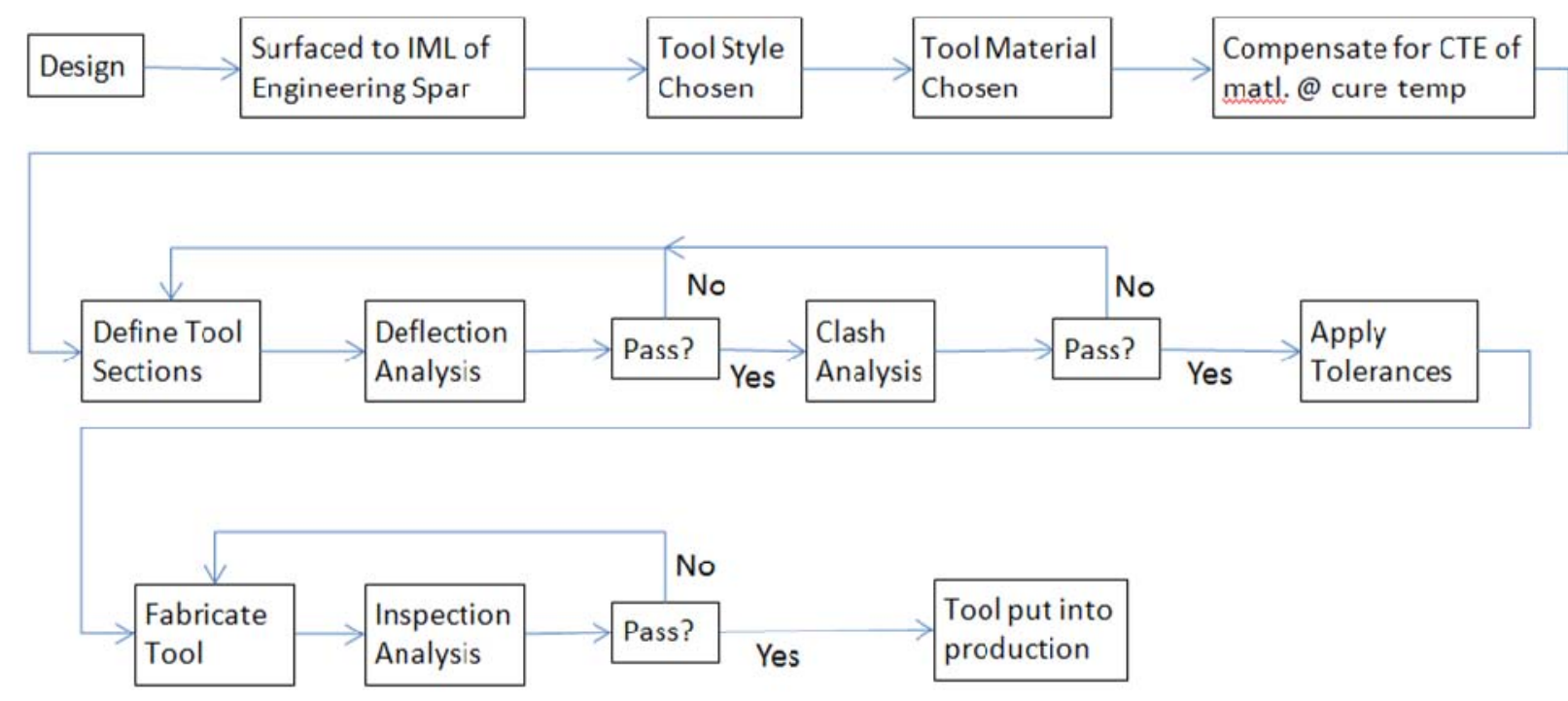

Figure 26: Design Process Flow Diagram

Aluminum was chosen as the primary material of the tool for its structural and thermal properties. The material properties for these materials can be found in Table 2. A bladder will also be pulled over the mandrel. During lay-up, the bladder will be vacuumed to the mandrel. During the cure cycle the bladder will be pressurized to push material away from the mandrel and onto the clamshell outer mold. Aluminum will assist with this process by expanding at temperature more than the outer mold which will apply pressure directly in the corners.

Table 2: Comparison of Possible Tooling Materials [17]

\begin{tabular}{|c|c|c|c|c|c|c|c|c|c|}
\hline & \multirow{2}{*}{$\begin{array}{c}\text { Specific Weight } \\
\mathrm{lb} / \mathrm{in}^{3}\end{array}$} & \multicolumn{2}{|c|}{ Ultimate Strength } & \multicolumn{2}{|c|}{ Yield Strength } & \multirow{2}{*}{$\begin{array}{c}\text { Modulus of } \\
\text { Elasticity } \\
\left(10^{6} \mathrm{psi}\right)\end{array}$} & \multirow{2}{*}{$\begin{array}{l}\text { Modulus of } \\
\text { Rigidity } \\
\left(10^{6} \mathrm{psi}\right)\end{array}$} & \multirow{2}{*}{$\begin{array}{c}\text { Coefficient of } \\
\text { Thermal Expansion } \\
\left(10^{-6} /{ }^{\circ} \mathrm{F}\right)\end{array}$} & \multirow{2}{*}{$\begin{array}{c}\text { Ductility } \\
\left(\% \text { elongation in } 2^{\prime \prime}\right)\end{array}$} \\
\hline & & Tension (ksi) & Shear (ksi) & Tension (ksi) & Shear (ksi) & & & & \\
\hline AL 6061-T6 & 0.098 & 38 & 24 & 35 & 20 & 10.1 & 3.7 & 13.1 & 17 \\
\hline A36 Steel & 0.284 & 58 & - & 36 & 21 & 29 & 11.2 & 6.5 & 21 \\
\hline $\begin{array}{c}\text { Annealed } \\
\text { Stainless AISI } 302\end{array}$ & 0.286 & 95 & - & 38 & 22 & 28 & 10.8 & 9.6 & 50 \\
\hline
\end{tabular}

The principal reason for redesigning the tooling is to ensure a repeatable process that will create a quality spar void of manufacturing defects. The largest hurdle from a design engineering standpoint is to design a tool that can be removed from the final part although there 
is a built-in trapped area. The nomenclature used to describe the design stations and geometry is shown in Figure 27. The design process will require two main steps, the first being to design a solid tool that will create the appropriate part geometry. The second will be to split the tool into sections that can be assembled and removed from the cured part.

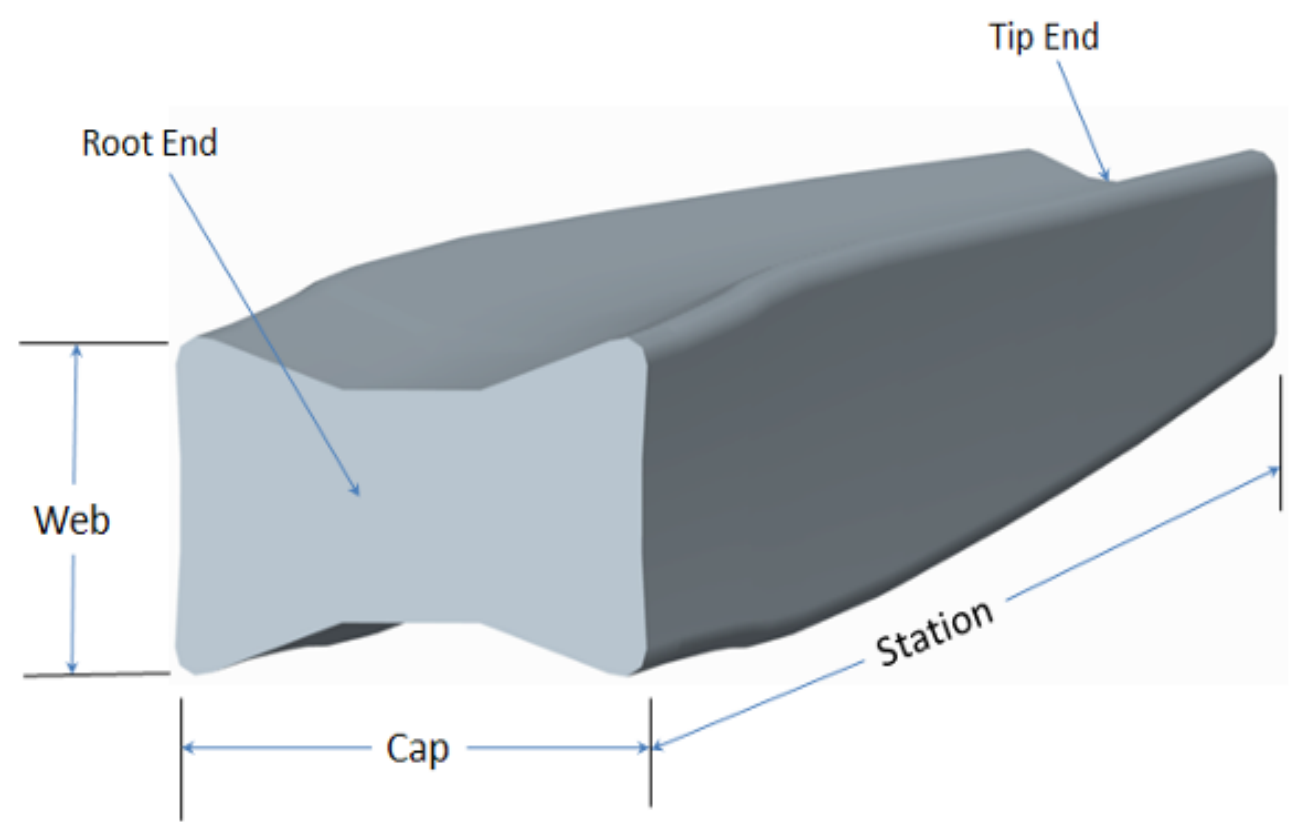

Figure 27: Spar Tooling Nomenclature

Figure 28 shows a graphical map of the IML part profile along the length of the part which has been analyzed from the customer provided model and broken down into 2” stations (STA). Figure 28 illustrates the trapped area of the part to be between STA 8 and STA 72 on the web and between STA 8 and STA 32 on the cap. Station 0 is a representation of the end of the part geometry at the root end and STA 162 is the EOP at the tip end so we will see that the tool is designed from STA -7.25 to STA 169.25. The outer mold (clamshell mold) is 177.2” long so the mandrel tool will produce a lay-up of 176.7 ” long which will allow for .25” of gap at either end of the mold at room temperature. 


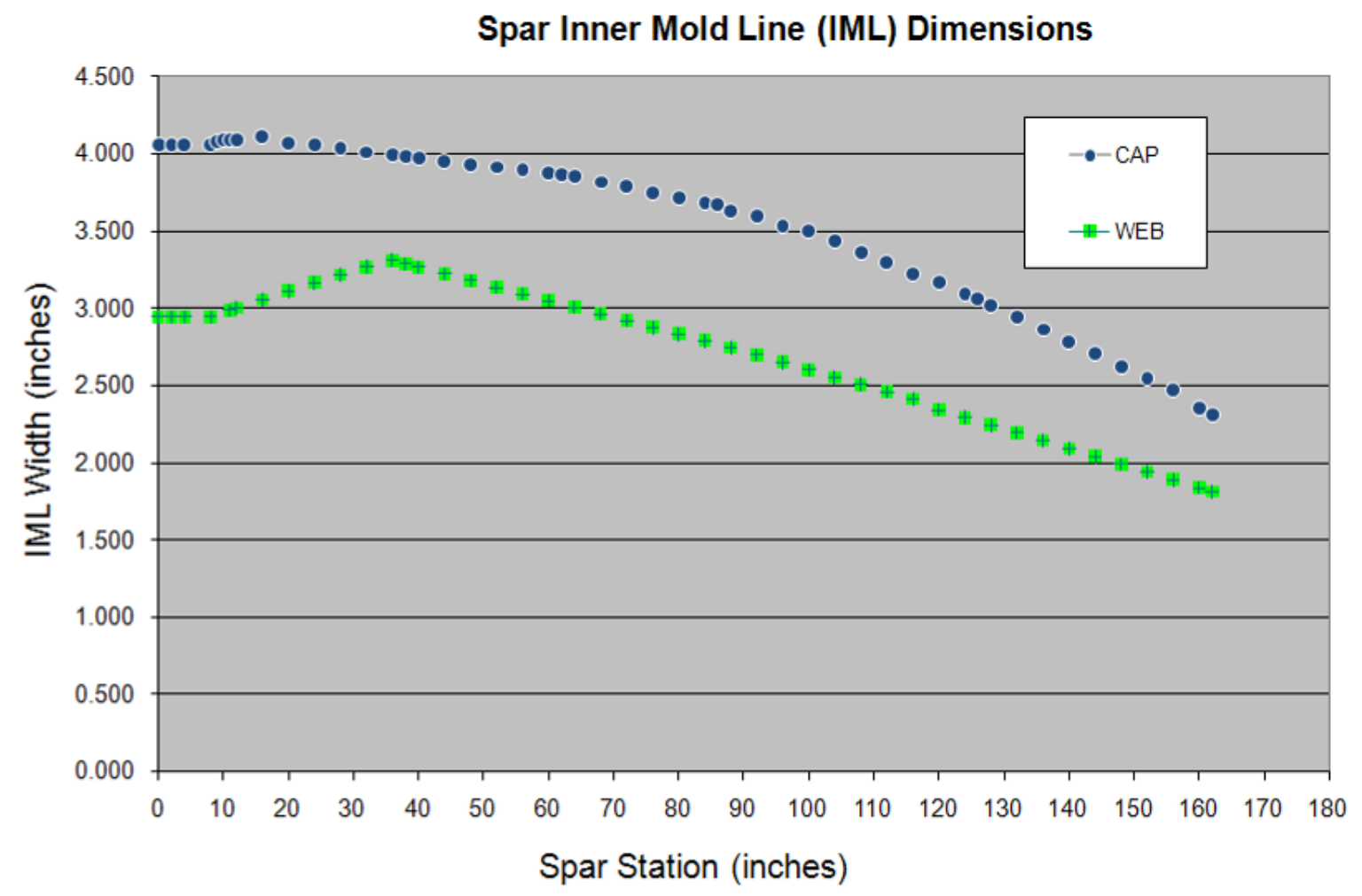

Figure 28: IML Dimensions

To determine the size of the theoretical mandrel at each section the engineering part must be evaluated at each section to determine the ply thickness. There will always be variability in the actual thickness of the laid up plies due to debulk factors and variations in the resin content. To compensate for the variability in the thickness of the plies, curvature must be incorporated into the design in the cap section to ensure the material can be laid on the tool and will fit into the outer mold with a sufficient amount of material to be pressed into the corners. The .060” thickness of the bladder must also be subtracted to size the aluminum mandrel. For a high temp cure cycle, the tooling would typically be scaled; however, in this case the mandrel will be used to apply pressure on the plies which will push the material into the corners of the outer steel mold. Table 3 shows the calculated growth of the mandrel at the cure temperature of $250^{\circ} \mathrm{F}$. 
The CTE calculation used is shown below:

$$
\chi=\beta \bullet(1+((\alpha-\varphi) \bullet C T E))
$$

\section{Equation 1: Coefficient of Thermal Expansion Calculation}

Where $x$ is the calculated dimension, $\beta$ is the original dimension, $\alpha$ is the ambient temperature (typically $68^{\circ} \mathrm{F}$ ), $\varphi$ is the maximum cure temperature (in this case $250^{\circ} \mathrm{F}$ ), and CTE is the coefficient of thermal expansion of the material to be scaled.

The sizing calculation must also consider the silicone bladder that covers the tool surface. It is a .060” silicone caul rubber. Under 28psi of bag pressure, the silicone will compress .005”. Figure 29 show a sample of the rubber bladder.

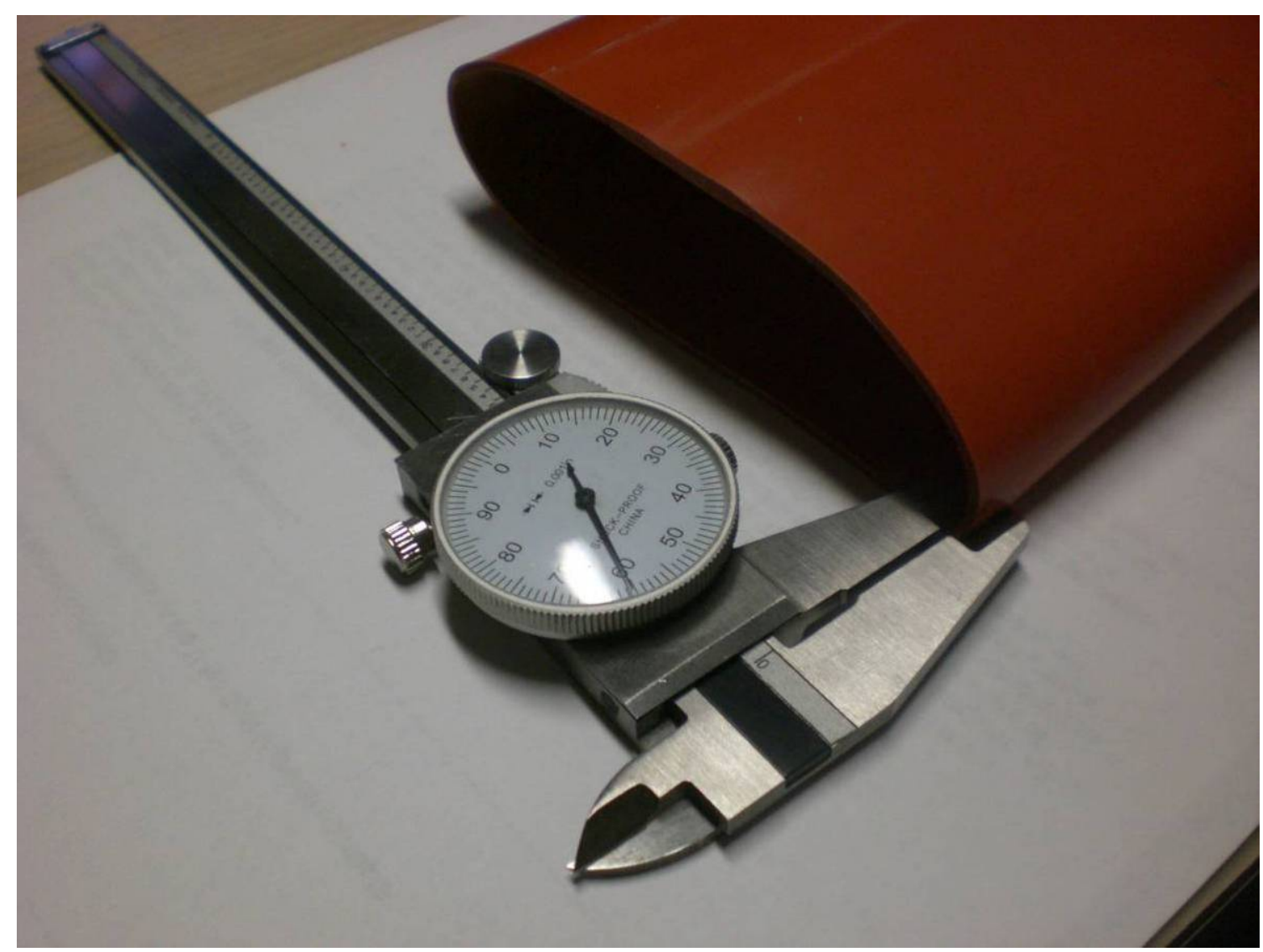

Figure 29: Rubber Bladder 
Table 3: Calculated Growth at Mandrel Stations

\begin{tabular}{|c|c|c|c|c|c|c|}
\hline \multirow[t]{3}{*}{ Material: } & \multirow[t]{3}{*}{ Al 6061-T6 } & \multicolumn{5}{|l|}{ CTE (in/in ${ }^{\circ} \mathrm{F}$ ): } \\
\hline & & \multicolumn{3}{|c|}{ Ambient Temperature $\left({ }^{\circ} \mathrm{F}\right)$ : } & & \\
\hline & & \multicolumn{2}{|c|}{ Cure Temperature $\left({ }^{\circ} \mathrm{F}\right)$ : } & \multicolumn{2}{|l|}{250} & \\
\hline STA & \begin{tabular}{|c|} 
Nominal \\
Dimension at \\
Ambient Temp \\
\end{tabular} & \begin{tabular}{|c|}
$\begin{array}{c}\text { Dimension } \\
\text { at Highest } \\
\text { Cure Temp }\end{array}$ \\
\end{tabular} & & \begin{tabular}{|c|} 
Nominal \\
Dimension at \\
Ambient Temp \\
\end{tabular} & \begin{tabular}{|l} 
Dimension \\
at Highest \\
Cure Temp \\
\end{tabular} & \\
\hline & Web (in) & Web (in) & $\Delta$ (in) & Cap (in) & Cap (in) & $\Delta$ (in) \\
\hline 0 & 2.405 & 2.41073 & 0.00573 & 3.732 & 3.74090 & 0.00890 \\
\hline 2 & 2.405 & 2.41073 & 0.00573 & 3.732 & 3.74090 & 0.00890 \\
\hline 4 & 2.405 & 2.41073 & 0.00573 & 3.732 & 3.74090 & 0.00890 \\
\hline 8 & 2.405 & 2.41073 & 0.00573 & 3.732 & 3.74090 & 0.00890 \\
\hline 12 & 2.49 & 2.49594 & 0.00594 & 3.732 & 3.74090 & 0.00890 \\
\hline 16 & 2.49 & 2.49594 & 0.00594 & 3.732 & 3.74090 & 0.00890 \\
\hline 20 & 2.469 & 2.47489 & 0.00589 & 3.732 & 3.74090 & 0.00890 \\
\hline 24 & 2.54 & 2.54606 & 0.00606 & 3.732 & 3.74090 & 0.00890 \\
\hline 28 & 2.635 & 2.64128 & 0.00628 & 3.722 & 3.73087 & 0.00887 \\
\hline 32 & 2.731 & 2.73751 & 0.00651 & 3.696 & 3.70481 & 0.00881 \\
\hline 36 & 2.772 & 2.77861 & 0.00661 & 3.675 & 3.68376 & 0.00876 \\
\hline 40 & 2.774 & 2.78061 & 0.00661 & 3.656 & 3.66472 & 0.00872 \\
\hline 44 & 2.722 & 2.72849 & 0.00649 & 3.637 & 3.64567 & 0.00867 \\
\hline 48 & 2.688 & 2.69441 & 0.00641 & 3.618 & 3.62663 & 0.00863 \\
\hline 52 & 2.643 & 2.64930 & 0.00630 & 3.599 & 3.60758 & 0.00858 \\
\hline 56 & 2.591 & 2.59718 & 0.00618 & 3.579 & 3.58753 & 0.00853 \\
\hline 60 & 2.549 & 2.55508 & 0.00608 & 3.56 & 3.56849 & 0.00849 \\
\hline 64 & 2.515 & 2.52100 & 0.00600 & 3.541 & 3.54944 & 0.00844 \\
\hline 68 & 2.481 & 2.48692 & 0.00592 & 3.503 & 3.51135 & 0.00835 \\
\hline 72 & 2.428 & 2.43379 & 0.00579 & 3.473 & 3.48128 & 0.00828 \\
\hline 80 & 2.33 & 2.33556 & 0.00556 & 3.404 & 3.41212 & 0.00812 \\
\hline 88 & 2.236 & 2.24133 & 0.00533 & 3.318 & 3.32591 & 0.00791 \\
\hline 104 & 2.045 & 2.04988 & 0.00488 & 3.126 & 3.13345 & 0.00745 \\
\hline 116 & 1.924 & 1.92859 & 0.00459 & 2.912 & 2.91894 & 0.00694 \\
\hline 124 & 1.818 & 1.82233 & 0.00433 & 2.784 & 2.79064 & 0.00664 \\
\hline 132 & 1.714 & 1.71809 & 0.00409 & 2.626 & 2.63226 & 0.00626 \\
\hline 140 & 1.608 & 1.61183 & 0.00383 & 2.469 & 2.47489 & 0.00589 \\
\hline 152 & 1.44 & 1.44343 & 0.00343 & 2.232 & 2.23732 & 0.00532 \\
\hline 160 & 1.345 & 1.34821 & 0.00321 & 2.041 & 2.04587 & 0.00487 \\
\hline 162 & 1.326 & 1.32916 & 0.00316 & 1.998 & 2.00276 & 0.00476 \\
\hline
\end{tabular}


To construct the model, the required tool profile was calculated by sectioning the customer provided spar model every 4" thru STA 72 then every 8" between STA 72 and STA 162 (because it is a constant taper) and compiling the measurements which can be found in Appendix B. A length of .120” was then subtracted from the IML cap and web dimensions to compensate for the .060 " thick bladder surrounding the tool on each end. A radius chosen by the manufacturing engineering staff was added to the cap sides to increase the perimeter of the tool. This will allow slightly more material to be laid on the tool to compensate for manufacturing inconsistencies such as debulk factors and human error when splicing the carbon plies together. Pro/Engineer was used to construct the solid model geometry for this tool. A generic master section was created to define the profile shape of the mandrel. Although the dimensions change over the length of the tool, the general profile shape remains constant. A variable is set up for each feature in the profile as seen in Figure 30.

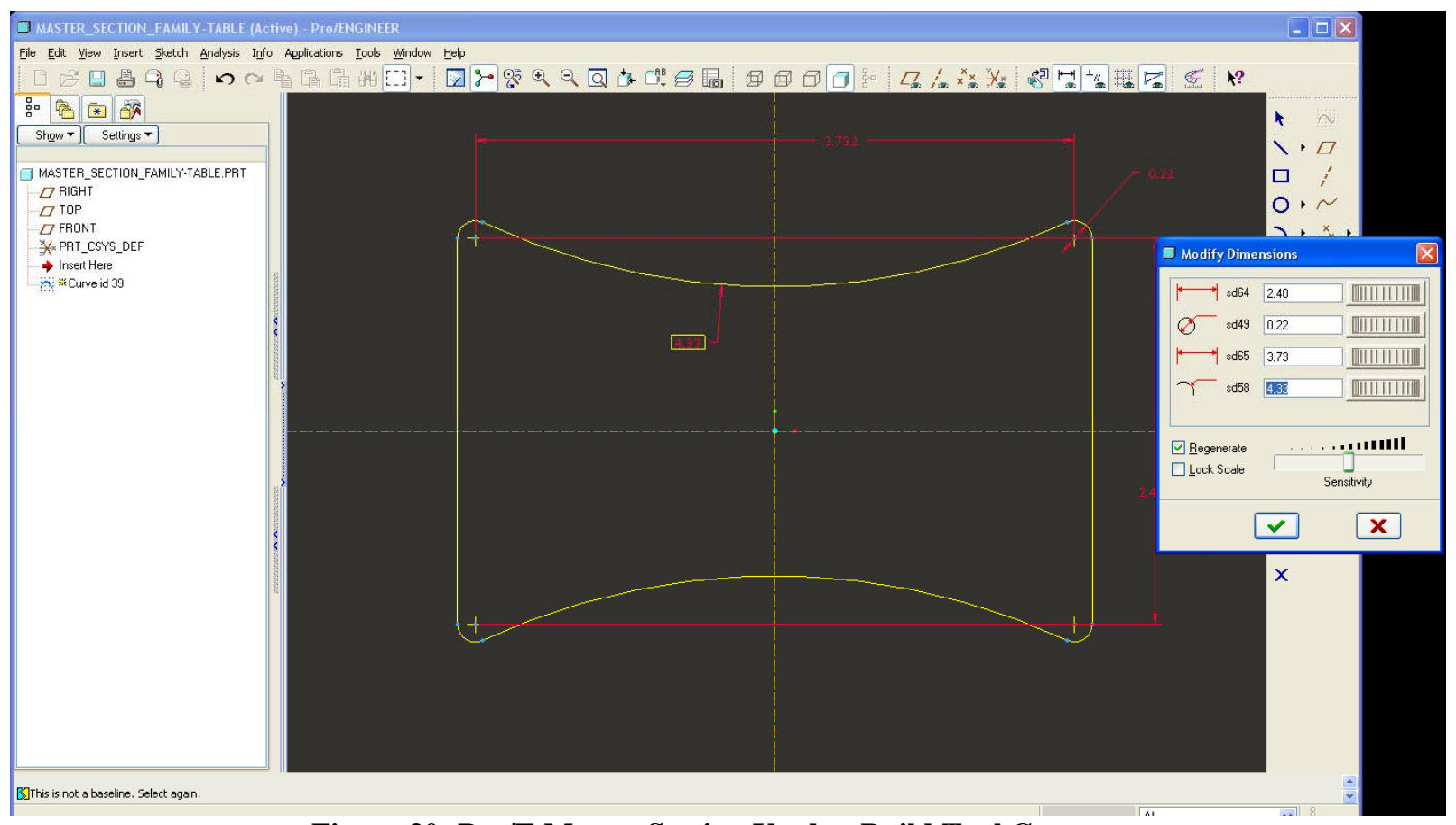

Figure 30: Pro/E Master Section Used to Build Tool Geometry 
Table 4 was then created to characterize the 30 necessary stations that will define the shape of the mandrel which are shown in Figure 31.

Table 4: Mandrel Definition

\begin{tabular}{|c|c|c|c|c|c|c|c|c|}
\hline \multicolumn{8}{|c|}{$\square$ Family Table :MASTER_SECTION_FAMILY-TABLE } & $-\square x$ \\
\hline \multicolumn{9}{|c|}{ 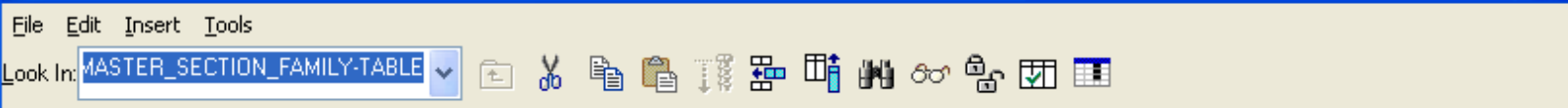 } \\
\hline \multirow[t]{2}{*}{ Type } & Instance Name & d15 & d16 & d14 & d13 & d10 & & \\
\hline & MASTER_SECTIO... & 2.405 & 3.732 & 4.33 & 0.22 & 0.00 & & \\
\hline \multirow[t]{31}{*}{ 国 } & STATION & WEB HEIGHT & CAPWIDTH & CAP RAD & CORNERS & STATION OFFS... & & 슬 \\
\hline & STA-0 & 2.405 & 3.732 & 4.33 & 0.22 & 0.00 & & \\
\hline & STA-2 & 2.405 & 3.732 & 4.33 & 0.22 & 2.00 & & \\
\hline & STA-4 & 2.405 & 3.732 & 4.33 & 0.22 & 4.00 & & \\
\hline & STA-8 & 2.405 & 3.732 & 4.33 & 0.22 & 8.00 & & \\
\hline & STA-12 & 2.490 & 3.732 & 4.33 & 0.22 & 12.00 & & \\
\hline & STA-16 & 2.490 & 3.732 & 4.33 & 0.22 & 16.00 & & \\
\hline & STA. 20 & 2.469 & 3.732 & 4.33 & 0.22 & 20.00 & & \\
\hline & STA.24 & 2.540 & 3.732 & 4.60 & 0.22 & 24.00 & & \\
\hline & STA. 28 & 2.635 & 3.722 & 4.87 & 0.22 & 28.00 & & \\
\hline & STA.32 & 2.731 & 3.696 & 5.15 & 0.22 & 32.00 & & \\
\hline & STA-36 & 2.772 & 3.675 & 5.49 & 0.22 & 36.00 & & \\
\hline & STA-40 & 2.774 & 3.656 & 5.89 & 0.22 & 40.00 & & \\
\hline & STA-44 & 2.722 & 3.637 & 5.92 & 0.22 & 44.00 & & \\
\hline & STA-48 & 2.688 & 3.618 & 5.95 & 0.22 & 48.00 & & \\
\hline & STA.52 & 2.643 & 3.599 & 5.98 & 0.22 & 52.00 & & \\
\hline & STA.56 & 2.591 & 3.579 & 6.02 & 0.22 & 56.00 & & \\
\hline & STA-60 & 2.549 & 3.560 & 6.05 & 0.22 & 60.00 & & \\
\hline & STA-64 & 2.515 & 3.541 & 6.09 & 0.22 & 64.00 & & \\
\hline & STA-68 & 2.481 & 3.503 & 6.06 & 0.22 & 68.00 & & \\
\hline & STA.72 & 2.428 & 3.473 & 6.07 & 0.22 & 72.00 & & \\
\hline & STA-80 & 2.330 & 3.404 & 6.04 & 0.22 & 80.00 & & \\
\hline & STA-88 & 2.236 & 3.318 & 5.96 & 0.22 & 88.00 & & \\
\hline & STA-104 & 2.045 & 3.126 & 5.72 & 0.22 & 104.00 & & \\
\hline & STA-116 & 1.924 & 2.912 & 5.29 & 0.22 & 116.00 & & \\
\hline & STA-124 & 1.818 & 2.784 & 5.05 & 0.22 & 124.00 & & \\
\hline & STA-132 & 1.714 & 2.626 & 4.71 & 0.22 & 132.00 & & \\
\hline & STA-140 & 1.608 & 2.469 & 4.36 & 0.22 & 140.00 & & \\
\hline & STA.152 & 1.440 & 2.232 & 3.85 & 0.22 & 152.00 & & \\
\hline & STA- 160 & 1.345 & 2.041 & 3.39 & 0.22 & 160.00 & & t. \\
\hline & STA-162 & 1.326 & 1.998 & 3.29 & 0.22 & 162.00 & & $v$ \\
\hline & $\underline{Q} K$ & & & 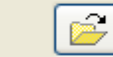 & & & Cancel & \\
\hline
\end{tabular}




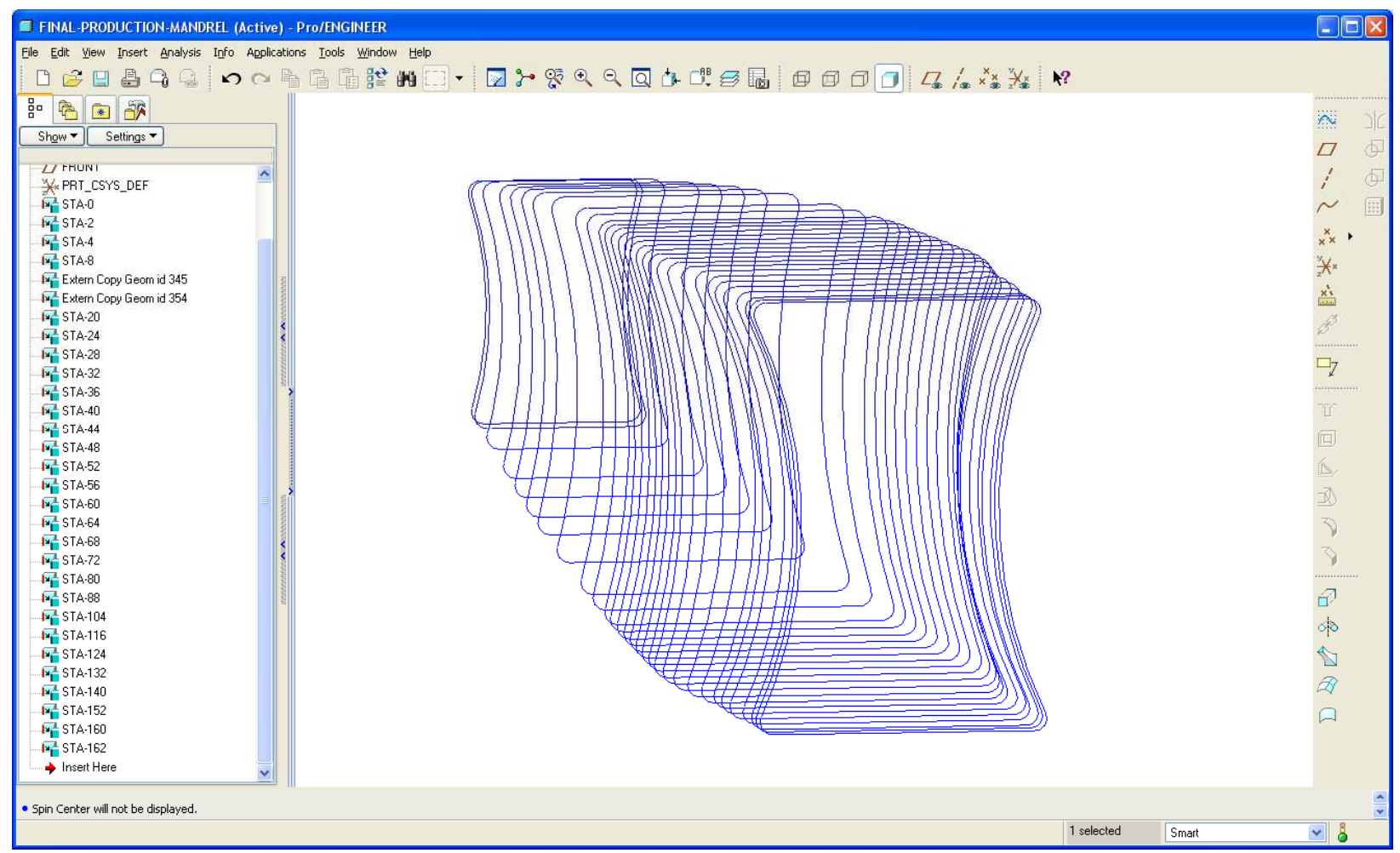

Figure 31: Spar Mandrel Profile Sections

A solid extrusion was created by making a parallel blend through each of the 30 station profiles. 7.25" was then extruded from each end using the last profile section at the root and tip.

Once the solid tool geometry has been constructed it was necessary to split the model into removable sections. The split sections must allow the tool to come out of the cured mandrel and be reassembled after removal with little maintenance. All of the sections must be removed from the root end.

Based on the analysis of the customer provided model, the spar has no trapped sections at the root end from STA -7.25 to STA 12. Based on this, the first station split was determined to be at STA 8. This “cap” section is 15.25” long and has a constant profile. The trapped section is between STA 12 and STA 80. The center section was designed to start at STA 8 and end at STA 59.75 making it 51.75” long. This entire section will be trapped and must be split into multiple pieces again for removal. The last and outermost section will be the longest. It is designed to be 
109.7" long and will start at STA 59.75 and continue to STA 169.45. To match the spar geometry, this is a constant taper from STA 59.75 to STA 162.2 then it is a constant profile for 7.25” from STA 162.2 to 169.45 .

Because the mandrel was designed with curvature on the cap sides, the bladder that covers the tool must be drawn down to the tool surface using vacuum pressure. This requires that the sections are not solid so air can be drawn from both ends and through holes along the entire mandrel to ensure uniform vacuum along the entire length of the tool. During the cure cycle the vacuum fittings at the end of the tool will be used to pressurize the bladder and press the material out against the clamshell mold.

A steel rod was designed to hold all of the sections of the tool together. The 109.7” long end section was split in two to be machined but will be bolted and doweled back together and act as one piece. A 2.5 ” 1.5 ” x 1 ” thick threaded steel block has been designed to fit in the large end of the section which will be trapped when each piece is bolted together. The steel rod can then be threaded into this block and will serve as the primary clamp to hold all of the sections together. The tie rod is fabricated from 13/16 diameter 4340 steel with a 3/4-10 UNC-2B thread at one end which will be threaded into the steel block. The 1" thick block will allow for 10 threads of engagement.

The long tapered section was split symmetrically down the web section. Areas of each side were hogged out to help reduce the weight of the tool and also to ensure uniform heat-up during the cure cycle. Areas of large mass will cause the carbon on the tool to heat up at different rates which could cause issues with resin flow and material hardening. Six ribs were left as seen in Figure 32 as stiffeners and also to create flats where the two sections can be bolted and doweled together. Dowels guarantee that the pieces will not slip on the parting plane once 
they are bolted together. The sections are also bolted together using $1 / 4-20$ socket head cap screws. The cap section is counter bored so the heads of the bolts are below the tool surface. Each of the webs also has a small pocket machined out to allow for air to be drawn through the entire length of the tool.

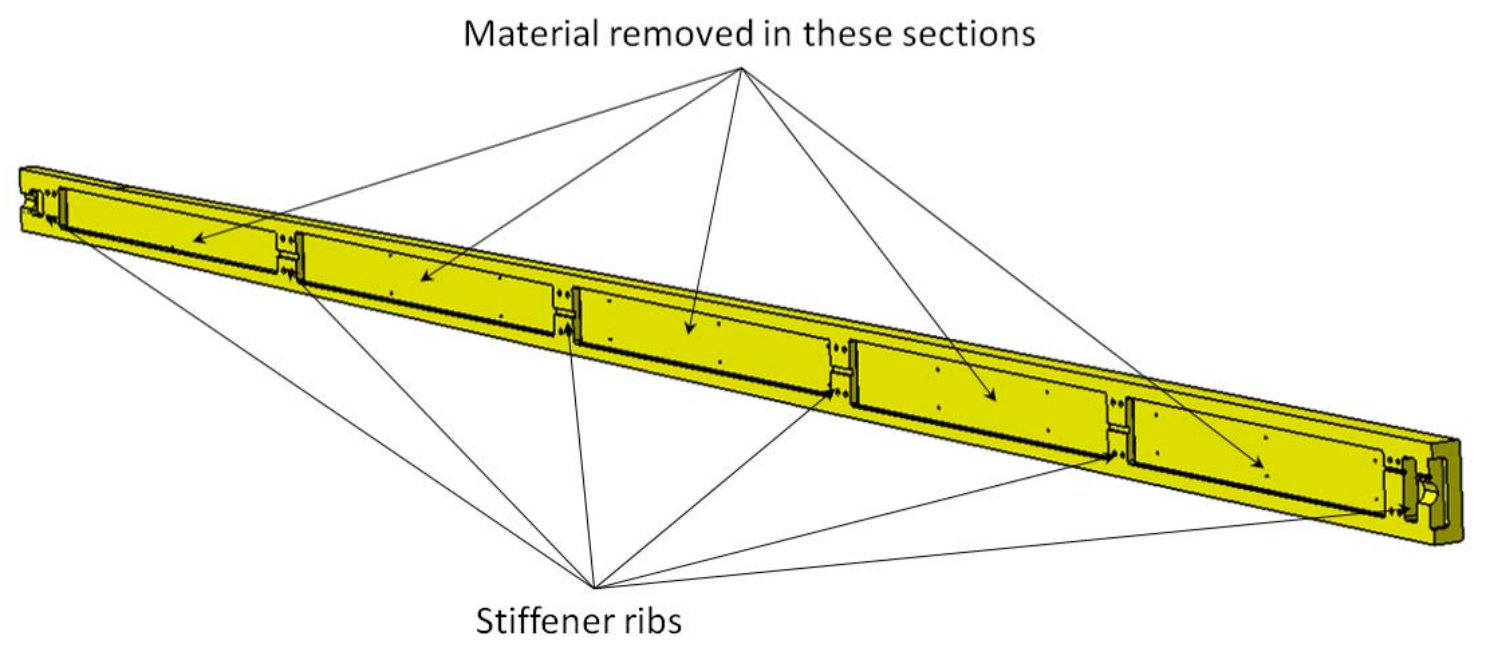

Figure 32: Detailed View of Tapered Section

At the opposite (root) end of the tool, the "cap" section can be removed as a solid section. Since it is only 15.25 ” long and the tie rod runs through a $7 / 8$ " clearance hole through this section, there was no need to split the parts to save weight. The machined cap section weighs 11.42 lbs. This section will be machined from one solid aluminum billet. As shown in Figure 33 the root end of this cap section will have a large counter bore that will capture a standard nut and 1.25” outside diameter washer. The root end of the tie rod has a 5/8-11 thread which will be used to tie the entire structure together. At the other end of the cap piece a pocket is machined .3 ” deep to accept the ends of the center trapped sections as shown in Figure 33. 


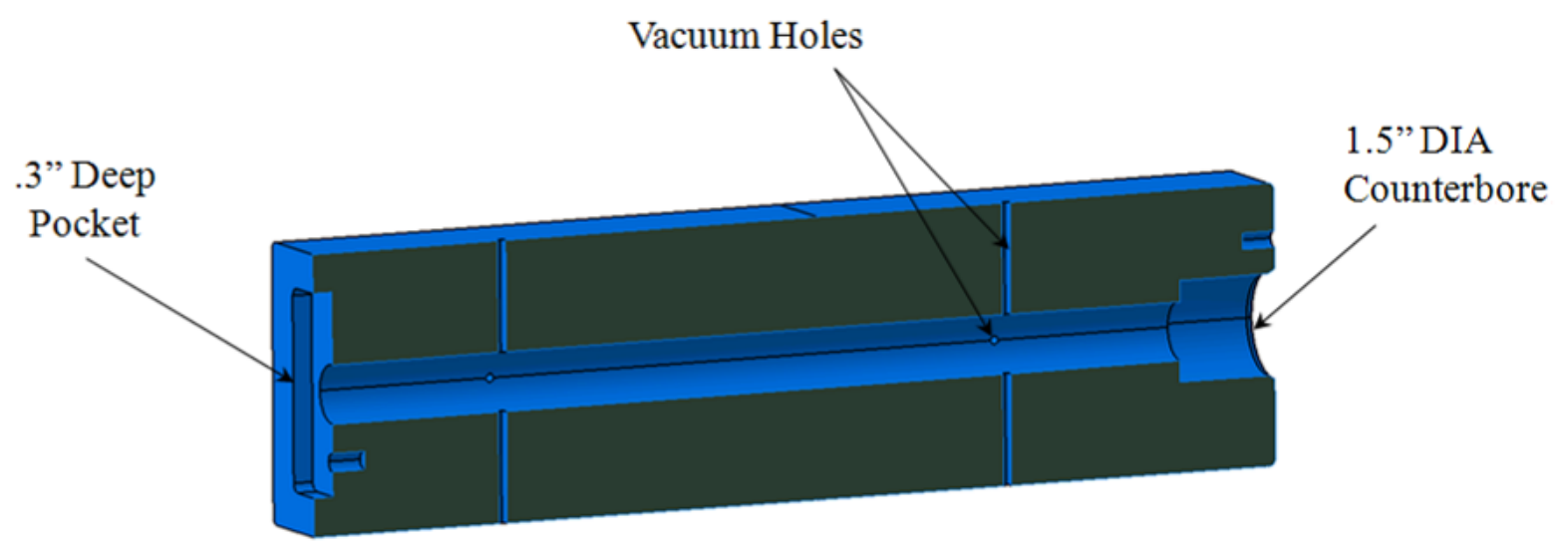

Figure 33: Cross Sectional View of Cap Section

The 51.75” long trapped section of the tool requires the most splits and incorporates the majority of the design features. This section had to be split into multiple sections but cannot be bolted together because only one end is accessible prior to curing the part. This trapped section has been designed to be split long ways into 3 pieces. Since the slight trapped portion of the web has been disregarded and will be overcome by the CTE and tolerance stack the center section does not have any trapped features so this will be the first one removed from this section. The center section slides over the steel tie rod. The end of the long tapered section has been pocketed .3 ” so the center of the trapped section will fit into the end with a .25” extension feature machined into the end as seen in Figure 34. 


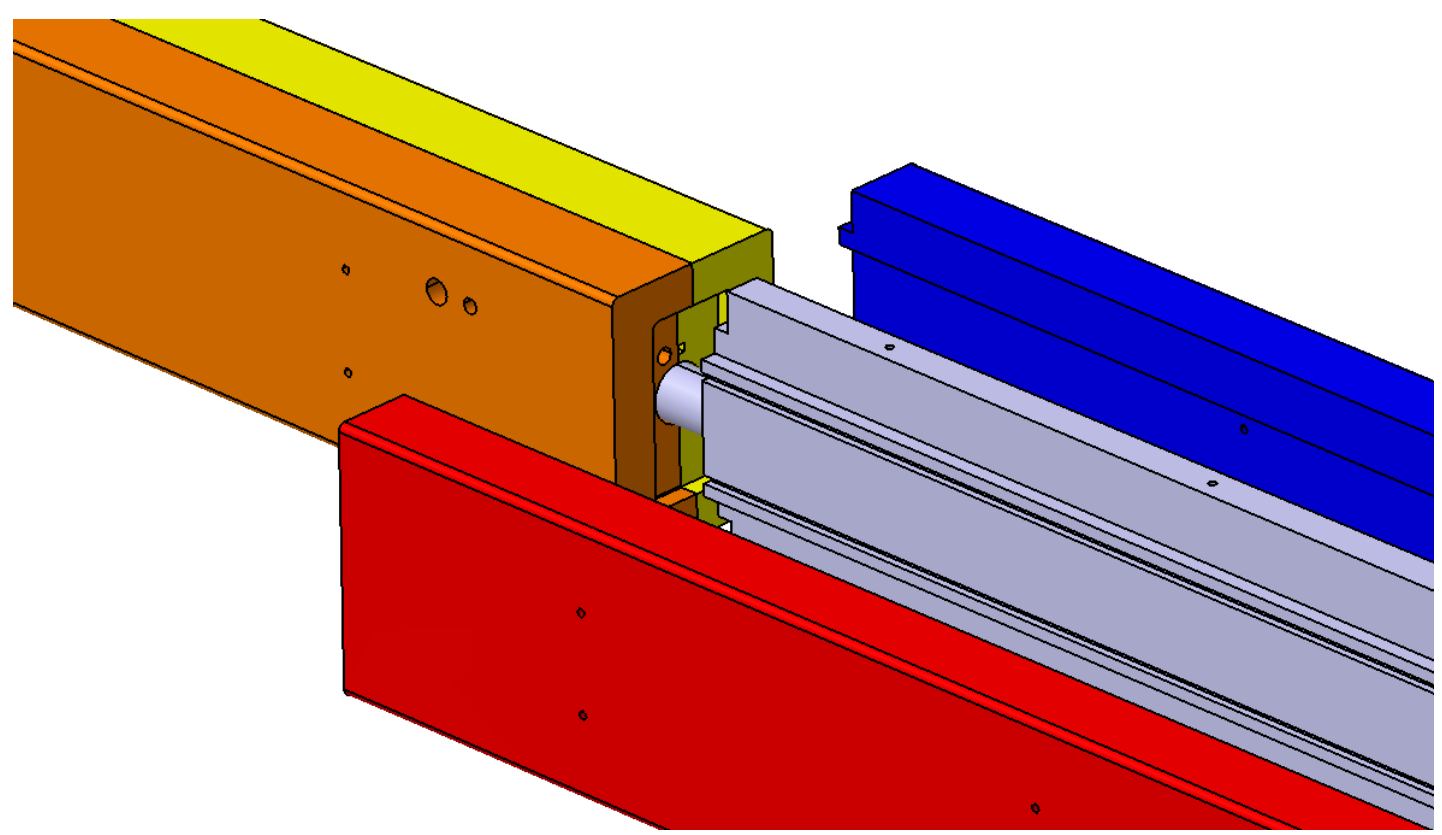

Figure 34: Pocketed Area of Tapered Segment to Accept Trapped Segments

There is also a .25" alignment dowel that will clock the center section and ensure it is not installed upside down. This clocking feature can also bee seen in Figure 35.

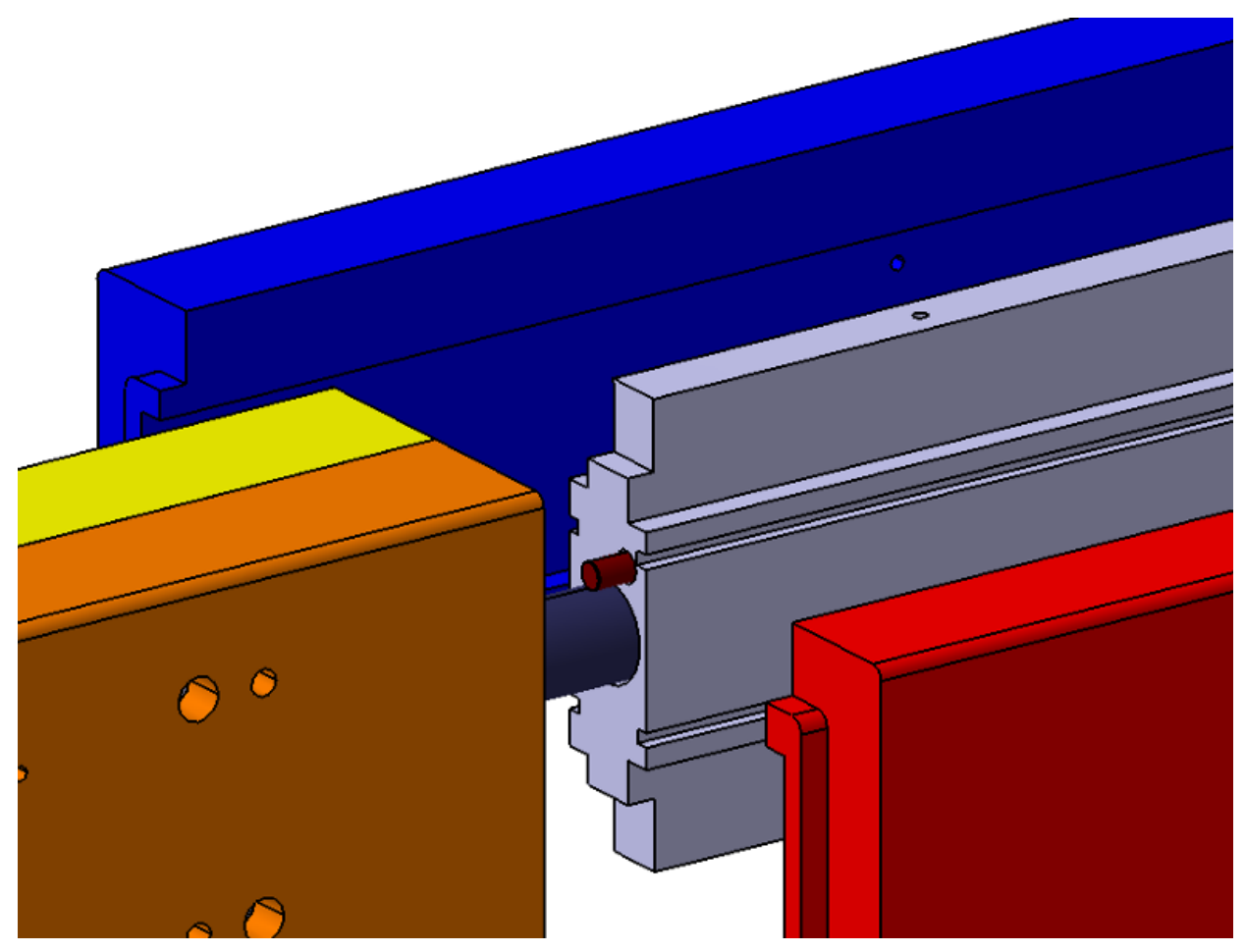

Figure 35: Clocking Feature Shown in Trapped Center Segment 
On either side of the center trapped segment are sides designed to fit into the long tapered section in the same manner as the center section. This will hold each of the sides against the center segment. As illustrated in Figure 36 precision machined pockets are also designed into each side member so they fit securely onto the center section and will not move in the cap direction and cause a step in the mold surface. Since they are symmetric portions of the tool, the pocket in the right segment is designed at a height of 2.25” while the right is designed to be 2.00” high. This will guarantee that the tool is put back together the same way every time it's used.

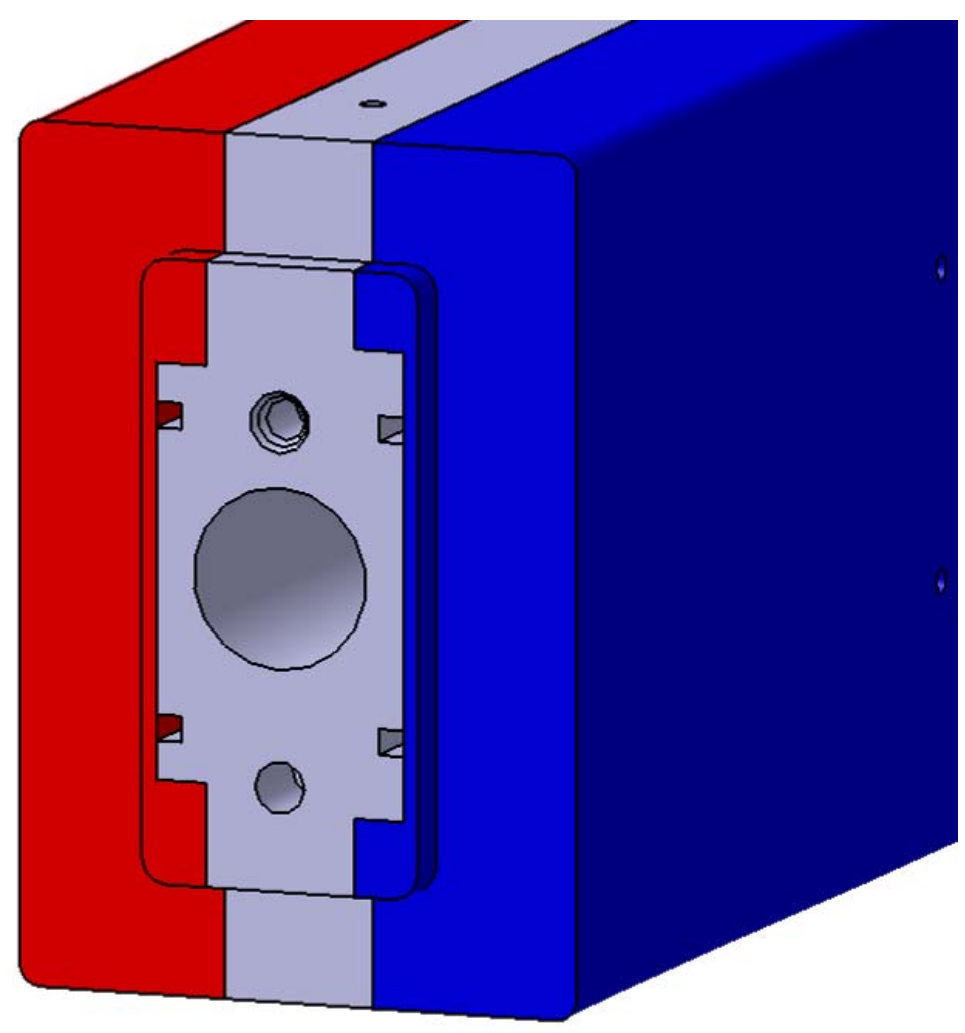

Figure 36: Machined Pockets Allow Sides to Fit on Center Section

In order to lay carbon plies on the mandrel efficiently and ergonomically, the mandrel must be at a comfortable level for the technician and able to rotate in order to easily position plies all around the tool. Additional tooling to hold the mandrel tool was required to make layup efficient. Lifting provisions also needed to be included in the design to move the tool from 
location to location and lift the tool with the carbon stack into the clamshell mold. Vacuum fittings cannot be incorporated into any of the mandrel sections so a fitting had to be designed for each end of the mandrel.

At the root end the closeout fitting, as shown in Figure 37, bolts directly to the end of the cap segment. Since this closeout fitting must be installed and removed each time the tool is used, steel key inserts were used in the cap to ensure the threads will not pull out of the aluminum. The bladder must be sealed around this fitting so this closeout fitting cannot simply fasten to the cap segment because air will leak around the bolts.

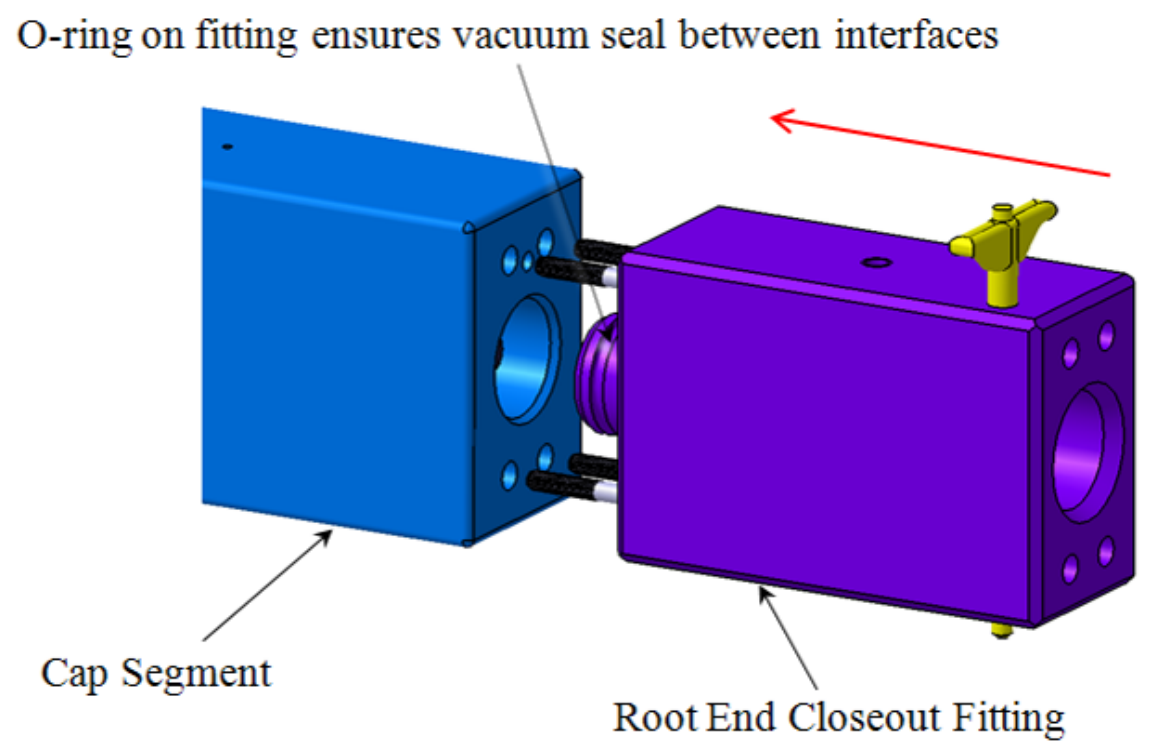

Figure 37: Root End Closeout Fitting

Figure 37 also illustrates how the closeout fitting will fit into the cap section and use an o-ring to ensure vacuum integrity between the two pieces. As illustrated in Figure 38, a vacuum fitting was then designed as a cylindrical section to fit into the end of the closeout fitting using a series of o-rings. The ball lock pin locks the vacuum fitting in the closeout fitting without jeopardizing the integrity of the vacuum system. This vacuum fitting will also serve as the bearing surface to 
rotate the mandrel on a custom designed trunnion support stand shown in Figure 39. Retaining rings were designed into this segment at 3.18” apart for safety. They will make certain that the tool does not slip out of the end of the support stand.

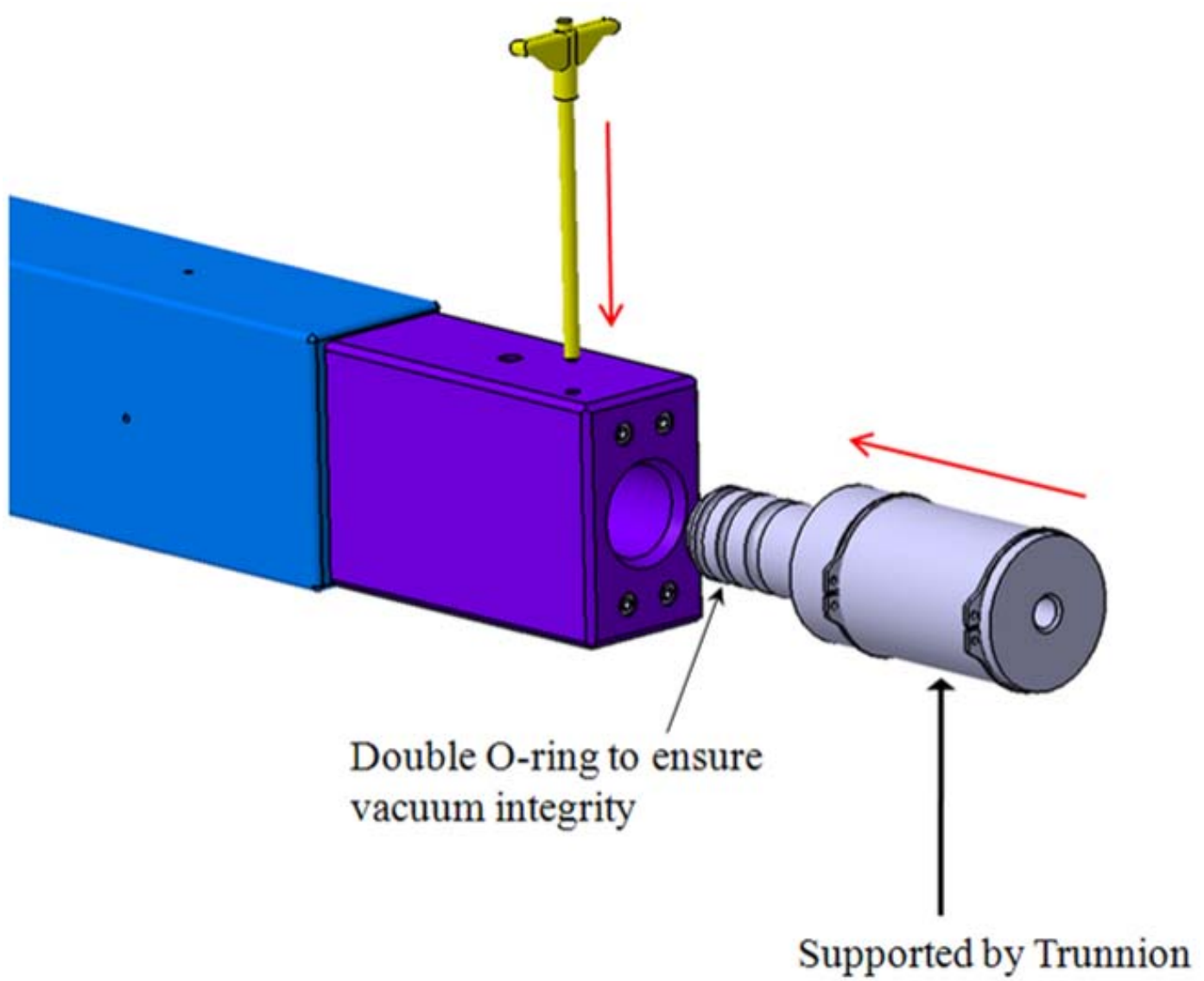

Figure 38: Root End Vacuum Fitting 


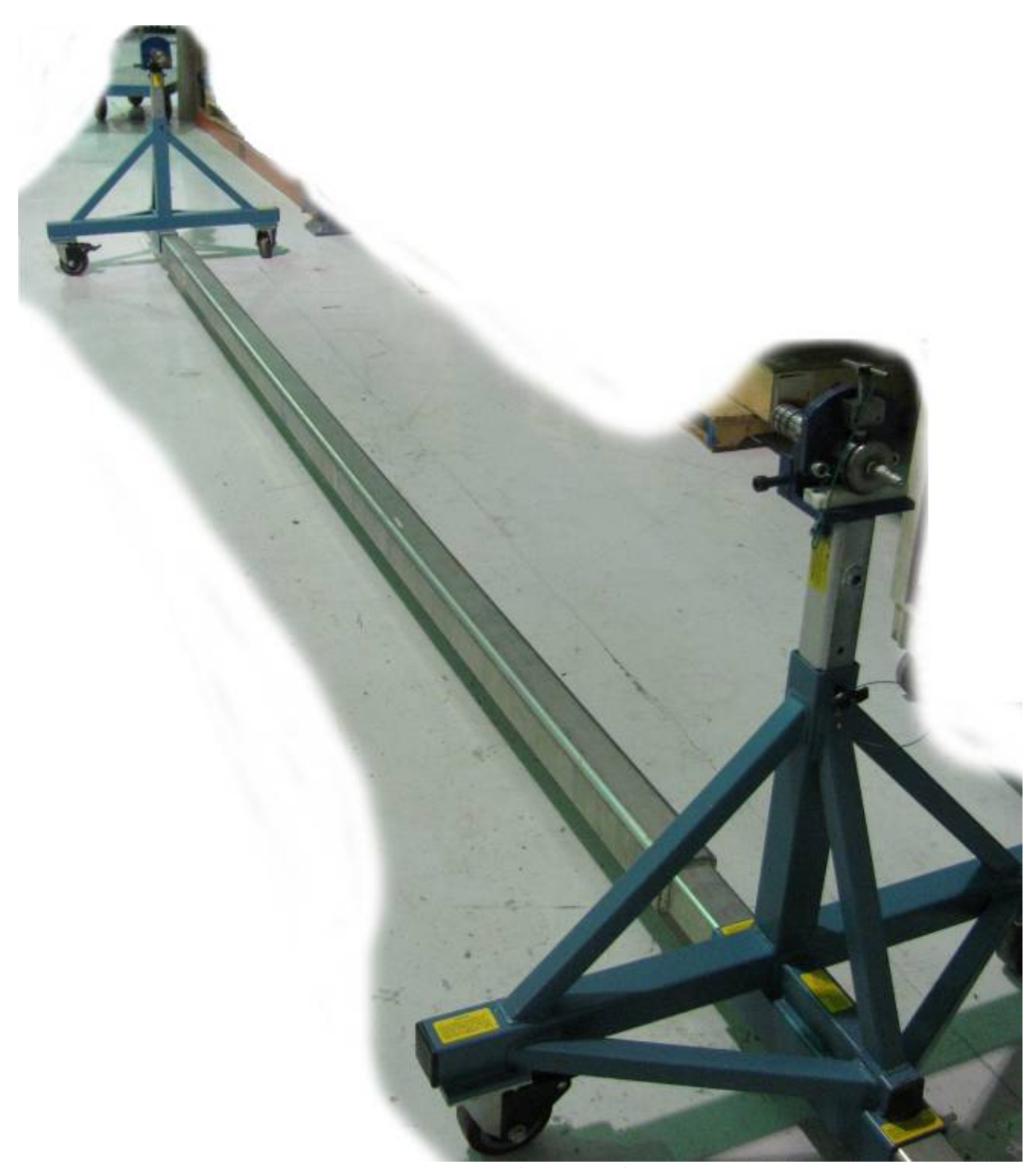

Figure 39: Trunnion Support Stand

At the tip end there is not enough area to fasten the closeout fitting using multiple bolts. The long tapered sections were redesigned to accommodate another steel block to be trapped between them when they are bolted together. This 1.00” x 1.00” x .75” block will have a 1/2-13 threaded thru hole in the center to accommodate a 5.00” long bolt that will hold the closeout fitting onto the mandrel. This area of the mandrel is illustrated in Figure 40. The bladder must be sealed around this fitting so this closeout fitting cannot simply fasten to the cap segment because air will leak around the center bolt. The tip end of this closeout fitting was designed to encapsulate the designed vacuum fitting as illustrated in Figure 41. This vacuum fitting will also 
serve as the bearing surface to rotate the mandrel on the designed support stand shown in Figure 39. Again, retaining rings were designed into this segment at 3.18” apart for safety. They will make certain that the tool does not slip out of the end of the support stand.

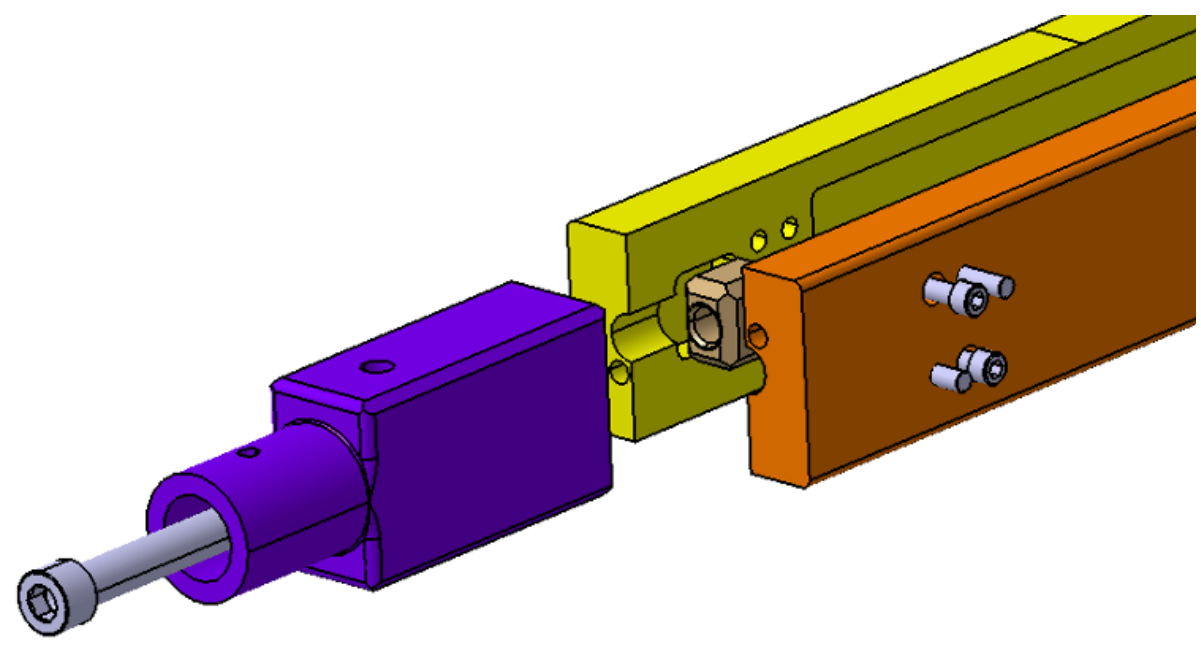

Figure 40: Tip Section with Closeout Fitting

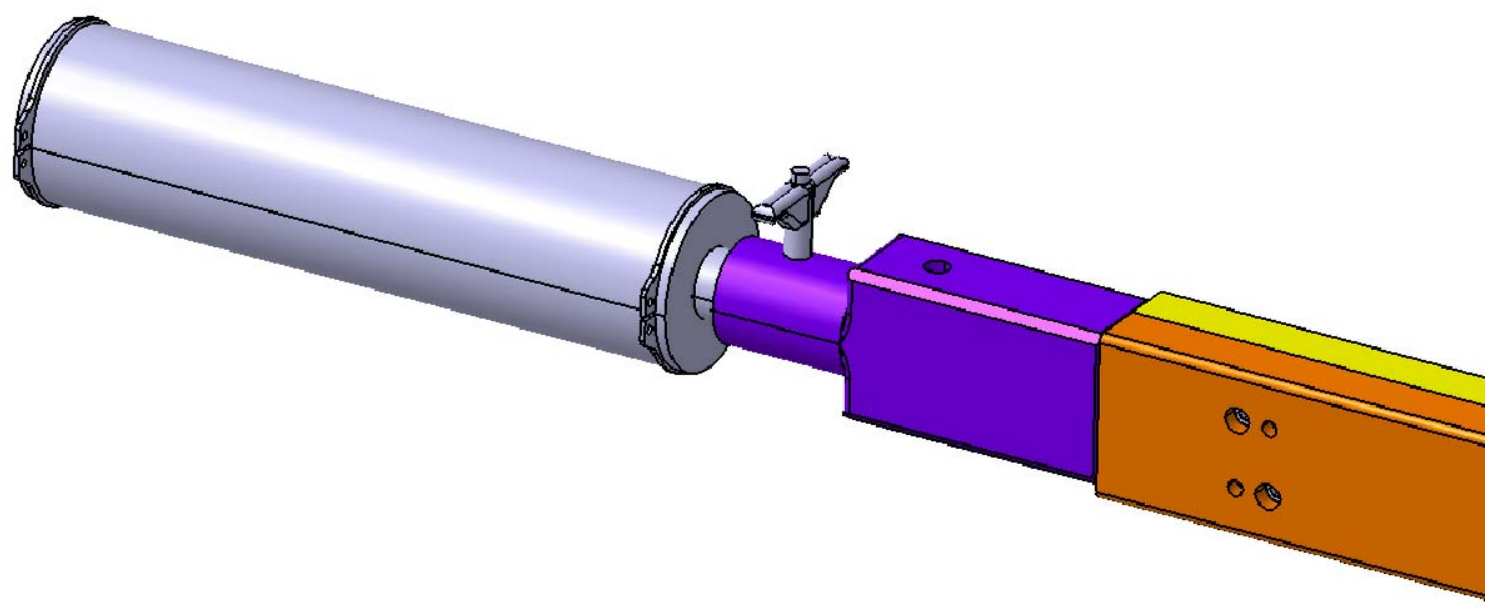

Figure 41: Tip Section with Closeout Fitting

FEA was run on the entire assembly to calculate deflection during the worst case scenario. In this scenario, the weight of the tool and the weight of the carbon layup are combined totaling 231.91 lbs (203.91lbs for mandrel tool and 28lbs for the carbon part using the standard density of $.056 \mathrm{lb} / \mathrm{in}^{3}$ for the layup). As illustrated in Figure 42, under worst case scenario loading the deflection at STA 102 is .183”. This loading includes the weight of the 
mandrel coupled with the distributed weight of the full carbon layup under a gravity load of $32.2 \mathrm{ft} / \mathrm{sec}^{2}$. It also includes a $10 \mathrm{lb}$ load which simulates the layup technician pressing down plies. This is still within customer limits and will not cause wrinkling in the final part. Some temporary ply buckling can be seen in Figure 43, but will is not present when the mandrel is placed in the outer mold.

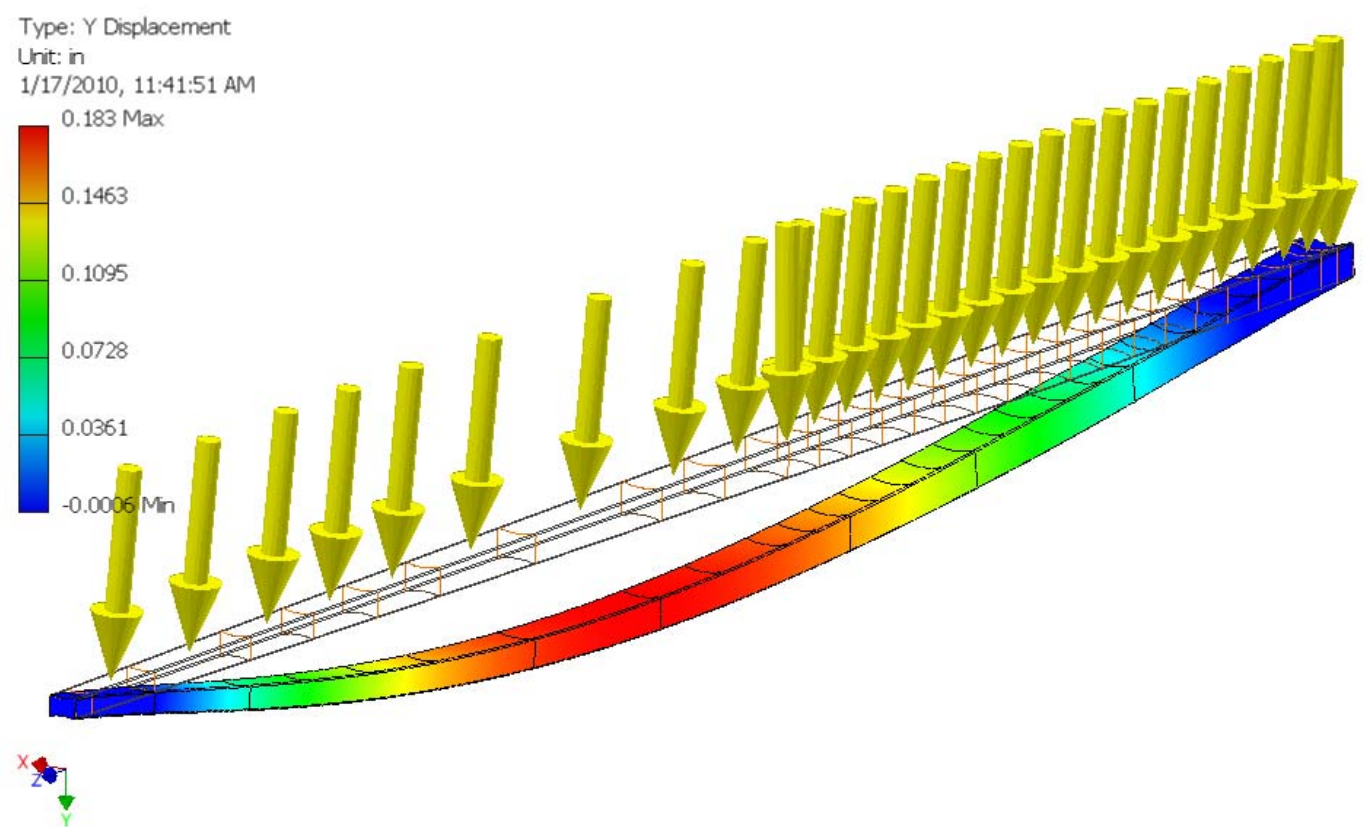

Figure 42: Worst Case Scenario Loading 


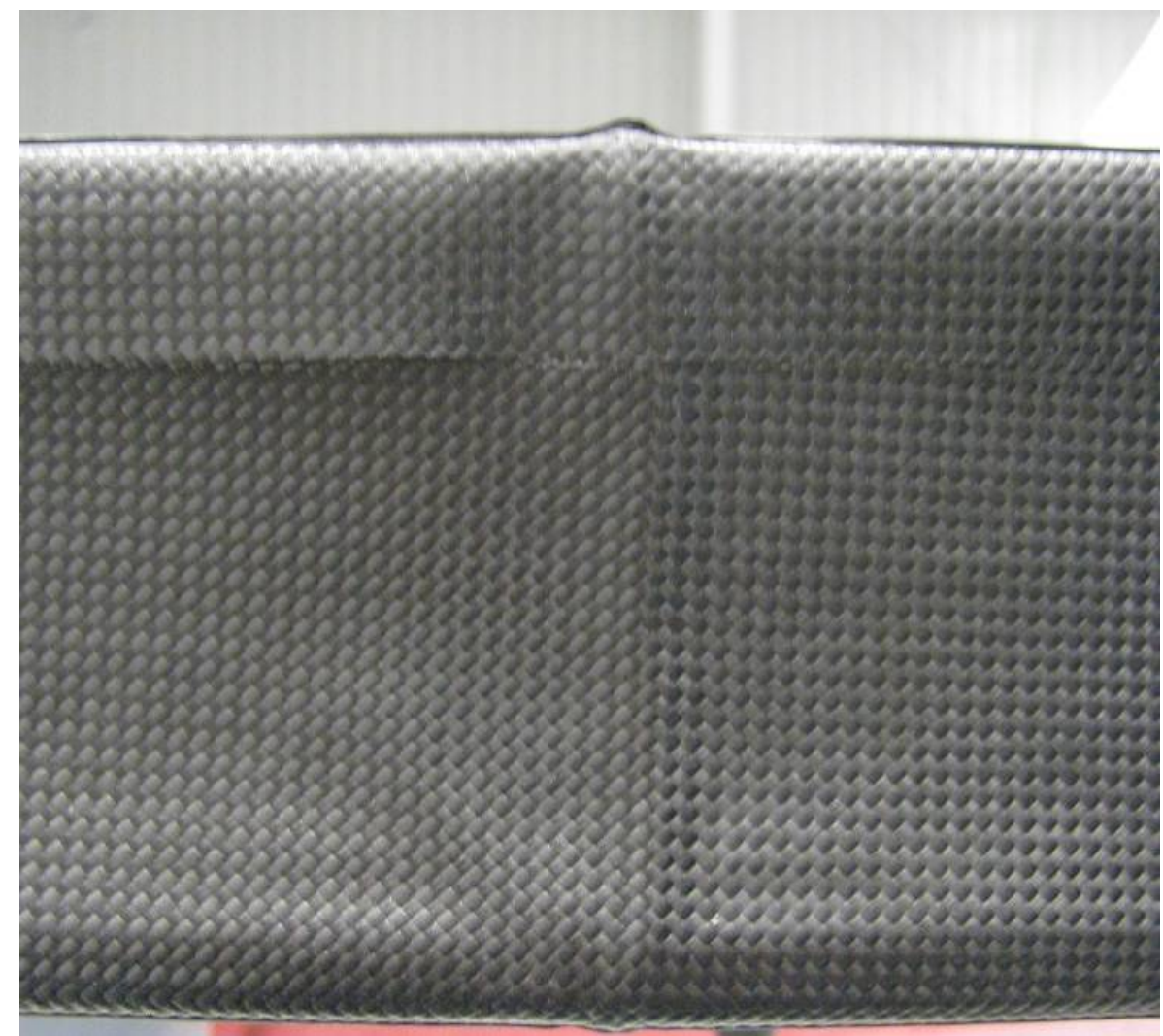

Figure 43: Temporary Ply Buckling

\subsubsection{Mandrel Assembly and Usage}

Once all the segments of the mandrel have been machined they need to be assembled.

The two threaded steel blocks are placed in one half of the long tapered section and the other half is doweled in place. The tool fabricators ensure there is no mismatch between the halves and the sections are then bolted together using twelve (12) 1/4-20 grade socket head cap screws as illustrated in Figure 44. 


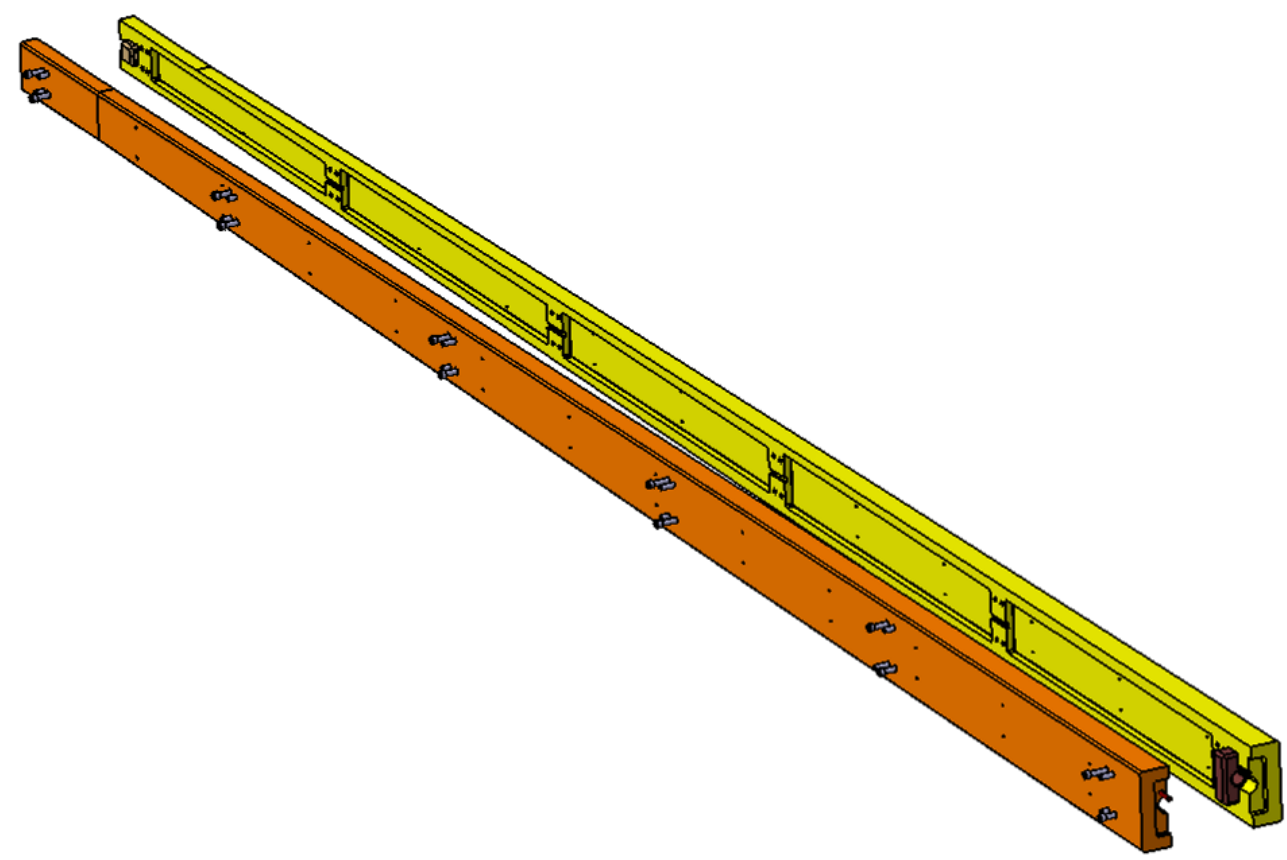

Figure 44: Assembly Step \#1: Tapered Section Halves

The tie rod is then threaded into the larger end of the tapered section and the center trapped segment is slid over the tie rod. Next, both side trapped sections are assembled by sliding them on the center section and into the pocket at the end of the tapered sections as shown in Figure 45. The final segment to be installed is the cap section. It must be slid over the tie rod making sure the pocket fits over the ends of all three flanges of the trapped center sections. Secure the cap assembly on the mandrel using a standard 5/8 -11 nut with a 1.25” outside diameter shown in Figure 46. 


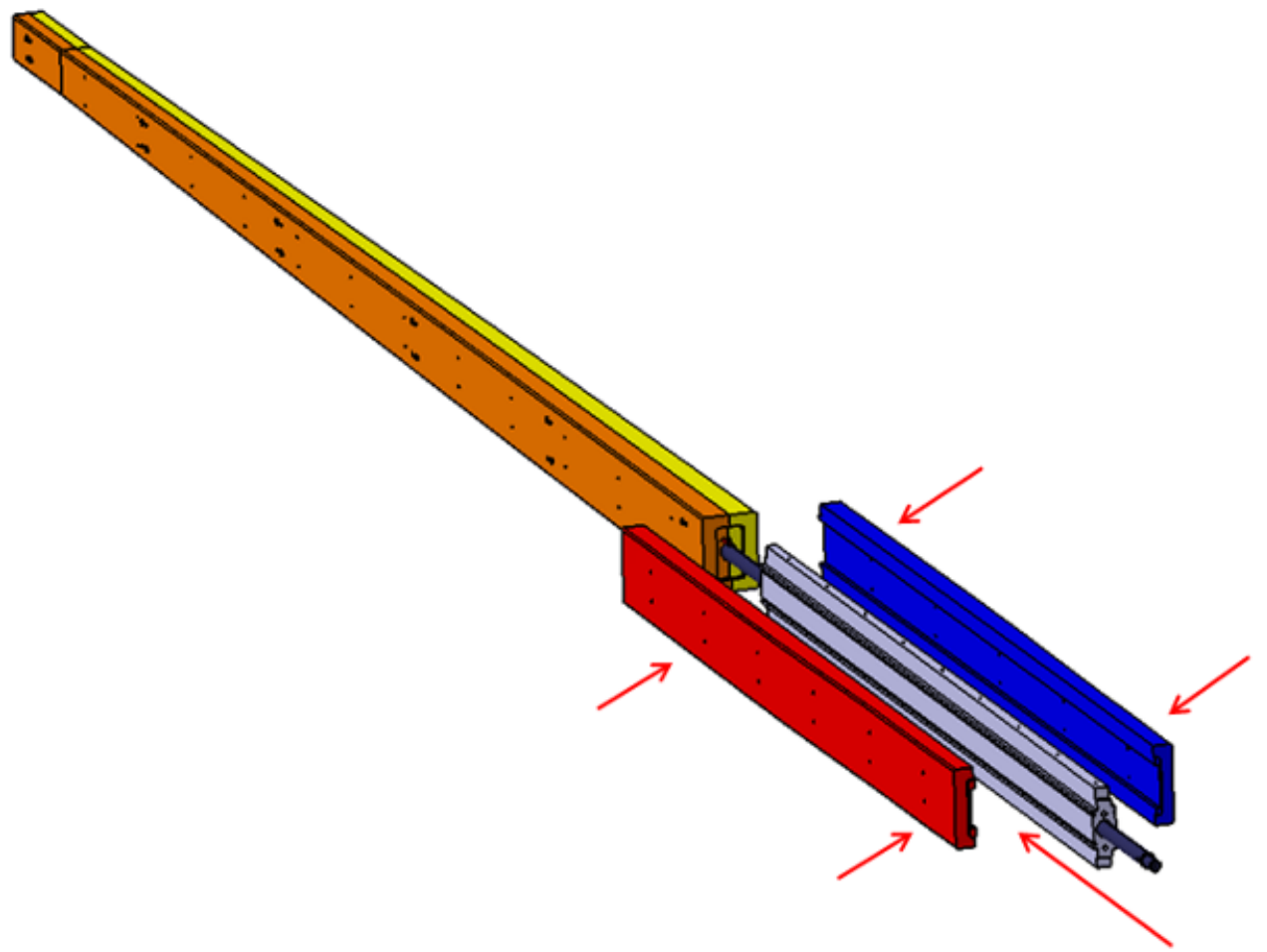

Figure 45: Assembly Step \#2: Stud and Trapped Sections

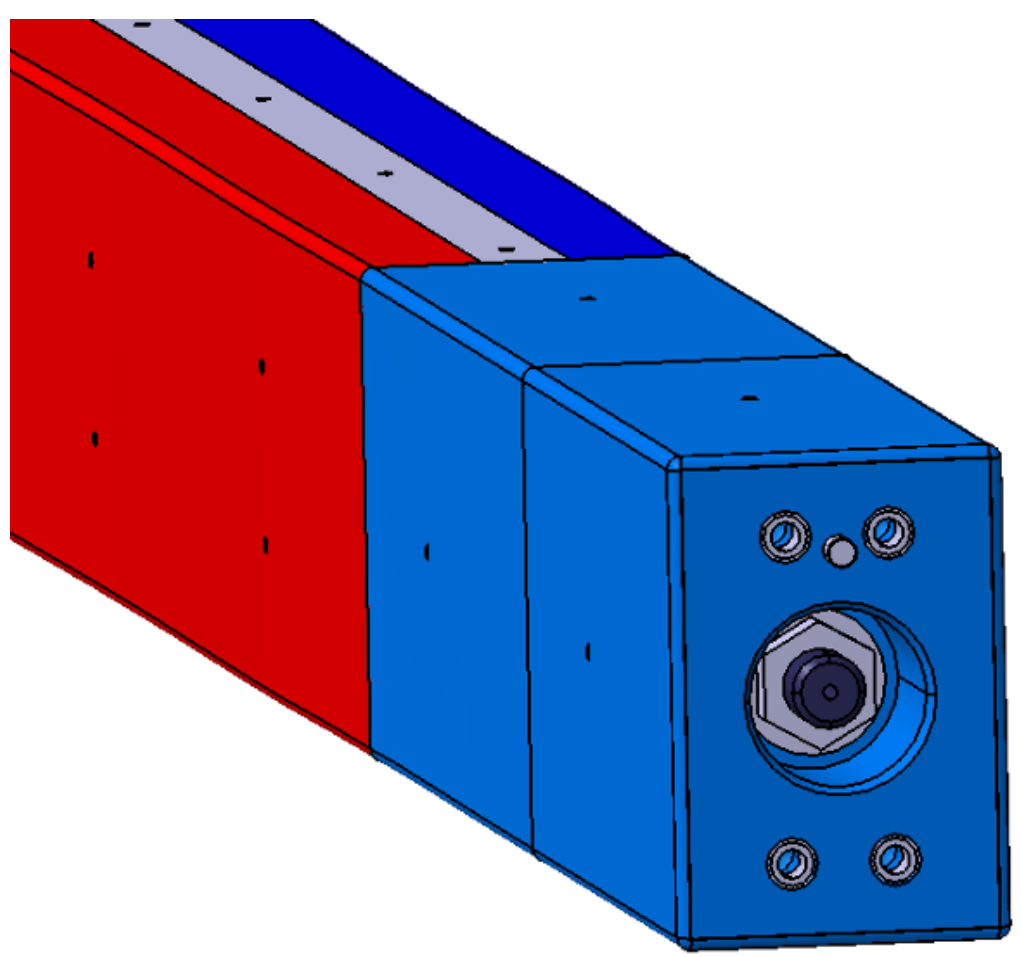

Figure 46: Assembly Step \#3: Cap 
The last step of the assembly is to install the closeout fittings onto the ends of the mandrel. Once all of the eleven sections are assembled, a .060" thick silicone bladder must be installed on the tool. The bladder tool used on the original mandrel can still be used to install the bladder over the newly designed mandrel. The silicone bladder is placed inside the sealed box tool shown in Figure 47. The ends of the bladder are then pulled over the plastic fittings on the bladder tool. Vacuum draws the bladder against the insider surfaces of the box. The mandrel is then slid in the stretched bladder, the vacuum is released, and the bladder is drawn down to the surface of the mandrel. The ends of the bladder are sealed to the closeout fittings using tacky tape. The entire tool can now be placed in the trunnion support stand shown in Figure 39.

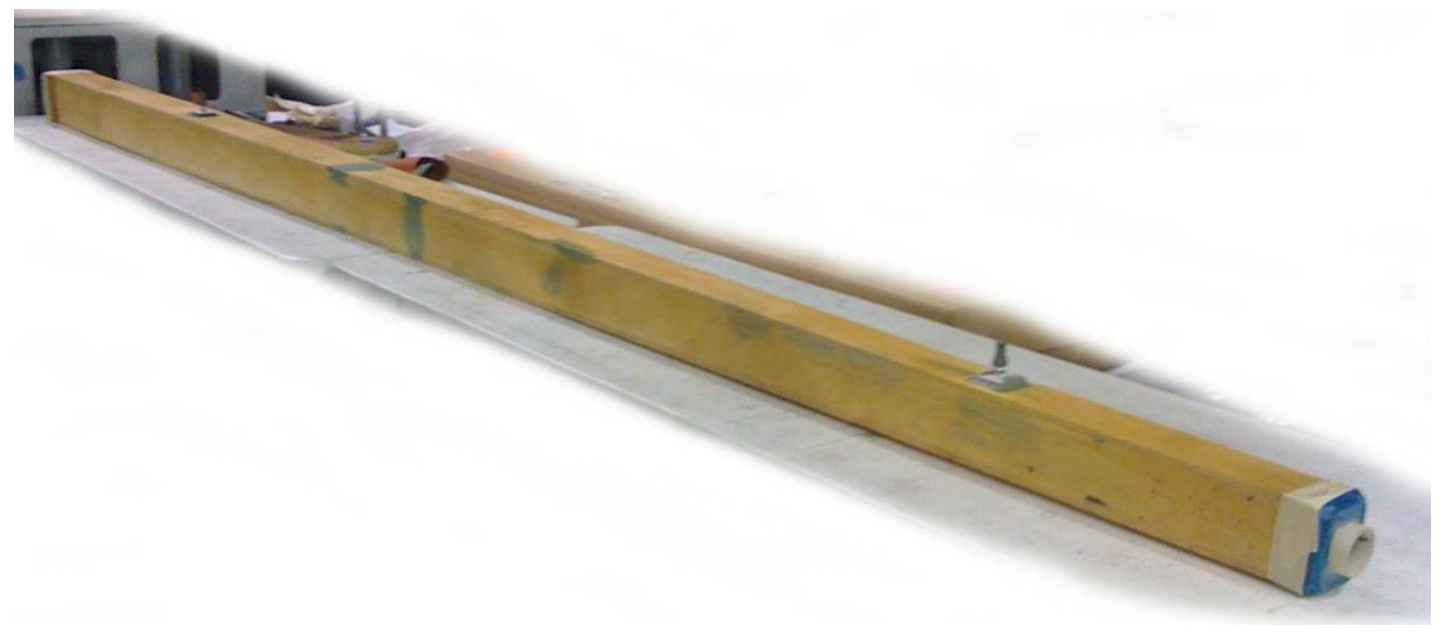

Figure 47: Bladder Installation Tool

The mandrel sections were designed to have zero gaps so the segments will act as one. This creates an issue when removing the sections from the cured part. When removing the segments of the tool there will be a considerable amount of friction to overcome over the length of each segment. It was determined that a taper must be designed into each of the three trapped segments to assist in removal. The trapped section is still split into three sections but a taper has been designed into each so they are not uniform thickness over the entire 51.75”. The center section is thicker by .2" at the root end so as soon as it is pulled towards the root end, it will 
break free from the side segments. It will then have clearance from the sides until is it completely removed from the cured part.

Prior to removing the trapped sections, the nut and washer must be loosened and removed. The nut must be taken off without loosening the stud from the trapped block. To do this, a 3/16" hole was drilled into the end of the tie rod stud. A threaded t-handle can then be inserted into the end of the stud holding it in place while the nut is removed.

Once the cap and center segments are removed, neither of the sides are supported and can fall freely away from the trapped area and into the tie rod. They can then be extracted separately from the mandrel without being stuck in the trapped area. The long tapered section can then be removed using the tie rod steel stud. A 1/4-20UNC-2B hole was designed into each of the three trapped sections to aid in removal of the segments using a standard piece of 16 ” long all thread. A dynamic analysis was run on the assembly to check for interference during the removal process. Based on this design, each segment of the tool can be removed individually from the cured spar with no less than .050" of clearance around the periphery of the tool.

The last segment to be removed from the cured part is the long tapered section. The tie rod is unthreaded from the steel block and a 90" long piece of all thread is threaded back in. A plate is then installed over the end of the new all thread and onto then end of the clamshell mold. An oversized washer and standard nut are placed on the all thread and rotated in a clockwise direction to draw the tapered section out of the mandrel. This method allows the technician to overcome the frictional forces between the bladder and the carbon.

Once all the segments are removed, the part can be removed from the outer clamshell mold, trimmed and put into production. 


\section{Results and Conclusions}

The primary goal of this design was to develop a new tool configuration for a composite wing spar with geometry that allows inner mold line tooling to be removed from the cured spar and be reused so new tooling is not required to be remade after each cure cycle. The new tool was specified to make the spar manufacturing process more efficient. The new tool requires 2 hours of maintenance to reassemble the tool and install the bladder over the tool it also does not require any new fabrication materials to remake or repair the tool each time. This is a 38 hour and $\$ 500$ savings each time the tool is used. The main objective was achieved by designing a new solid tool that is reusable and maintenance on the tool has been reduced by $94.7 \%$. By using an aluminum structure tied together with a steel support rod, the 14.725 ' long tool is easily maneuverable and provides sufficient support for layup. It also provided ideal thermal properties to work in conjunction with the outer mold to supply pressure on the carbon layup.

The new tool was first designed to meet all of the minimum requirements required to make this particular wing spar. The main advantage of this tool design is that it is repeatable for each cure cycle and will replicate the characteristics of the finished part each time. The design was then optimized to hold higher tolerances and reduce the number of working parts without greatly increasing the cost of the tooling as discussed in Chapter 3. The tool is able to compensate for small changes in variables during manufacturing however the tool is still limited by human error in the manufacturing process.

After the design and analysis was complete, each mandrel section was machined and inspected separately to the standards specified in the drawing. The inspection was performed using a Faro laser tracker which holds tolerances of $+/-.001$ ”. Each segment was then assembled according to the drawings and the most critical tolerance which is surface profile of $+/-.010$ is 
checked at this level. Inspection data is taken for the entire final assembly. Twenty four points are taken every two inches the entire length of the mandrel. Three points are taken on each radius and three points on each flat of the tool. These points are knows as the actuals and are compared to the theoretical tooling model to verify the surface profile. The mandrel was checked and verified to be within the specified tolerance of +/-.010.

Deflection under worse case scenario loading was measured to validate the FEA that was run during the design phase. All the plies of the carbon part were laid up on the tool. At that time the tool was rotated so the tool was held in the trunnion stand in the weak direction and a force gauge was used to measure 10lbs of load pressed down in the center of the tool. At that time, a line was tightly stretched from both ends of the tool and a measurement was taken at STA 102. Figure 48 shows the actual measurement taken of .19”. The calculated theoretical value was .183" at this station. This is a difference of only 3.8\%. The stiffness of the design has been optimized so it can take additional loading that would not be typical in the manufacturing process without affecting the finished part.

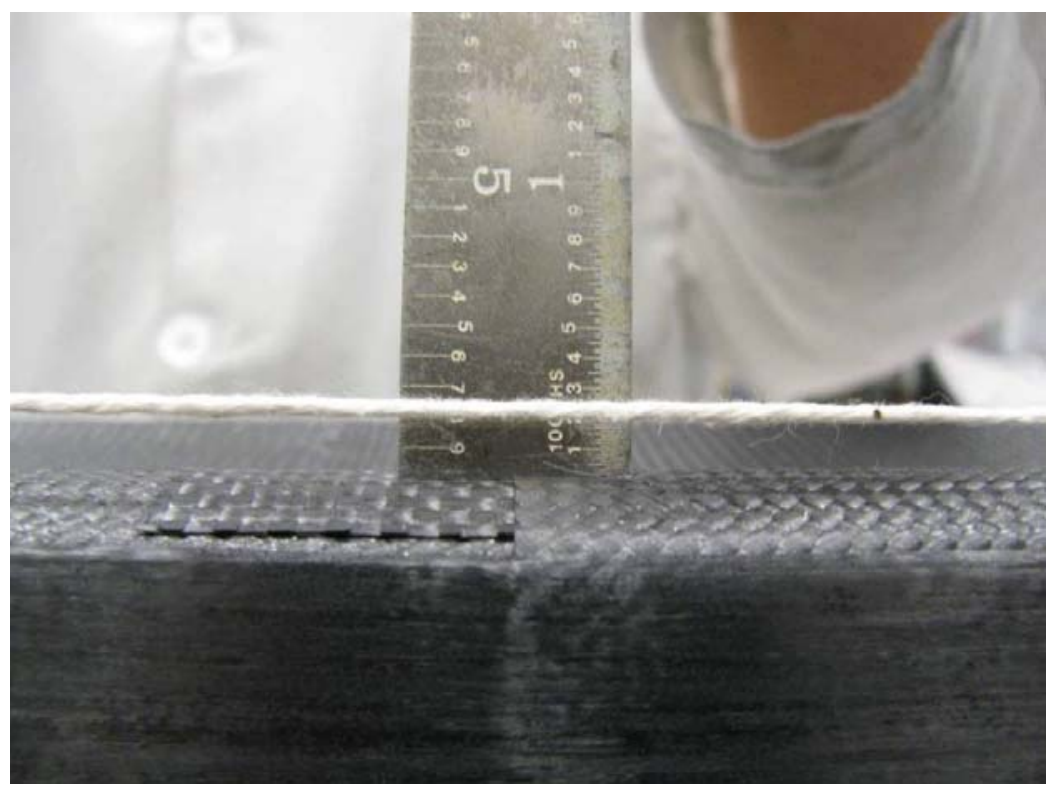

Figure 48: Actual Measurement under Worst Case Static Loading 
Photos of the machined mandrel can be seen in Figure 49. 14 spars have been fabricated to date using the new tooling. The redesigned spar mandrel has produced spars that meet the .060 ” profile tolerance along with the customers wrinkle and void specifications with no defects due to tooling. The tool has gone through fourteen cure cycles since being put into production. Since the design of the tool and the written procedure ensures the tool is able to be assembled exactly the same each time and meet the tooling profile tolerance of .020”.

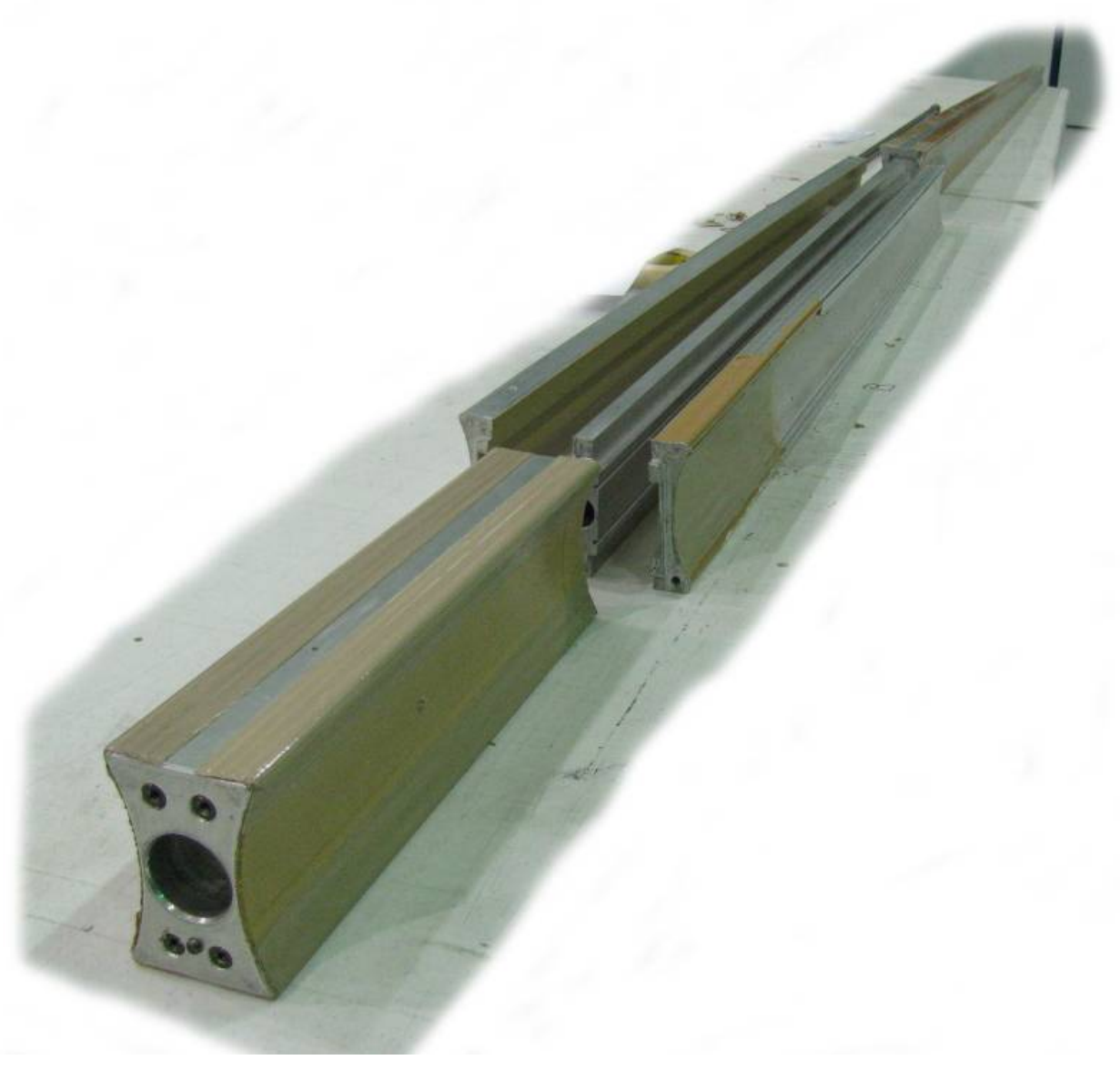

Figure 49: Final Machined Mandrel 


\section{Recommendations}

The following suggestion will be made to expand on additional conclusions about this study. These recommendations are based on parameters that were not or could not be controlled in this work.

There were some minor issues with the bladder sticking to the cured carbon after the cure cycle was run and the tool was ready to be removed. Talcum powder or an equivalent that will not contaminate the carbon is recommended to be placed between spar and bladder to help removability. To help with this issue it was also recommended that air pressure be blown over the bag to also help it release from the cured carbon.

The real challenge in designing a tool of this magnitude with so many variables is designing the profile to provide the correct amount of CTE pressure against the carbon. If at any time in the future that it is determined that the mandrel needs to be larger, aluminum tape can be used as a build-up on the corners to provide more pressure at temperature in the corners of the carbon.

The final suggestion is also to aid in removal of the mandrel from the cured spar. Shop aid needs to be designed to help overcome the frictional forces of center trapped section. It is in full contact with both side trapped sections along with having an interface with the bladder on the top and bottom. A simple extraction tool that uses all thread will aid in the removal of this section and will reduce the time it takes to extract the entire spar mandrel. 


\title{
Appendix A
}

\author{
Glossary of Terms
}

EOP: Edge of Part

IML: Inside Mold Line

OML: Outside Mold Line

Autoclave: Closed vessel pressure chamber for applying controlled heat and pressure to cure production parts. Chamber has loading ramp, vacuum and air outlets, and control cabinets for air input. Autoclave is monitored and controlled by temperature, pressure, and elapsed time monitoring devices.

Bagging: Operation consisting of thermocouple placement, bleeder cloth and blanket arrangement, placement of caul sheet (if required), installation of vacuum bag and vacuum lines, and sealing of vacuum bag. Bag leak test is performed prior to cure cycle start.

Bleeder Cloth: Nonstructural layer of material used in manufacture of composite parts to allow escape of excess gas and absorption of excess resin during laminate cure. Bleeder cloth is removed after curing process and is not part of final assembly.

Breather Cloth: Two or more layers of dry cloth placed between bond assembly and vacuum bag to prevent bag from sealing off against assembly. This assures complete evacuation of air from bond assembly when vacuum is applied.

Composite: Material consisting of high strength fibers, usually graphite or glass, embedded in epoxy resin. Referred to as graphite/epoxy (gr/ep) and glass/epoxy (gl/ep). The two forms in which fibers are used are woven cloth and unidirectional tape. Woven cloth consists of two sets of fibers positioned at 90 degrees to each other. Unidirectional tape is a series of fibers running parallel to each other.

Composite Bonding: Layup and cure of laminate composite structures, and joining of composite and metal structures, by use of heat-activated adhesives.

Cure: Changing physical properties of material by chemical reaction. Usually accomplished by action of heat and accelerators (catalysts) with or without pressure.

Debulk: Compacting of plies and removal of air from composite laminate prior to curing. Done in stages, under full vacuum.

Graphite Epoxy (Gr/Ep): Composite made of graphite fibers and epoxy matrix, usually autoclave cured.

Layup: Fabrication process involving placement of successive layers of glass cloth and resin or similar materials. In varying sequences, cloth and tape are laid up to desired ply thicknesses, with fiber direction of each successive layer alternating per engineering drawing.

Pre-Preg: (Pre-Impregnated)

Term applied to cloth of glass fibers, kevlar fibers, or other woven material pre-impregnated with heat curable plastic such as epoxy or polyester resin.

Resin: Any of a class of solid or semi-solid organic products of natural or synthetic origin, generally of high molecular weight with no definite melting point. Resins are generally waterinsoluble and have little or no tendency to crystallize. However, certain resins such as some polyvinyl alcohols and polyacrylates are readily dispersible in water. Others such as polyamides and polyvinylidene chloride are readily crystallized.

Scale Factor: Scaling factor applied to tool CAD model based on CTE delta. 
Test Coupon (Specimen): Bond assembly area containing materials and adhesives representative of production assembly. Coupons receive same cleaning, priming, layup, and cure cycle operations at same time as production assembly. Specimens are destructive-tested to measure quality of bonding and test results help determine acceptance or rejection of production bond assembly.

Unidirectional: Composite fabric having fibers oriented only parallel to each other Vacuum Bag: Thin outer blanket that is placed over bonding assembly and sealed to working surface of bond tool. Vacuum bag applies clamping pressure to parts or assemblies when vacuum is drawn, or autoclave is pressurized.

Vacuum Bagging: Process in which the p/p layup is compacted under pressure generated by drawing a vacuum in the space between the layup and the vacuum bag that is sealed around the perimeter.

Vacuum Integrity: Ability of tool or plumbing system to maintain vacuum and resist autoclave pressure.

Virtek Laser Projector: System used to project ply definition on to tool surface. 
Appendix B

\begin{tabular}{|c|c|c|c|c|}
\hline Station & Max Width (Cap) & $\begin{array}{c}\text { Thickness of Plies on } \\
\text { each side of } \\
\text { Cap Section }\end{array}$ & Max Height (Web) & $\begin{array}{c}\text { Thickness of Plies on } \\
\text { each side of } \\
\text { Web Section }\end{array}$ \\
\hline 0 & 5.491 & 0.601 & 3.797 & 0.426 \\
\hline 4 & 5.492 & 0.602 & 3.797 & 0.426 \\
\hline 8 & 5.492 & 0.602 & 3.797 & 0.426 \\
\hline 11 & 5.492 & 0.5945 & 3.797 & 0.405 \\
\hline 12 & 5.492 & 0.592 & 3.797 & 0.398 \\
\hline 16 & 5.492 & 0.583 & 3.797 & 0.37 \\
\hline 20 & 5.46 & 0.567 & 3.776 & 0.332 \\
\hline 24 & 5.381 & 0.541 & 3.724 & 0.279 \\
\hline 28 & 5.302 & 0.514 & 3.671 & 0.227 \\
\hline 32 & 5.223 & 0.488 & 3.618 & 0.175 \\
\hline 36 & 5.143 & 0.462 & 3.566 & 0.128 \\
\hline 38 & 5.104 & 0.45 & 3.5395 & 0.126 \\
\hline 40 & 5.065 & 0.438 & 3.513 & 0.124 \\
\hline 44 & 4.986 & 0.414 & 3.461 & 0.119 \\
\hline 48 & 4.908 & 0.39 & 3.408 & 0.114 \\
\hline 52 & 4.829 & 0.366 & 3.355 & 0.11 \\
\hline 56 & 4.75 & 0.341 & 3.303 & 0.105 \\
\hline 60 & 4.672 & 0.317 & 3.25 & 0.1 \\
\hline 62 & 4.6325 & 0.305 & 3.224 & 0.098 \\
\hline 64 & 4.593 & 0.293 & 3.198 & 0.096 \\
\hline 68 & 4.514 & 0.269 & 3.145 & 0.091 \\
\hline 72 & 4.436 & 0.245 & 3.092 & 0.086 \\
\hline 76 & 4.357 & 0.221 & 3.04 & 0.082 \\
\hline 80 & 4.278 & 0.196 & 2.987 & 0.077 \\
\hline 84 & 4.2 & 0.172 & 2.935 & 0.072 \\
\hline 86 & 4.1605 & 0.16 & 2.9085 & 0.07 \\
\hline 88 & 4.121 & 0.148 & 2.882 & 0.068 \\
\hline 92 & 4.076 & 0.141 & 2.829 & 0.066 \\
\hline 96 & 3.997 & 0.133 & 2.777 & 0.063 \\
\hline 100 & 3.918 & 0.124 & 2.724 & 0.061 \\
\hline 104 & 3.84 & 0.116 & 2.672 & 0.059 \\
\hline 108 & 3.761 & 0.107 & 2.619 & 0.056 \\
\hline 112 & 3.682 & 0.099 & 2.567 & 0.054 \\
\hline 116 & 3.603 & 0.091 & 2.514 & 0.051 \\
\hline 120 & 3.523 & 0.082 & 2.461 & 0.059 \\
\hline 124 & 3.445 & 0.082 & 2.408 & 0.058 \\
\hline 126 & 3.4055 & 0.082 & 2.382 & 0.057 \\
\hline
\end{tabular}




\begin{tabular}{|l|l|l|l|l|}
128 & 3.366 & 0.082 & 2.356 & 0.056 \\
\hline 132 & 3.287 & 0.082 & 2.304 & 0.055 \\
\hline 136 & 3.21 & 0.082 & 2.251 & 0.054 \\
\hline 140 & 3.13 & 0.082 & 2.198 & 0.053 \\
\hline 144 & 3.051 & 0.082 & 2.145 & 0.052 \\
\hline 148 & 2.972 & 0.082 & 2.093 & 0.051 \\
\hline 152 & 2.893 & 0.082 & 2.041 & 0.05 \\
\hline 156 & 2.815 & 0.082 & 1.988 & 0.049 \\
\hline 160 & 2.702 & 0.082 & 1.935 & 0.048 \\
\hline 162 & 2.659 & 0.082 & 1.916 & 0.052 \\
\hline
\end{tabular}

*all dimensions are in inches 


\section{References}

1. Griffiths, Bob. "Boeing sets pace for composite usage in large civil aircraft." High-Performance Composites 25 Feb. 2010. Web. 1 Mar. 2010.

2. "Fact Sheet." Boeing 787 Dreamliner. Boeing, n.d. Web. 6 Mar. 2010. <http://www.boeing.com/commercial/787family/787-8prod.html>.

3. Milauskas, Michael. Composites-By-Design. 18 Jan. 2009 <http://www.composites-bydesign.com/index.htm>.

4. "mandrel." Merriam-Webster Online Dictionary. 2009.Merriam-Webster Online. 15 January 2009 http://www.merriam-webster.com/dictionary/mandrel

5. Hege, Eric. "Psycho-Tek T-Maxx Racing Chassis." RC Universe May 2005. 17 Jan. 2009 $<$ http://www.rcuniverse.com/magazine/article_display.cfm?article_id=503>.

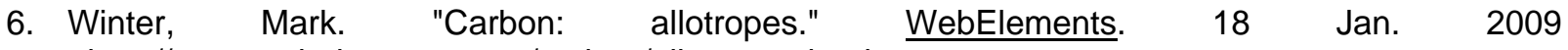
$<$ http://www.webelements.com/carbon/allotropes.html>.

7. Song, Xiaolan., "Vacuum Assisted Resin Transfer Molding (VARTM): Model Development and Verification." (PhD dissertation, Virginia Polytechnic Institute and State University ,2003), 17-20.

8. Allen, Abraham Keith. A Method for Winding Advanced Composites of Unconventional Shapes Using Continuous and Aligned Fibers. Thesis (M.S.)--Brigham Young University. Dept. of Technology, 2004, 2004.

9. Whitehead, David, and Brian Wilson. Composite Boss Technology. Ft. Belvoir: Defense Technical Information Center, 1998. <http://handle.dtic.mil/100.2/ADA350976>.

10. Clements, Linda. "Trapped Tooling: Build the Unbuildable." Composites Manufacturing June 2005: 26-30.

11. Everhart, Matthew C, and Beth A Knapp. High-Temperature Reusable Shape Memory Polymer Mandrels (Preprint). Ft. Belvoir: Defense Technical Information Center, 2006. <http://handle.dtic.mil/100.2/ADA455510>.

12. Becker, Wayne. "Autoclave Tooling for Thermoplastic/ Graphite Composites." SAE Techinical Paper Series 1989. Paper No. 891043

13. Kopeliovich, Dmitri. SubsTech. 22 Mar. 2009

<http://www.substech.com/dokuwiki/doku.php?id=main_page>.

14. Windmill Blade. Private collection. Web. Web. 16 Jan. 2010. <www.flickr.com/photos/10372533@N06/2469745542/>.

15. Virtek LaserEdge. Productivity Tools for Aerospace Templating. Digital.

16. "Overview of materials for Silicone, RTV, Encapsulation Grade." MatWeb Material Property Data. N.p., n.d. Web. 6 Mar. 2010. <http://www.matweb.com/search/DataSheet.aspx?bassnum=05201\&ckck=1>.

17. Beer, Ferdinand P., E. Russell Johnston, Jr., and John T. DeWolf. Mechanics of Materials. Third ed. New York: McGraw-Hill, 2002. 746. Print. 